University of South Florida

DIGITAL COMMONS

Digital Commons @ University of

@ UNIVERSITY OF SOUTH FLORIDA

South Florida

USF Tampa Graduate Theses and Dissertations

USF Graduate Theses and Dissertations

7-2-2008

\title{
Low Temperature Polymer Electrolyte Fuel Cell Performance Degradation
}

John Andrew Fedock

University of South Florida

Follow this and additional works at: https://digitalcommons.usf.edu/etd

Part of the American Studies Commons

\section{Scholar Commons Citation}

Fedock, John Andrew, "Low Temperature Polymer Electrolyte Fuel Cell Performance Degradation" (2008). USF Tampa Graduate Theses and Dissertations.

https://digitalcommons.usf.edu/etd/233

This Thesis is brought to you for free and open access by the USF Graduate Theses and Dissertations at Digital Commons @ University of South Florida. It has been accepted for inclusion in USF Tampa Graduate Theses and Dissertations by an authorized administrator of Digital Commons @ University of South Florida. For more information, please contact digitalcommons@usf.edu. 
Low Temperature Polymer Electrolyte Fuel Cell Performance Degradation

by

John Andrew Fedock

\begin{abstract}
A thesis submitted in partial fulfillment of the requirements for the degree of Master of Science in Mechanical Engineering

Department of Mechanical Engineering College of Engineering University of South Florida
\end{abstract}

Major Professor: D. Yogi Goswami, Ph.D. Elias Stefanakos, Ph.D., P.E. Muhammad Rahman, Ph.D.

Date of Approval:

July 2, 2008

Keywords: Subzero, Alternative Energy, Catalytic Reactor, Cryogenic, Ice Formations

(C) Copyright, 2008 John Andrew Fedock 


\section{Dedication}

I would like to dedicate this work to my family, friends and my God whom has inspired and guided me throughout my entire life. Their constant encouragement and wisdom has helped me to realize the eternal and real truth, on my own I am weak, but by pure faith everything is possible. 


\section{Acknowledgments}

I would like to thank Dr. Yogi Goswami for giving me the opportunity to work under his guidance at the Clean Energy Research Center. Secondly, I would like to thank Chuck Garreston, Nikhil Kothurkar, and Sesha Srinivasan for their patience, guidance, and helpful suggestions. Thirdly, I would like to thank Refrigeration for their donation of cryogenic freezer materials. Finally, I would like to thank my father, John Robert Fedock, for providing the valuable insight, guidance and encouragement without which this work would not have come to fruition. 


\section{Note to Reader}

The original of this document contains color that is necessary for understanding the data. The original dissertation is on file with the USF library in Tampa, Florida. 


\section{Table of contents}

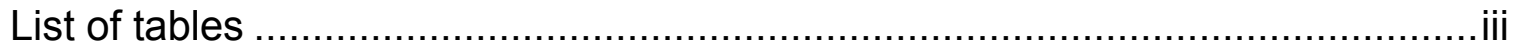

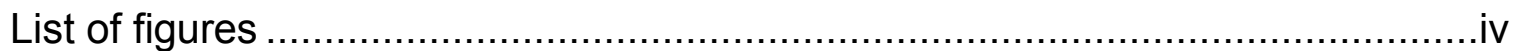

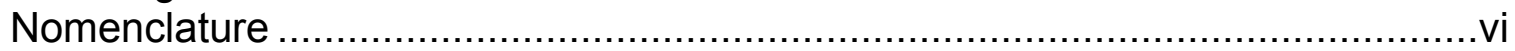

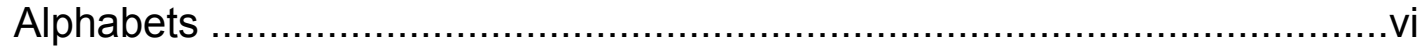

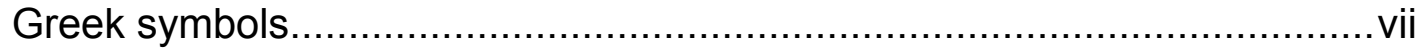

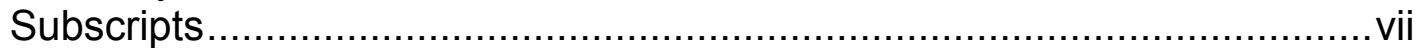

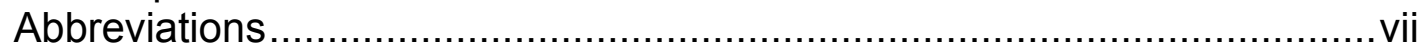

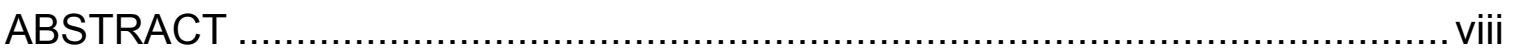

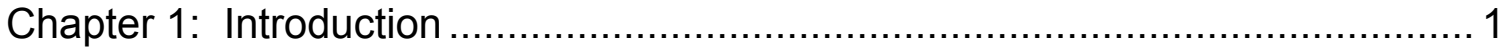

Chapter 2: Background and literature review ............................................. 3

Sulfonated tetrafluoroethylene copolymer history ................................. 7

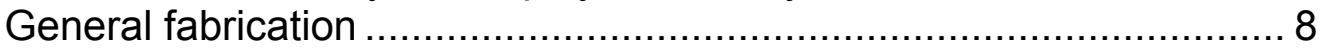

Nafion water balance.............................................................. 10

Water balance in a sub zero climate........................................ 11

Effects of ice formation ....................................................................... 13

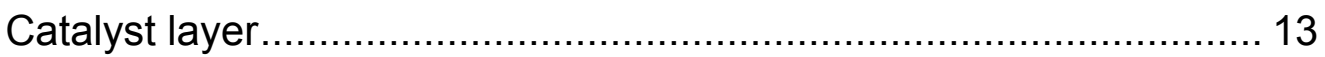

Gas diffusion layer................................................................ 16

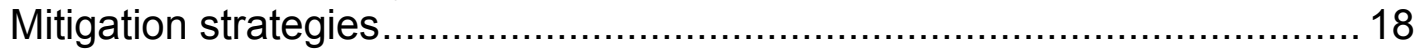

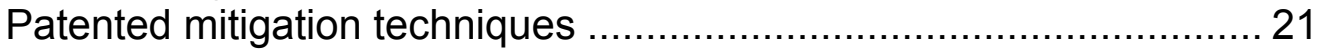

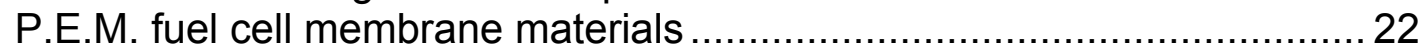

Finite element modeling simulation .................................................. 26

Chapter 3: Experimental facility and testing procedures................................ 31

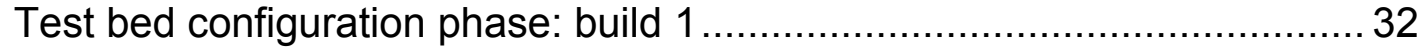

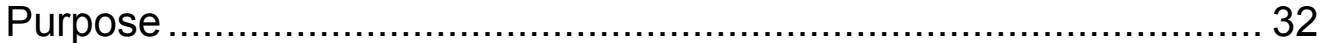

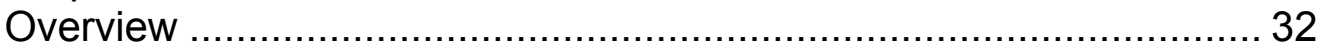

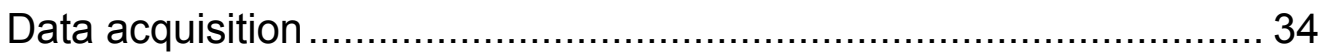

Test bed configuration phase: build 2 ............................................ 36

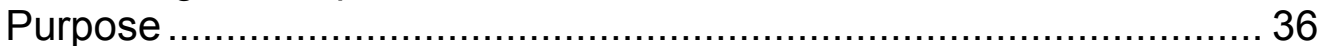

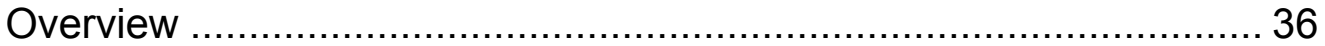

Cryogenic expansion climate chamber .................................................. 37

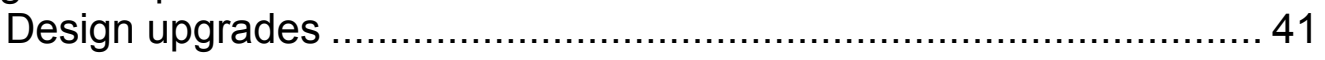

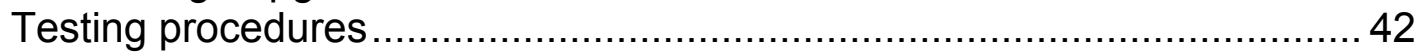

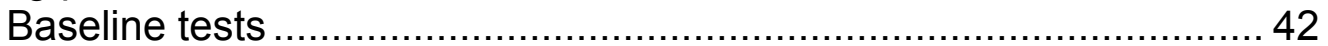

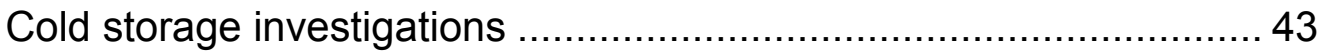

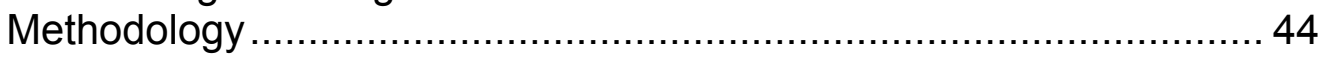

Investigated membrane electrode assembly ................................ 46

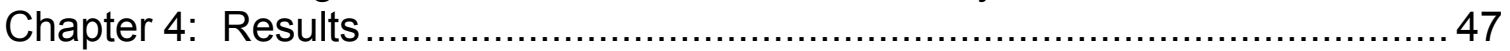

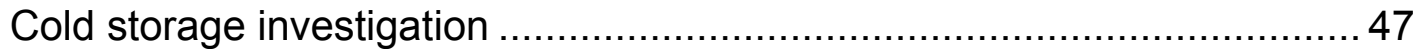

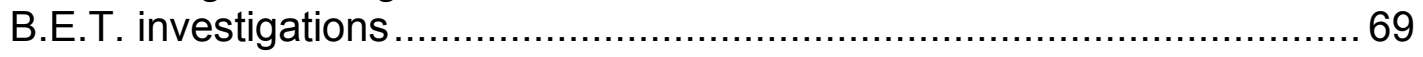




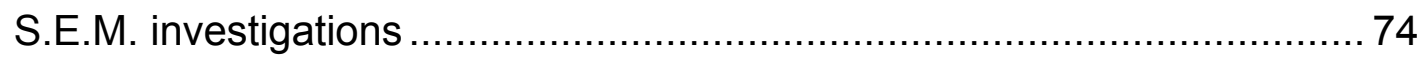

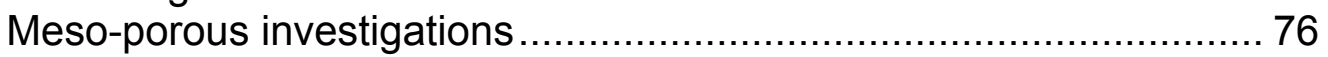

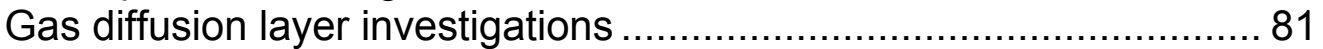

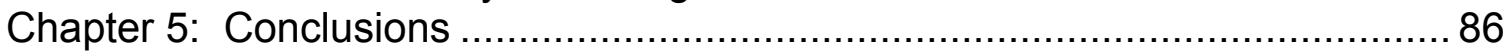

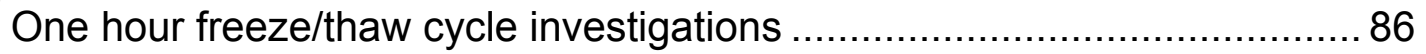

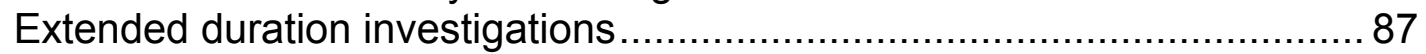

Twenty-four hour freeze/thaw duration investigations ............................. 87

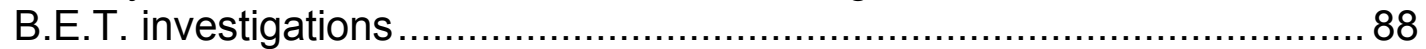

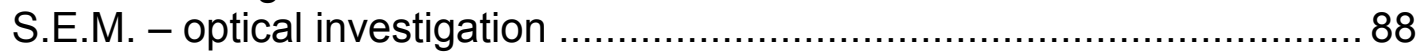

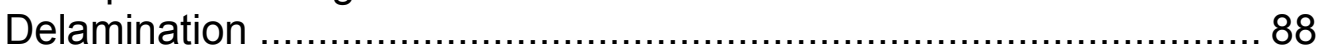

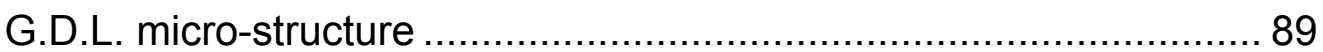

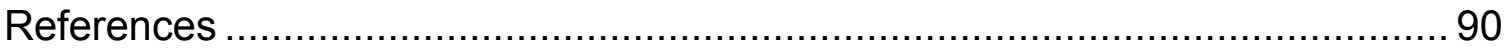

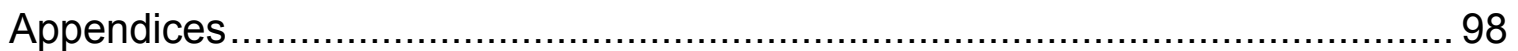

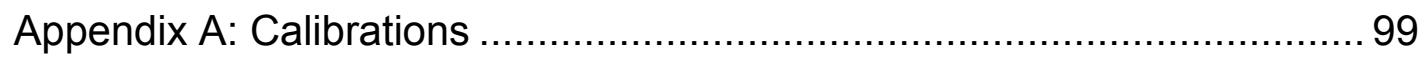

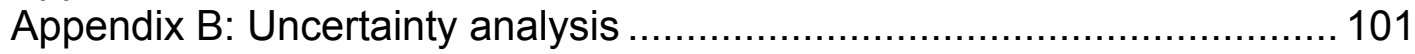

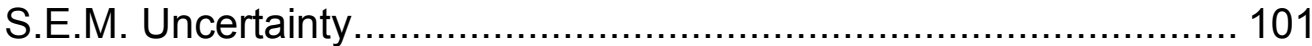

Appendix C: Scanning electron microscope (S.E.M.) …….................. 102

Energy dispersive x-ray spectroscopy (EDS) ............................... 104

Burnauer, Emmett and Teller (B.E.T.) surface area and pore size

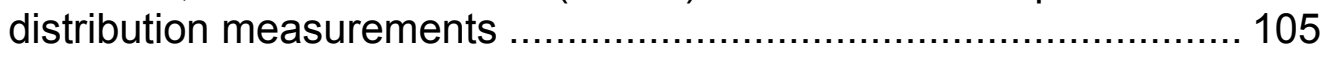




\section{List of tables}

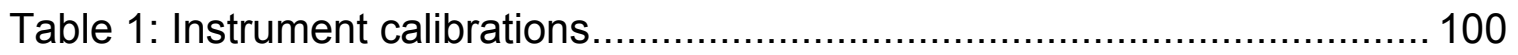

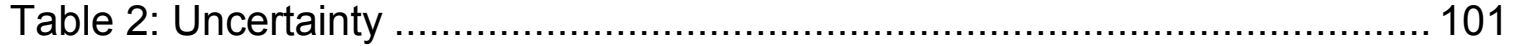




\section{List of figures}

Figure 1: Electro-chemical energy balance........................................... 4

Figure 2: Basic fuel cell operation.................................................. 5

Figure 3: Standard fuel cell assembly ................................................... 7

Figure 4: Micro-sized ion passage illustration......................................... 9

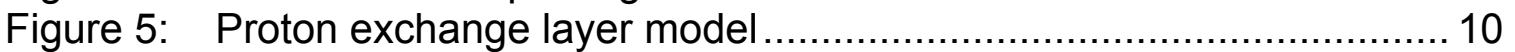

Figure 6: Ice formation and subsequent power losses ............................... 12

Figure 7: Ice formation effects on agglomerate pores ................................ 15

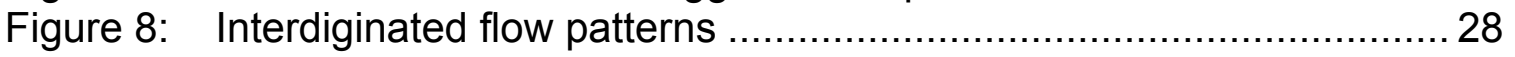

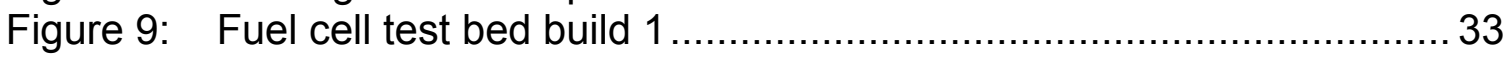

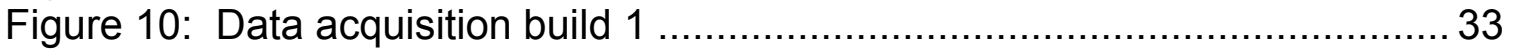

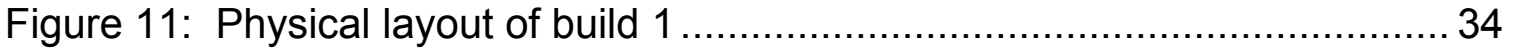

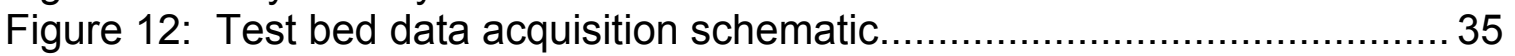

Figure 13: Climate chamber heat exchanger............................................. 38

Figure 14: C.A.D. representation of the climate chamber ............................. 39

Figure 15: Completed build 2 test bed ................................................. 40

Figure 16: Polarization curve comparison ................................................ 47

Figure 17: One hour freeze/thaw cycle investigation - polarization graph $60 \%$ relative humidity..................................................................... 49

Figure 18: One hour freeze/thaw cycle investigation - power v. current graph $60 \%$ relative humidity ............................................................ 50

Figure 19: One hour freeze/thaw cycle investigation - voltage v. power graph $60 \%$ relative humidity .............................................................. 51

Figure 20: One hour freeze/thaw cycle investigation - polarization graph $70 \%$ relative humidity

Figure 21: One hour freeze/thaw cycle investigation - power v. current graph $70 \%$ relative humidity.

Figure 22: One hour freeze/thaw cycle investigation - voltage v. power graph $70 \%$ relative humidity.

Figure 23: One hour freeze/thaw cycle investigation - polarization graph $80 \%$ relative humidity.

Figure 24: One hour freeze/thaw cycle investigation - power v. current graph $80 \%$ relative humidity .............................................................. 56

Figure 25: One hour freeze/thaw cycle investigation - voltage v. power graph $80 \%$ relative humidity. 57

Figure 26: Freeze/thaw cycle duration investigation - polarization graph .........58

Figure 27: Freeze/thaw cycle duration investigation - power v. current graph .. 59

Figure 28: Freeze/thaw cycle duration investigation - voltage v. power graph.. 60 
Figure 29: Freeze/thaw cycle duration investigation - voltage v. power (high

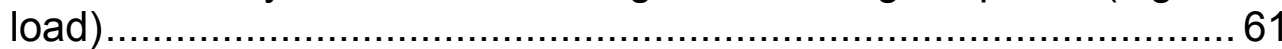

Figure 30: Twenty four hour freeze/thaw cycle - polarization graph.................62

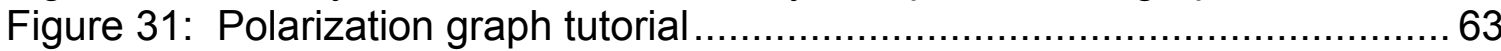

Figure 32: Post twenty four hour freeze/thaw cycle - area specific resistance .. 64

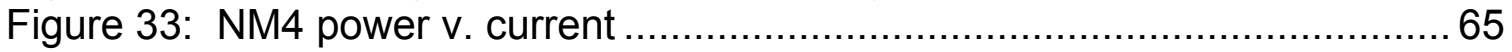

Figure 34: Twenty four hour freeze/thaw cycle - voltage v. power graph...........67

Figure 35: Twenty four hour freeze/thaw cycle - polarization graph (full load

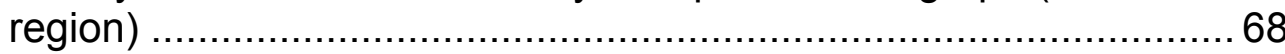

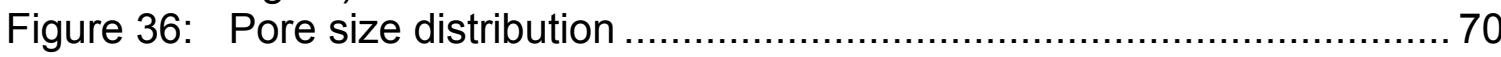

Figure 37: Surface area: adsorbed nitrogen v. relative pressure ................... 71

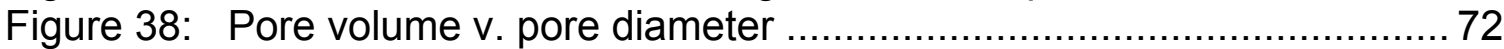

Figure 39: Proton exchange membrane cross-section ............................... 75

Figure 40: Control (OS1) proton exchange - M.P.L. interface $x 1100 \ldots \ldots \ldots \ldots . .76$

Figure 41: NM3 proton exchange - M.P.L. interface $x 2500 \ldots \ldots \ldots \ldots \ldots \ldots \ldots \ldots \ldots . .77$

Figure 42: Control (OS1) proton exchange - M.P.L. interface $\times 10,000 \ldots \ldots \ldots . .78$

Figure 43: NM3 proton exchange - M.P.L. interface $x 5,000 \ldots \ldots \ldots \ldots \ldots \ldots \ldots \ldots . .79$

Figure 44: Control (OS1) proton exchange - M.P.L. interface $x 70,000 \ldots \ldots \ldots . . .80$

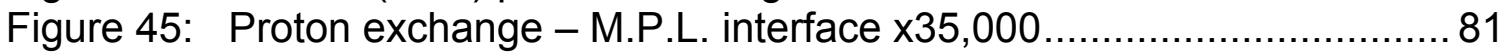

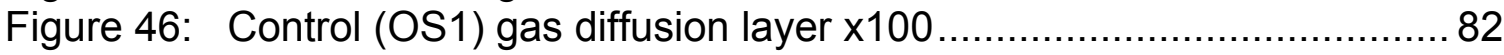

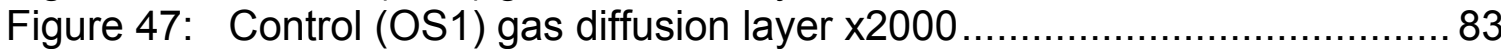

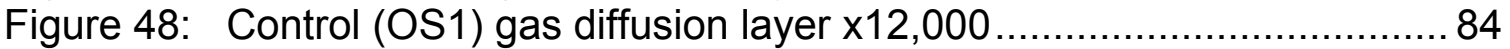

Figure 49: Comparison of NM3 and control (OS1) G.D.L.

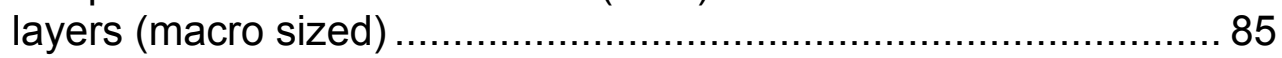

Figure 50: Comparison of NM3 and control (OS1) G.D.L.

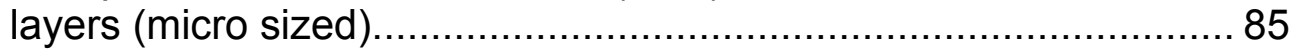

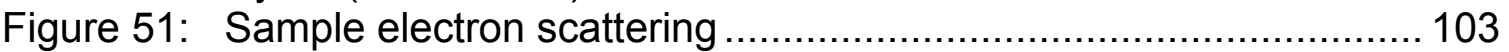

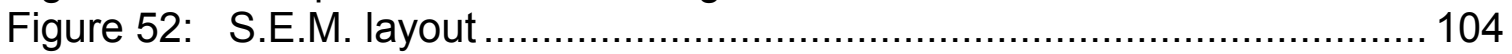

Figure 53: Nitrogen adsorption process................................................ 106 


\section{Nomenclature}

\section{Alphabets}

A

C

D

E

E

F

G

$\mathrm{H}$

I

$\mathrm{R}$

$\mathrm{T}$

V

Vo

i

i0

k

n

$\mathrm{p}$

p0

$\mathrm{S}$

V

$\mathrm{X}$

z active area of the fuel cell (m2)

concentration, constant (mol)

constant, diffusion coefficient

ohmic voltage loss (V)

voltage (V)

Faraday constant (96485 Cmol-1)

Gibbs energy (kJmol-1)

enthalpy (kJmol-1)

current $(A)$

resistance, gas constant $(\Omega)$, (8.314 Jmol-1K-1)

temperature $(\mathrm{K})$

volume flow rate (NTP) (m3s-1)

standard molar volume (0.002 $241 \mathrm{m3mol}-1)$

current density (Am-2)

exchange current density (Am-2)

gas permeability (m2)

mass flow rate (mols-1)

pressure $(\mathrm{Pa})$

atmospheric pressure (101325 Pa)

line slope

flow velocity (ms-1)

molar fraction

charge number of the electrochemical reaction 


\section{Greek symbols}

$\begin{array}{ll}\Delta & \text { change } \\ \alpha & \text { charge transfer coefficient } \\ \zeta & \text { thickness of the diffusion layer } \\ \eta & \text { potential difference, loss }(\mathrm{kgm}-1 \mathrm{~s}-1, \mathrm{~V}) \\ \lambda & \text { stoichiometry } \\ \rho & \text { density }(\mathrm{kgm}-3) \\ \vee & \text { kinetic viscosity }(\mathrm{m} 2 \mathrm{~s}-1)\end{array}$

\section{Subscripts}

$\begin{array}{ll}\text { O } & \text { reference } \\ \text { a } & \text { anode } \\ \text { b } & \text { bulk } \\ \text { C } & \text { cathode } \\ \text { d } & \text { diffusion } \\ \text { L } & \text { limiting } \\ \text { m } & \text { measured } \\ \text { s } & \text { surface } \\ \text { real } & \text { actual gas flow } \\ \text { H2 } & \text { hydrogen } \\ \text { O2 } & \text { oxygen }\end{array}$

\section{Abbreviations}

ASR Area Specific Resistance

BET Burnauer, Emmett and Teller porosity scanning technologies

GDL Gas Diffusion Layer

MEA Membrane Electrode Assembly

MPL Micro Porous Layer

ORR Oxygen Reduction Reaction

PEMFC Polymer Electrolyte Membrane Fuel Cell

PTFE Poly-Tetra-Fluoro-Ethylene

SEM Scanning Electron Microscope 


\title{
Low Temperature Polymer Electrolyte Fuel Cell Performance Degradation
}

\author{
John Andrew Fedock
}

\begin{abstract}
The goal of this research was to quantify the degradation experienced by a polymer electrolyte fuel cell after storage at subzero temperatures ranging from 0 to $-40^{\circ} \mathrm{C}$. The performance loss was determined by comparing the polarization and other applicable power curves before and after the subzero storage cycle. The causes of this performance degradation were investigated by the use of Scanning Electron Microscope, Energy Dispersive x-ray Spectroscopy, and porosity scanning technologies. It was found that there are two distinct types of degradation experienced by the membrane. The first type was identified as a variance of the actual voltage - current relationship of the cell. The membrane experienced a $2-15 \%$ power reduction depending on the load applied to the cell. This mode of degradation only pertained to the initial freeze/thaw cycle and was not observed after any number of subsequent cycles. The cause of this type of degradation has been hypothesized to be related to the delamination of the proton exchange, gas diffusion, and micro porous layers. The second type of degradation was only observed during the subsequent cycles, and mainly affected the high power regions of the operating range. A $5 \%$ reduction in current density and power output was observed as a result of further freeze/thaw cycles. Mass transport limitations may have been caused by the destruction of the meso-porous gas diffusion and micro-porous layers. The pore size, volume,
\end{abstract}


and membrane surface area were quantified using a B.E.T. porosity scanner. The results showed that the pore diameter of the catalyst and proton exchange layer did not increase significantly. The porosity scanner did indicate that a pore volume increased by a factor of ten and was confirmed by the surface area measurements of the membrane. The S.E.M. investigations allowed visual inspection of the membrane's structural integrity. Physical separation of the catalyst and gas diffusion layers was observed in the experimental sample, while a more homogeneous assembly was seen in the control sample. 


\section{Chapter 1: Introduction}

In the 2003 State of the Union Address, President George W. Bush pledged to pursue alternative energy technologies such as hydrogen fuel cells. The Department of Energy developed a goal to "Develop and demonstrate fuel cell power system technologies for transportation, stationary and portable applications" [1] The following objectives were outlined as part of this initiative[1]:

- By 2010, develop a 60\% peak-efficient, durable, direct hydrogen fuel cell power system for transportation at a cost of $\$ 45 / \mathrm{kW}$; by 2015 , at a cost of $\$ 30 / \mathrm{kW}$.

- By 2010, develop a distributed generation PEM fuel cell system operating on natural gas or LPG that achieves $40 \%$ electrical efficiency and 40,000 hours durability at $\$ 400-\$ 750 / \mathrm{kW}$.

- By 2010, develop a fuel cell system for consumer electronics with ( $<50 \mathrm{~W})$ an energy density of $1,000 \mathrm{Wh} / \mathrm{L}$.

- By 2010, develop a fuel cell system for auxiliary power units (3-30 kW) with a specific power of $100 \mathrm{~W} / \mathrm{kg}$.

In order for fuel cells to be a viable option for the transportation industry, the Department of Energy requires not only durable, but reliable operation for at least a 5000 hours (150,000 mile equivalent) lifespan under heavy loading, and a power density of $100 \mathrm{~W} / \mathrm{L}[2]$. In order for a fuel cell system to be termed reliable, the cell must be able to operate efficiently in sub zero climates. The Department of Energy determined that the following minimal temperature criteria should be obtained [1]: 
- Operating range: $-40^{\circ} \mathrm{C}$ to $150^{\circ} \mathrm{C}$

- Response time: in the $-40^{\circ}-100^{\circ} \mathrm{C}$ range $<0.5 \mathrm{sec}$ with $1.5 \%$ full-scale accuracy; in the $100^{\circ}-150^{\circ} \mathrm{C}$ range, a response time $<1 \mathrm{sec}$ with $2 \%$ full-scale accuracy

- Gas environment: high humidity reformer/partial oxidation gas: $\mathrm{H} 230 \%-75 \%$, $\mathrm{CO} 2, \mathrm{~N} 2, \mathrm{H} 2 \mathrm{O}, \mathrm{CO}$ at $1-3 \mathrm{~atm}$ total pressure

- Insensitive to flow velocity

Many problems arise when a Polymer Electrolyte Membrane (PEM) fuel cell is frozen, most of these are primarily caused by internal ice formation [2]. Internal ice crystallization causes physical tearing of the polymer membrane, clogging of internal fuel passages, dehydration of the membrane, and separation of the Gas Diffusion Layer (GDL) from the Membrane Electrode Assembly (MEA).

This research was conducted to experimentally study effect of the subfreezing conditions down to $-40^{\circ} \mathrm{C}$ for periods up to twenty four hours at a time, and for up to twenty cycles. The experimental procedures and results are described in the following chapters. Chapter 2 provides the background, fundamentals and a review of the literature. 


\section{Chapter 2: Background and literature review}

The first demonstration of the electrochemical cell principle was produced by William Grove in 1839 using the experiment illustrated below [3]. In figure 1, water is being electrolyzed into hydrogen and oxygen by facilitating an electric current around the circuit. If the power supply of figure 1 is replaced with a light bulb, as in figure 2, the bulb would be dimly lit. The low intensity of the bulb is due to the extremely small contact area between the catalyst, hydrogen, and oxygen gases. In order to increase this current density the electrodes are commonly thin, flat, and porous. This design helps to facilitate the largest available contact area between the electrode, the electrolyte, and the gases. The chemical reactions that take place within the acidic cell are as follows: At the anode $2 \mathrm{H}_{2}=4 \mathrm{H}^{+}+4 e^{-}$, and at the cathode $\mathrm{O}_{2}+4 e^{-}+4 \mathrm{H}^{+}=2 \mathrm{H}_{2} \mathrm{O}$. The governing chemical equation for this reaction is then $2 \mathrm{H}_{2}+\mathrm{O}_{2}=2 \mathrm{H}_{2} \mathrm{O}$ [3]. 


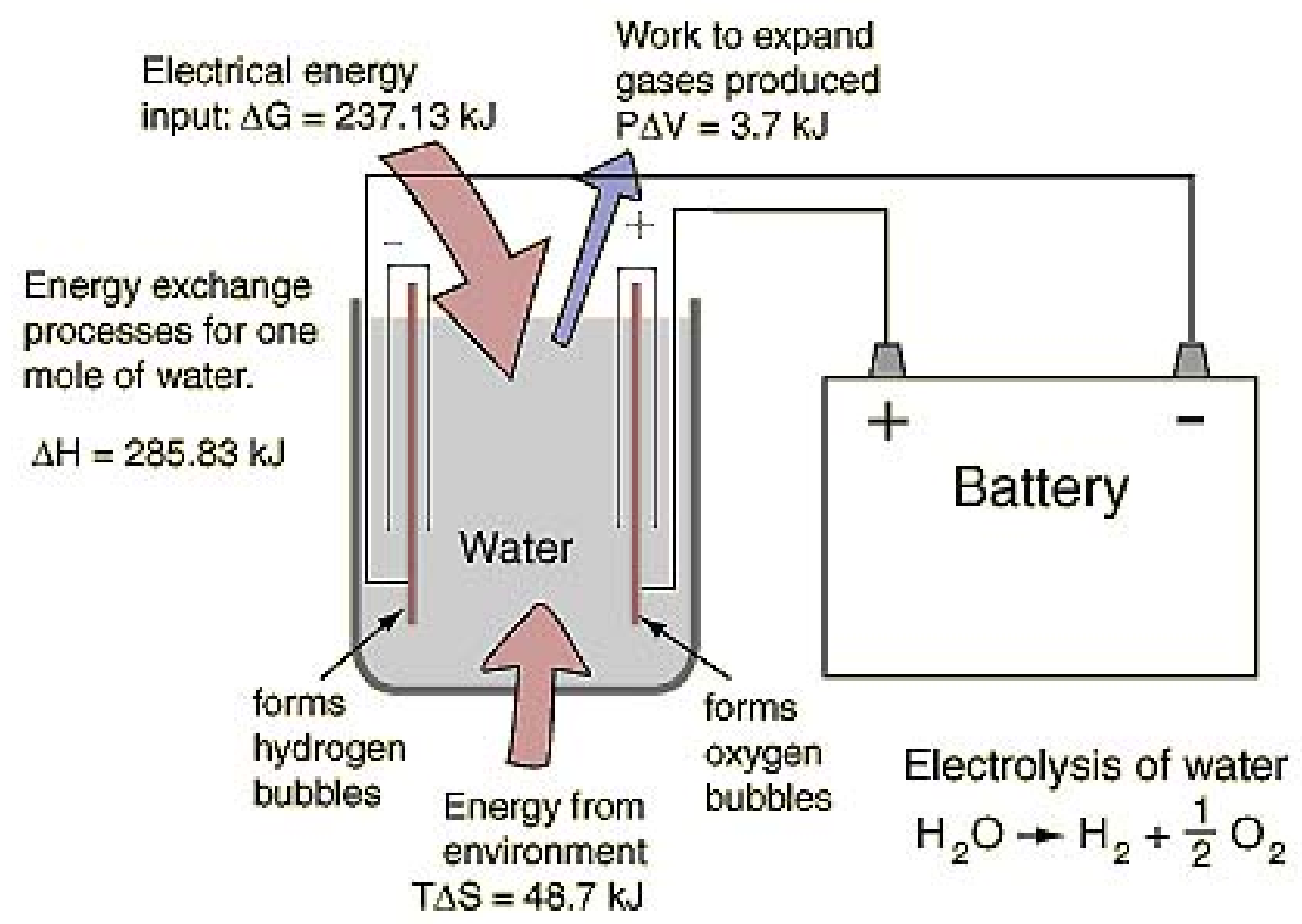

Figure 1: Electro-chemical energy balance

It cannot be assumed that because the system's potential energy is lowered during the chemical reaction that the reaction proceeds at an acceptable rate to suit the desired application. The amount of energy available to do work can be defined as the difference between the Gibb's free energy $(G)$ of formation of the products and the reactants. If there were no losses in the cell this value would represent the output of the cell. The change in Gibb's free energy equals the charge of one electron times the number of moles of electrons released per one mole of hydrogen multiplied by Faraday's constant $(F)$ [3].

The theoretical electro-motive force is defined as: $E=\frac{-\Delta G_{f}}{2 F}$

Where $F=96,485$ coulombs $/$ mole.

Due to the activation energy of the reaction, the probability of a molecule having enough energy to overcome this barrier is relatively low. Therefore, in 
order to reduce the activation over-voltage more effective catalysts, higher temperatures, larger electrode surface area, and increasing reactant concentration can all be utilized. The first two techniques are common to any chemical reaction, but the third is specific to fuel cells[3]. In order for the cell to operate correctly there must be a three phase contact on the electrode, so that an increase in the electrode area will proportionally increase the reaction rate.

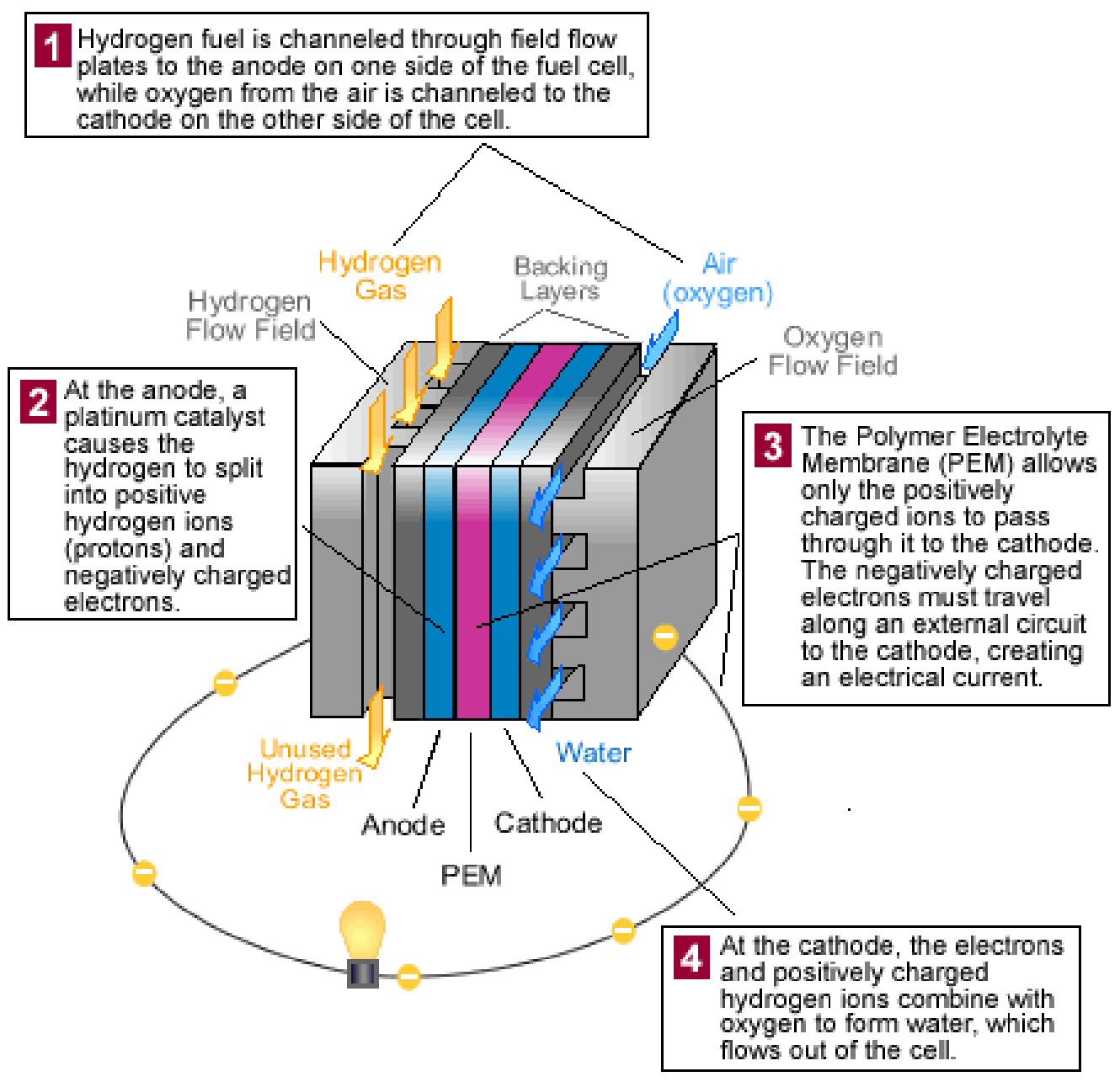

Figure 2: Basic fuel cell operation

A PEM fuel cell usually consists of an MEA, two graphite bipolar plates and two organic glass end plates. The graphite polar plates are used as collectors machined with parallel flow (fuel on one side, cooling on the other) channels. A silicon O-ring seals each fuel cell within the stack so the single cells 
operate in series. The operation of a fuel cell is similar to that of a battery except that the anode and cathode reactants are constantly fed from a remote reservoir instead of an internal one. Of course, the "reactants" of a PEM fuel cell (usually hydrogen and oxygen) are quite different from that a of nickel cadmium battery, yet the principle is similar. A chemical reaction occurs in the MEA releasing an electron at the anode; this allows the positive hydronium ion to pass through the semi-permeable membrane while the electrons travel through and external loop eventually returning to the cathode. The electrons join with the positive hydrogen ion and oxygen molecules to form water.

Water is essential to the operation of a PEM fuel cell because it facilitates the passage of hydrogen ions through the polymer electrolyte membrane. Figure 3 illustrates how critical water is to the operation of the cell, thus confirming that complete removal of water from a PEM fuel cell membrane is not possible. The complete dehydration of the membrane would not only limit the performance of the cell due to decreased proton conductivity, but actually cause permanent deterioration. Since water is vital to the cell's operation alternate ways of limiting the ice formation must be considered.

Fuel cells operate at a lower efficiency when the ambient temperature is below $0^{\circ} \mathrm{C}$. There are many probable causes for this performance loss such as decreased cell reaction rate, increased cell resistance, increased activation over potential, and possible mass diffusion over potential [4]. Once the ice formation begins, an additional inefficiency (primarily due to the blocking of fuel from reaching the reaction sites) is now present along with the other inefficiencies previously noted, thus restricting power production even further [5]. In P.E.M. fuel cells the reactant gases must be able to access the catalytically active sites, protons and electrons must conduct through the electrode, and the water product must be removed from the cathode to prevent flooding of the gas diffusion layer [6]. 


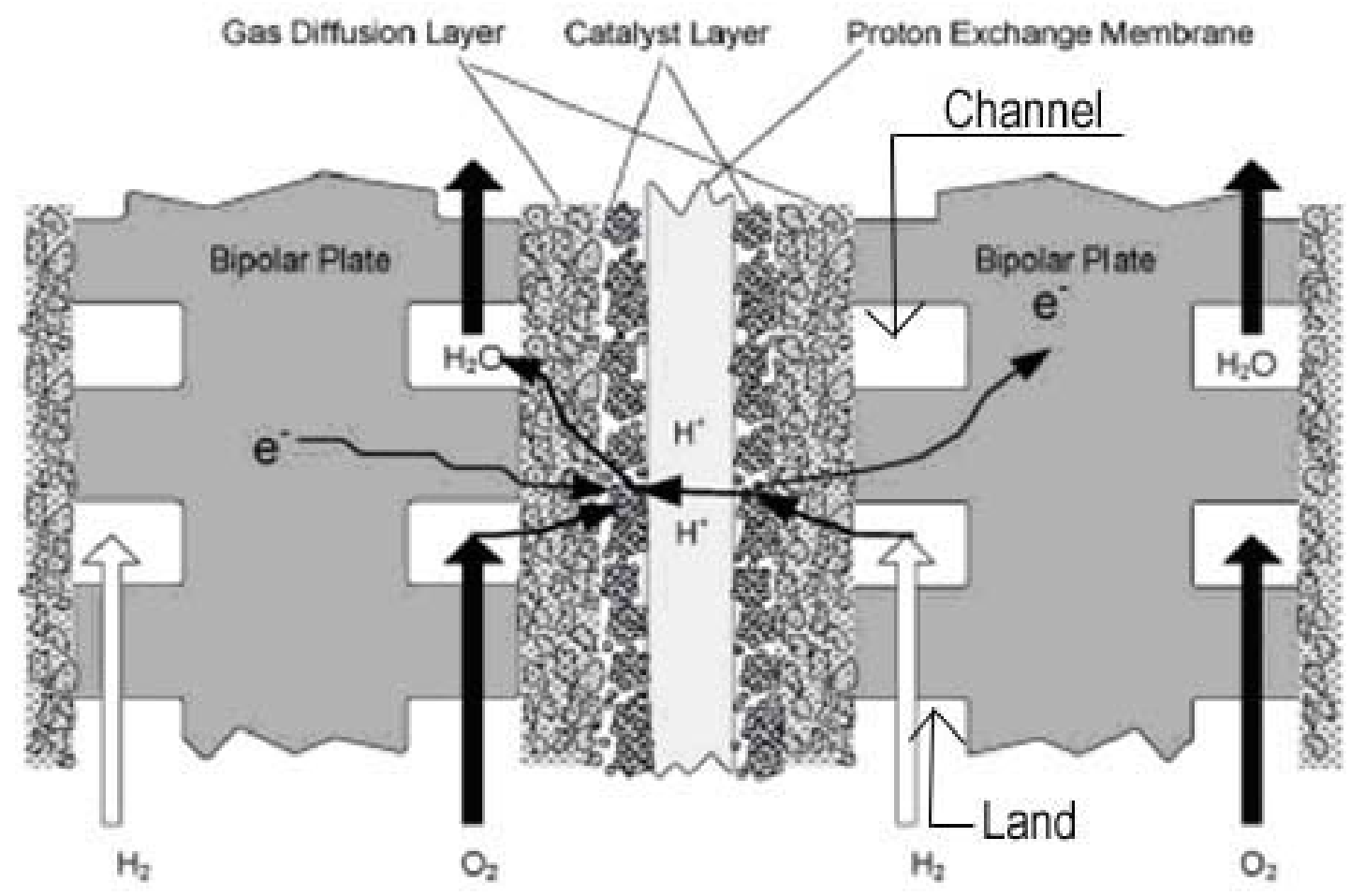

Figure 3: Standard fuel cell assembly

\section{Sulfonated tetrafluoroethylene copolymer history}

Nafion was developed in the 1960's by Walther Grot of DuPont de Nemours, but the numerous other uses of organic ion exchange resins (i.e. a micro encapsulation film, thermoplastic, and a coating) stirred research interest as early as the 1940's [3]. One type of ion exchange membrane consists of a linear chain fluorocarbon with a small percentage of sulfonic and carboxylic acid groups. These side chains are where hydrogen ions can be partially or fully exchanged with a number of differing cations. Many differing configurations were explored, but Grot eventually settled on a polytetrafluorol backbone with polyvinyl ether pendant side groups terminated with a sulfonate ion group [7]. The chemical formula is: 


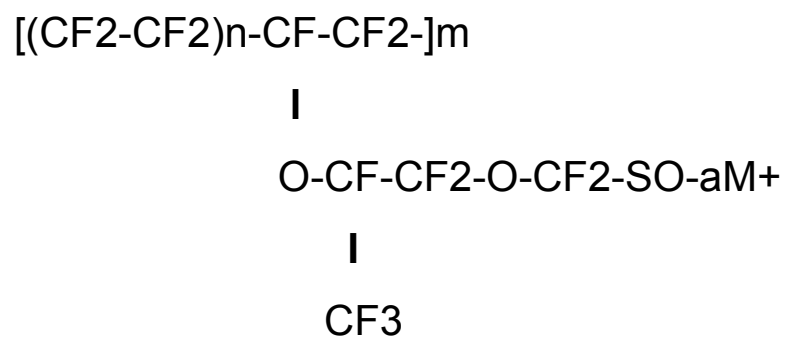

The $\mathrm{M}+$ can represent any number of counter ions such as $\mathrm{H}+, \mathrm{Li}+$, and $\mathrm{Na}+$. The membrane contains two phases of components which are the fluorocarbon and ionic phases. These phases are separated by the covalent bonds that tie them together. The structure of the membrane is of a cluster with the aqueous ions imbedded in the continuous fluorocarbon phase. Each ionic phase region is connected to the other regions by small channels determining the transport properties[8]. Figures 4 and 5 illustrate the layout of the ionic region of the membrane.

General fabrication

Since Nafion could be considered an industry standard when dealing with PEM fuel cells a review of the fabrication process is beneficial. The base of the membrane is polyethylene. This polymer is modified by exchanging the hydrogen molecules with fluorine in a process called perflourination. The resulting polymer is polytetrafluoroethylene (PTFE) also known as Teflon (a registered trade mark of $\mathrm{ICI}$ ). Next, the PTFE is sulphonated by adding HSO3 side chains. Since these side chains are ionically bonded, the SO3- ion resides at the end of this side chain producing an ionomer. The areas around these ionomers become highly hydrophilic within a generally hydrophobic structure, thus allowing for large quantities of water to be absorbed. In these hydrated 
regions the $\mathrm{H}+$ ions are weakly bonded to the SO3- groups and therefore are able to propagate [9].

\section{CLUSTER-NETWORK MODEL}

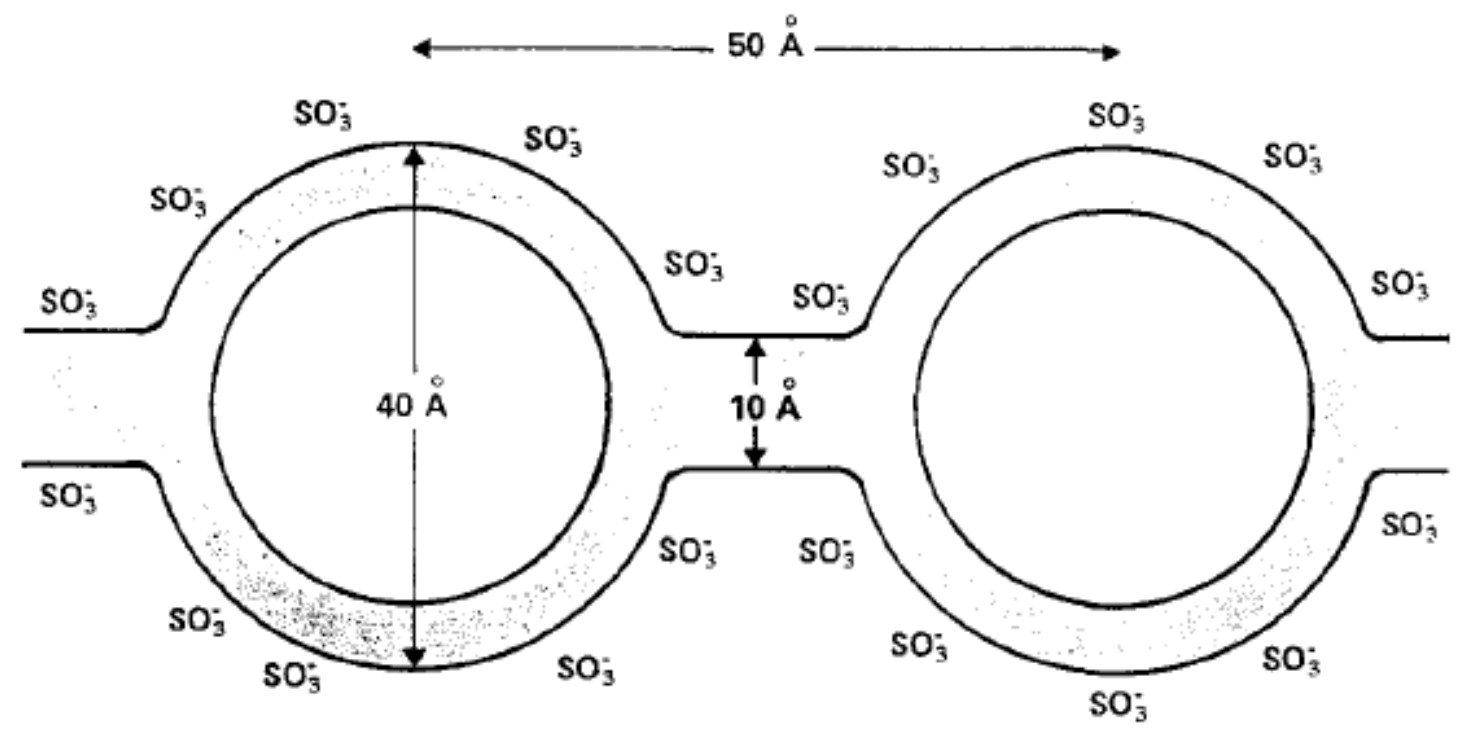

Figure 4: Micro-sized ion passage illustration

The amount of water present in the membrane is determined by the type of polymer and the selection of the counter ion. 


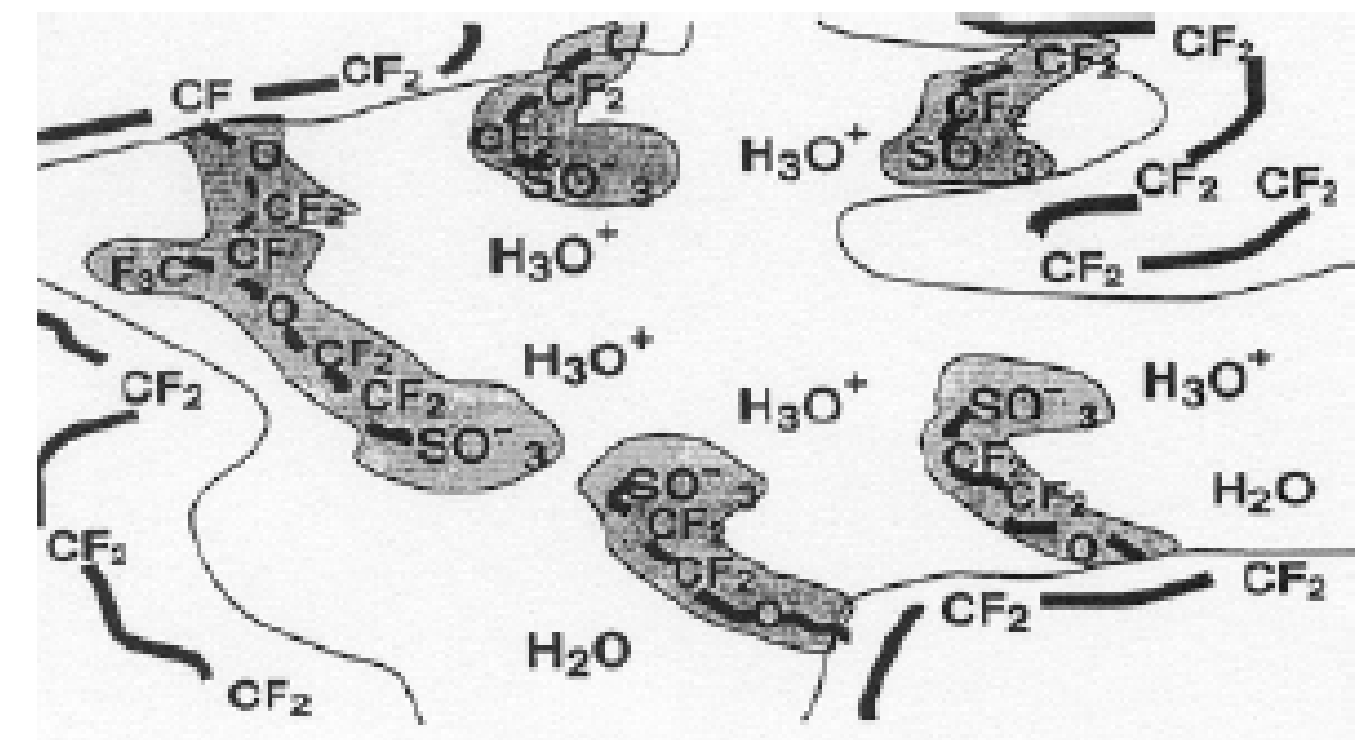

Figure 5: Proton exchange layer model

Nafion water balance

Since the development of the Nafion membrane material there has been an intricate relationship between the membrane's water content and the cell's power output. Since the water facilitates the diffusion of the hydrogen ion through the membrane it would be logical that the more water in the cell the higher the efficiency. Experience has shown that there is an optimal amount of hydration that the membrane should maintain. There are many theories to why over-hydration effects the power output, but the most widely accepted speculates that Gas Diffusion Layer on the cathode side of the cell becomes flooded with water [5, 9-13].This would block the diffusion of the oxygen to the reaction site within the membrane. This dictates that a delicate water balance must be maintained in order to efficiently operate the cell. Evenly hydrating the membrane has been identified as a critical development area and has become the main focus of a current field research [10,11]. Without the proper hydration levels the ion transfer (ohmic) resistance of the cell increases, thus limiting power output. 
Research has shown that as the cell operates the anode tends to dry out while the cathode has the propensity to flood.

A water balance of a standard PEM fuel cell has been outlined as follows: Water may enter the anode via the humidified hydrogen gas or by diffusion through the Nafion membrane driven by a large concentration gradient. Water exits the anode through the anode exhaust outlet or osmotic drag, caused by the hydrogen ion - water affinity, through the membrane. The cathode side has a similar balance except for the addition of water that is produced by the cells chemical reaction $2 \mathrm{H}_{2}+\mathrm{O}_{2}=2 \mathrm{H}_{2} \mathrm{O}$. It is this extra water produced on the cathode side which is the logical source of the cathode's tendency to flood, while on the other hand the osmotic force produced by the ion transfer through the cell tends to drag water molecules through the semi-permeable membrane causing the anode to dry out.

It has been shown that there can be dry and flooded areas co-existing in the same electrode region [12]. These internal variations can be related to both the membrane and GDL design parameters such as chemical structure, composition, and graphite plate fuel channel design. Sundaresan et al. [12] found that membranes tend to be more hydrated near the inlet and drier near the exhaust. Therefore, optimized fuel patterns must be utilized to evenly distribute the fuel gas over the electrode and minimize over hydration in a localized area. With a basic understanding of the continuous water cycle occurring within the cell, the ice formation can now be analyzed during sub freezing conditions.

Water balance in a sub zero climate

In order to achieve the performance and longevity that the Department of Energy has defined, an understanding of the destructive mechanisms must be 
obtained. In order to determine the water distribution within the cell, techniques such as neutron radiography, optical visualization, thermograph, and thermocouple investigations were performed [11]. Y. Ishikawa et al. developed a process using special mirrors, thermal imaging equipment and a peltier cooling element in order to simultaneously obtain visual and thermal images of the operating cell. It was found that liquid water was still generated on the surface of cathode when the cell was operated below freezing. The water was initially super-cooled, only warming to zero degrees Celsius upon freezing. It can be seen from as the generated water freezes the cell's performance is negatively affected.

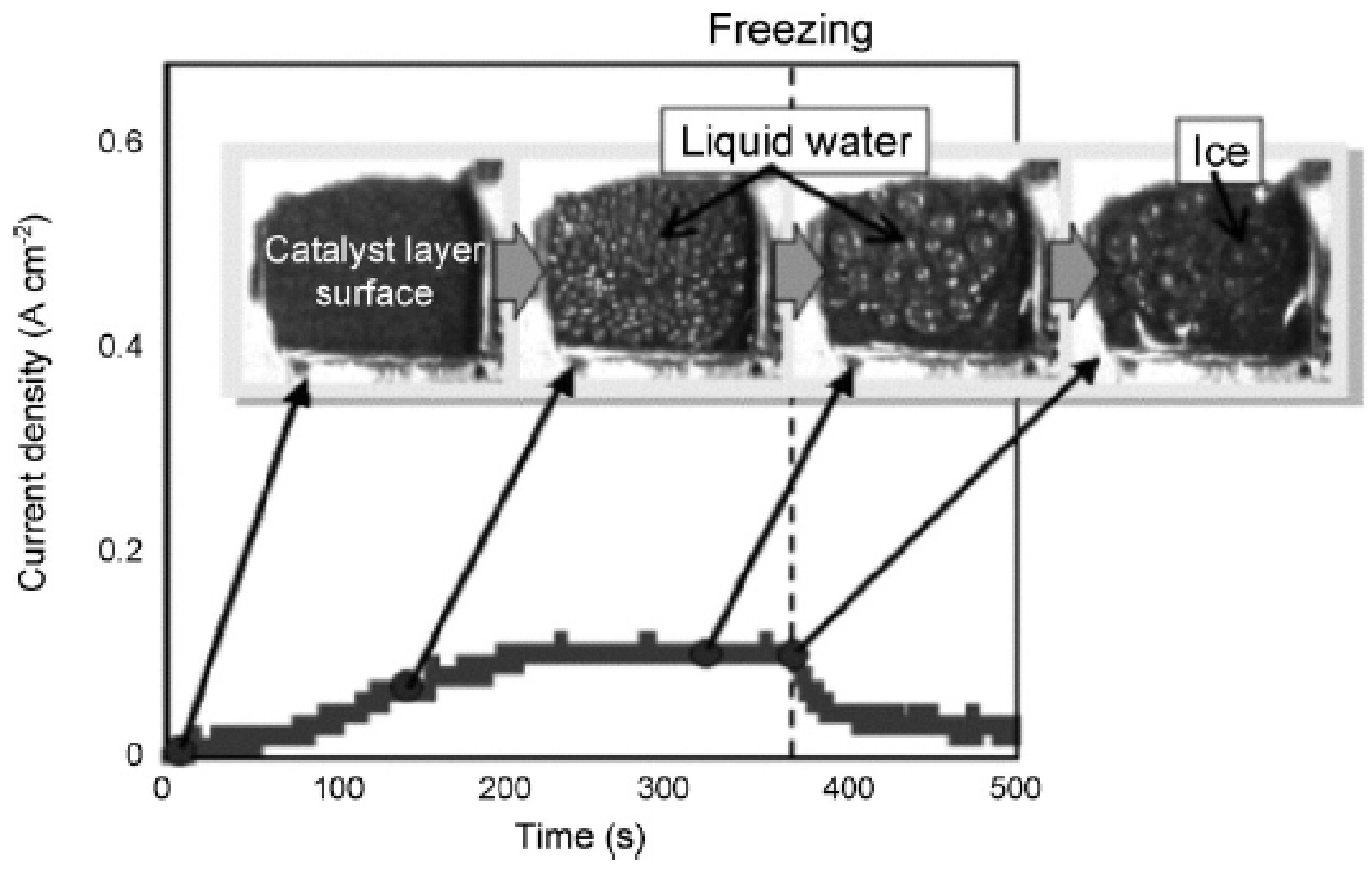

Figure 6: Ice formation and subsequent power losses

If the water could be kept in a super-cooled liquid state, the cell could be operated at sub-freezing conditions without negative degradation effects of ice formation [11]. It can also be noted that the freezing of the super cooled water droplets occurs once the small water droplets, approximately $10 \mu \mathrm{m}$ in diameter, 
combine to form larger droplets of approximately $100 \mu \mathrm{m}$ in diameter. The cause of the transformation, from super-cooled liquid to ice, has been theorized by Shichiri et al. [14] to be the result of bursting air bubbles, but further investigation is needed to properly explain this phenomenon. According to Cappadonia and Saito $[15,16]$, the water located within the Nafion membrane partially freezes near -20 degrees $C$. They speculate that there is still super-cooled water still remaining un-crystallized even at -20 Celcius. Furthermore, experiments conducted by Ishikawa et al. [11] show that water behaves differently during freezing if it is located in the ion phase of the membrane instead of being part of the cell's bulk water.

\section{Effects of ice formation}

Catalyst layer

The volumetric expansion during the phase change of water can cause destructive tearing of the porous catalyst layers [4]. Guo et al. [17] found that some areas of the catalyst were torn away from the membrane. This was confirmed after these areas showed no Electron Dispersion Spectroscopy signals which means they were initially beneath the surface layer. Gou [17] inferred this type of destruction could cause delamination of the catalyst layer from the membrane or the GDL, therefore increasing the contact resistance. According to Wannabe et al. [18] these membranes are physically made up of two distinct pore size distributions. The small pores (called primary pores sized from $.01 \mathrm{~nm}$ to 1 micrometer) are located within the primary particles, thus forming agglomerates (approximately one micrometer), while the secondary pores were located among the agglomerates. The microstructure of this catalyst layer can be viewed as carbon particles flooded with the electrolyte which will form agglomerates. The reactant gases diffuse through the ionomer thin film, the 
electrolyte, and then through the agglomerates to reach the reaction site. Therefore, since there is a porous electrode and a hydrated ionomer layer; the catalyst layer can only hold a certain amount of water. As the amount of residual water increases the pores are filled in the following order: small hydrophilic pores, large hydrophilic pores, large hydrophobic pores, and then the small hydrophobic pores. Once the water freezes the volumetric expansion of the ice enlarges the pores between the agglomerates and thus compresses the pores within the agglomerates. This sequence becomes evident after a few freeze thaw cycles because the number of small pores $(<20 \mathrm{~nm})$ decreases while the number of larger pores $(>20 \mathrm{~nm})$ increases [19]. Figure 7 illustrates the flooded agglomerates (a) before and (b) after the freeze degradation. Experiments conducted by Kim et al. suggested that the catalyst layer destruction is related to irregular pressure uniformity of the diffusion media upon the catalyst layer. It has been postulated that extra stress is incurred by the stress concentrations experienced at the channels and lands(raised area) that bipolar plates impose on membrane [20]. An example of these channels and lands can been seen in figure 3. Physical damage was observed to occur in regions directly in contact with these channel regions, while the regions located under the lands were not destroyed due to the stabilizing pressure provided by the land. Kim and Mench [20] proposed that a stiffer gas diffusion layer would help mitigate these stress concentrations during freezing. Although it was found that less physical damage resulted from flow patterns with high land/channel ratios, there was still performance losses experienced that could not be corrected unless all the water was removed from the membrane prior to freezing [20]. 

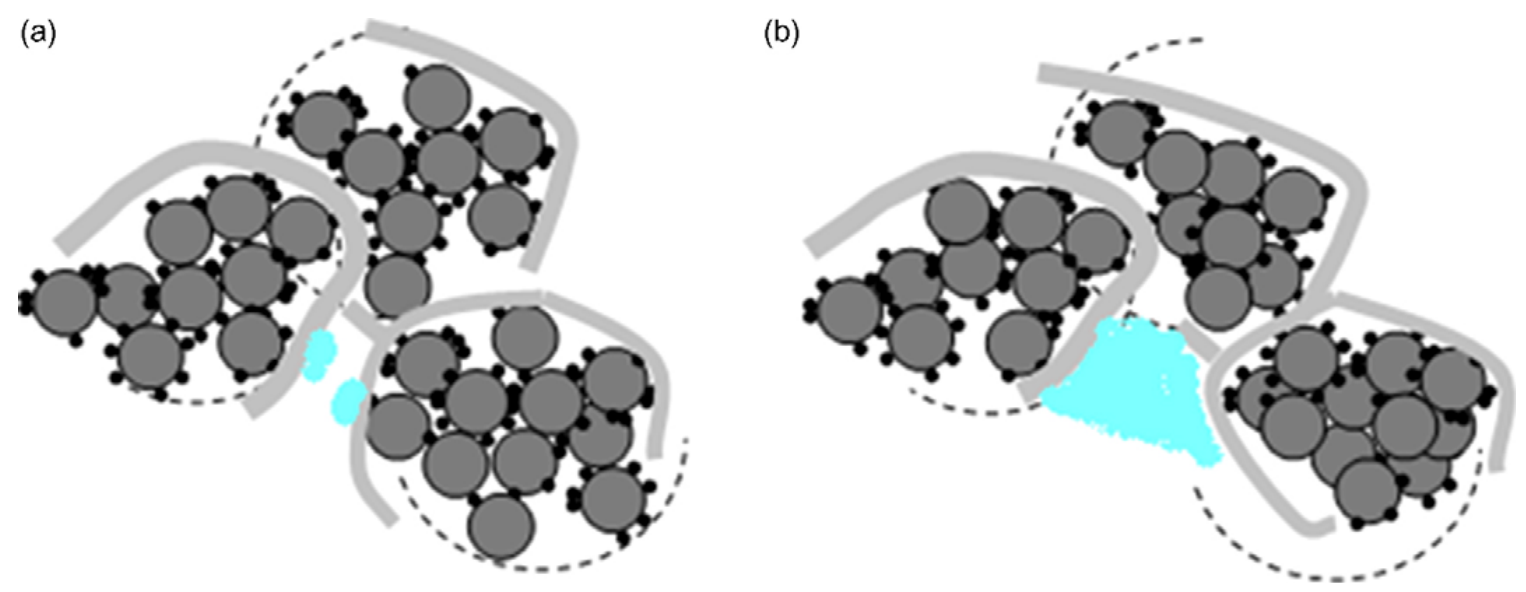

Figure 7: Ice formation effects on agglomerate pores

Hou [21] found that there was significant destruction of the catalyst layer's morphology which can be directly correlated to the amount of residual water contained in the membrane. The membranes investigated included water amounts of $.9 \mathrm{mg} / \mathrm{cm} 2$ with no significant performance loss at $1 \mathrm{~A} / \mathrm{cm} 2$, but when the residual water weight was increased to $3.6 \mathrm{mg} / \mathrm{cm} 2$ the performance degradation was about $16 \%$ when operated at the same temperature and pressure.

Hou [19] confirmed the assumptions made by Watanabe [17] by considering the increase in resistance as seen in the Tafel slope after sub-zero climate exposure. Hou observed that at higher current densities the Tafel slope became steeper indicating that there is an agglomerate diffusion effect within the catalyst layer. The Tafel slope increases after the freezing process especially for membranes with a large amount of residual water content. This suggests that the pores in the agglomerates have been compressed, so the agglomerate diffusion becomes greater thus increasing the Tafel slope. This experiment elucidates the fact that volumetric expansion that occurs within the agglomerates can be neglected when compared to the expansion of the pores among the agglomerates. 
By measuring the amount of nitrogen absorption with a BET surface area analysis, the number of pores with a size greater then $25 \mathrm{~nm}$ increased while the number of smaller sized pores decreased [9]. Cho et al. [22] found by means of cyclic voltammetry that a significant loss of electrochemical active surface was the result of the volumetric expansion. Ice can form on the gas diffusion layer blocking the reactants from reaching the membrane [23]. This result was confirmed by repetitive freeze/ thaw cycles on both a hydrated and de-hydrated membranes [24]. Zhang et al. [24] found that the current density at .6 volts dropped from $570 \mathrm{~mA} / \mathrm{cm}^{2}$ to $420 \mathrm{~mA} / \mathrm{cm}^{2}$ after nine freeze/thaw cycles. In comparison to the de-hydrated membrane which had almost indistinguishable polarization curves before and after the nine freeze cycles. It is known that the density of water and ice at $0{ }^{\circ} \mathrm{C}$ are $.9998 \mathrm{~g} / \mathrm{cm}^{2}$ and $.9168 \mathrm{~g} / \mathrm{cm}^{2}$ respectively, so the effective volume of ice can increase as much as $9 \%$. This volumetric increase induces a mechanical stress in the hydrated regions causing the porous structures to be altered. These mechanical stresses account for most of the irreversible degradation of the membrane.

Gas diffusion layer

The gas diffusion layer serves several essential functions such as reactant transport, water transport, electronic conductivity, thermal conductivity, and mechanical support. It is obvious that the G.D.L. has a critical role in facilitating maximum power output. The gas diffusion layer is typically constructed of carbon fiber paper treated with a hydrophobic polymer coating such as polyteterfluoroethylene (P.T.F.E.). This coating allows for efficient water removal and helps to prevent flooding at higher current densities. Gas diffusion layers are often treated with a micro porous layer (M.P.L.) on the catalyst side to help ensure sufficient water transport and electrical contact [25]. Some recent publications have focused on utilizing ex-situ methods to quantify the G.D.L.'s 
durability. A decrease in sessile drop contact angle was reported by Wood et al. [26] when the $\mathrm{GDL}$ was submersed in de-ionized water at $60^{\circ} \mathrm{C}$ and $80^{\circ} \mathrm{C}$. This process of submersing the GDL in constant temperature solution is known as aging and will be referenced later. Wood observed a decrease in hydrophobicity within in the first $100-150$ hours of submersion, and when the experiment was repeated in air the degradation was found to be even greater during the same duration of time. A possible cause of this degradation was not discussed and could be attributed to various processes. Another study [27] conducted examined the weight loss and MPL contact angle of the GDL while being aged in a hydrogen peroxide solution at $82^{\circ} \mathrm{C}$. Kangasniemi [28] found that both weight loss and contact angle increased with prolonged exposure time. This effect has been attributed to the oxidation of carbon within the MPL. The performance of the altered G.D.L.s was evaluated by insertion in to control M.E.A.s. The MEA performance showed increased mass transport losses, and was in agreement with results given for long term fuel cell tests conducted. The postulate that the MPL surface oxidation and the accompanying decrease in the sessile drop contact angle could affect the water transport and therefore the mass transport has also been investigated and confirmed by Williams et al. [29]. Lee et al. [30] investigated the effect of freezing conditions on the G.D.L.'s in-plane electrical resistivity, bending stiffness, plate-side surface contact angle, catalyst side surface, contact angle porosity, water vapor diffusion, In-plane air permeability, and through-plane air permeability. The only parameter which experienced any sort of degradation was air permeability of the membrane which increased by $18 \%$ and $80 \%$ (depending on if the G.D.L. was aged before freezing). The dry un-aged GDL did not exhibit any increase in permeability, thus concluding that this degradation is caused by the volumetric expansion experienced during the water/ice phase change. The dry aged G.D.L. (w/18\% permeability increase) has been theorized to be the result of M.P.L. material loss and not alteration of the pore structure during the ageing process. 


\section{Mitigation strategies}

Before fuel cells will be able to compete with internal combustion technology for market viability, cold temperature start up of the cell must be accomplished quickly and efficiently. Some of the problems faced during a cold start include slower chemical reaction rates, poor humidification of the membrane, and ice blockage of fuel lines. These problems have been addressed by using both passive and active heating schemes. A passive heating or start up scheme uses the irreversible heat produced by the chemical reactions within the fuel cell to raise the cell to the optimum temperature. An active heating scheme uses a secondary heat source (i.e. resistive or waste heat recovery) to quickly raise the fuel cell to the optimum operation temperature. An example of such a scheme would be to use the cooling loop of cell for heating during cold startup. It has also been proposed that the catalytic combustion of hydrogen/oxygen mixtures could also be a form of internal active heating [4, 31, and 32]. Oszcipok et al. found that when the efficiency of the passive and active start up processes are compared; the active start up method is at least twice as efficient. The active start up scheme (from $-20^{\circ} \mathrm{C}$ to $0^{\circ} \mathrm{C}$ ) uses 4.5 Watt hours (includes an $85 \%$ battery load efficiency and $52 \%$ fuel cell efficiency) as compared to 10 Watt hours required with the passive scheme [4]. Another mitigation technique involves the reduction of the membrane's water content in attempt to minimize the internal ice formation.

In order to minimize the effects, many differing start up and shut down strategies have been developed. The most common type of shut down strategy is to purge the cell with an inert gas $\left(\mathrm{CO}_{2}\right.$ or $\left.\mathrm{N}_{2}\right)$ so as to dehumidify the cell and minimize the cell's bulk water content before freezing [4]. A PEM fuel cell membrane fabricated from Nafion-117 was found to operate at temperatures as low as $-35^{\circ} \mathrm{C}$ at the Indian Scientific Research Station in Antarctica [17]. After the experiments were completed the membrane was purged with nitrogen gas before shut down in order to avoid the devastating effects of internal ice 
formation. While these experiments still had setbacks, as the cooling unit and humidification bubblers had a tendency to freeze, the successful operation of the fuel cells gives hope for the future for this technology.

A variation of this principle involves reducing the humidity of the fuel gases ( $\mathrm{H} 2$ and $\mathrm{O} 2$ ) between $50-60 \%$ in order to dry out the cell slowly to prevent overdrying [9]. Hou et al. conducted several cold start experiments at $-5^{\circ} \mathrm{C}$ and found while the cell did not have any problems upon startup there was a decrease in performance observed after each freeze/thaw cycle was completed. By using several membranes with differing amounts of hydration, Hou et al. were able to determine the effect that water has upon the performance. They found that as the water content increased, so did the amount of degradation seen after each cycle. Hou et al. also completed investigations concerning the physical structure of the membrane by comparison of SEM photographs [13].

Another variation of the concept presented above would be to manufacture thinner membranes which would be able to operate properly with dry reactant gases. Since the membrane is thinner, the back diffusion resistance is decreased, thus allowing more water to propagate across the membrane for the same concentration gradient. Vengatesan et al. [33] found these thinner membranes $(\sim 25 \mu \mathrm{m})$, increased cell's performance values at lower temperatures (from $35^{\circ} \mathrm{C}-50^{\circ} \mathrm{C}$ ), but experienced excessive performance losses at higher operating temperatures greater then $60^{\circ} \mathrm{C}$ due to the excessive drying of membrane and decreased proton conductivity [33].

Another strategy was to use an anti-freeze solution like methanol to prevent ice formation. Palan et al. found that the anti-freeze solution reduced the formation temperature, but did not reduce the amount of freezable water in the membrane [34]. Further studies conclude that the amount of freezable water actually increased from $23 \%$ to $63 \%$ after the methanol addition. This phenomenon can be attributed to the fact that super cooled methanol could 
replace water in the solvation of the ionic groups, thus driving more water out of the polymer and into the bulk volume [4].

Before fuel cells will be able to compete with internal combustion technology for market viability, cold temperature start up of the cell must not only be accomplished without performance degradation, but also quickly and efficiently. Some of the problems faced during a cold start include slower chemical reaction rate (caused by lower temperatures), poor humidification of the membrane, and ice blockage of fuel lines. These problems have been addressed by using both passive and active heating schemes. A passive heating or start up scheme uses the irreversible heat produced by the chemical reactions within the fuel cell to raise the cell to the optimum temperature so that maximum power output can be obtained. The process of the catalytic combustion of hydrogen/oxygen mixtures could also be a form of internal heating [4]. This mitigation technique will be further illustrated in the following Patented Techniques section.

An active heating scheme uses a secondary heat source (i.e. resistive or waste heat recovery) to quickly raise the fuel cell to the optimum operation temperature. An example of such a scheme would be to use the cooling loop of the cell for heating during cold startup. Wang et al. investigated another type of active startup scheme which utilizes an external current source during subfreezing startup. This technique transforms the fuel cell into a hydrogen pump, which not only helps to clear the pores of water, but actually helps increase the amount of reactant gases at the catalytic regions. Since one of the major problems with subzero startup is the restriction of fuel from reaching these catalytic sites, this technique showed a cell could warm from $-15^{\circ} \mathrm{C}$ to $0^{\circ} \mathrm{C}$ within 100 seconds [35]. Oszcipok et al. found that when the efficiency of the passive vs. active start up processes is compared the active start up method is more than twice as efficient. The active start up scheme (from $-20^{\circ} \mathrm{C}$ to $0^{\circ} \mathrm{C}$ ) uses 4.5 Watt 
hours (includes an $85 \%$ battery load efficiency and $52 \%$ fuel cell efficiency) as compared to 10 Watt hours required with the passive scheme [4].

Patented mitigation techniques

Although there are still many questions regarding sub-zero operation and the inherent degradation of fuel cells, there has been some progress in this area. United States patents are a preview of cutting edge technologies, and techniques soon to be employed. The following patents are focused upon solving the inherent problems associated with sub-zero storage and operation, although this is not a comprehensive list of available technologies a conscientious effort was made to include one patent from each mitigation type surveyed.

Patent number $6,777,115$ describes a battery assisted fuel cell which effectively uses a battery or a capacitor wired in series with the cell to aid in the heating of the cell [31]. According to the invention, the additional current provided by the battery forces the weak cells in the fuel cell stack to a negative cell voltage which produces heat as a consequence of polarizations within the cell. The performance of the weak cells quickly approaches the typical performance of good cells. Furthermore, while the battery is connected in series with the fuel cell, the excess fuel, which may be hydrogen or hydrogen-containing fuel, is supplied to the anodes of the fuel cell stack to further support the stack's efficient startup.

Patent number 6,103,410 illustrates how dilute hydrogen and air mixtures can be introduced into one of the electrodes in order to react with the noble metal catalyst to produce heat at sub-flame temperatures [32]. An embodiment of this concept includes a catalyst structure to be located in between the cathode and oxidant channels. The invention further explains that if the cell is not 
hydrophobic enough to prevent the freezing over of the pores, which facilitate the transportation of fuel to the catalyst region, that larger hydrophobic pores can be designed into the M.E.A. in order to ensure unrestricted flow of the hydrogen/air mixture.

Patent number $6,797,421$ describes a process which uses the available hydrogen to fuel an external catalytic burner in order to keep the fuel cell and the encapsulation device above freezing temperatures [36]. This invention describes a fuel cell climate chamber which would regulate the cells internal temperature to protect from ice formation. This concept, further investigated by Sun et al., proved that the catalytic hydrogen reaction is an effective way to heat a frozen fuel cell. Sun proposes that the fuel channels are small enough to operate similar to micro-channel reactors, thus confirming that a lean mixture will not explode when hydrogen concentrations are kept below 20 volume percent [37]. Sun reports the catalytic hydrogen does not have any effects on the performance of the cell according to cyclic voltammetry measurements and polarization curves.

\section{P.E.M. fuel cell membrane materials}

One plausible solution to the freeze degradation problem is to develop a material which can withstand the stresses and strains imposed by the formation of the ice crystals. There are many current endeavors which seek to mitigate this problem. Both organic and inorganic hybrid membranes have been considered and investigated. An example would be membranes manufactured from materials such as biphenyl sulfone [38] and polyphenylene sulfone copolymers [39]. These polymers may provide the delicate balance between conductivity, thermal and chemical stability, and mechanical integrity to make a stronger, more resilient membrane. Great strides have been made in the ion conduction ability 
of these membranes, but further developments in mechanical strength and chemical stability are still desired [2].

Vengatesan et al. developed a composite membrane which has the ability to retain water allowing for non humidified operation. This is accomplished by adding inorganic particles to the membrane such as $\mathrm{SiO} 2, \mathrm{TiO} 2$, and $\mathrm{ZrO} 2$ which keep the membrane well hydrated [40]. The actual composite material added to the membrane and electrodes is silica. Vengatesan found that low equivalent weight ionomers exhibited a greater ability to retain water then their heavier counter parts. The results of the initial performance evaluation showed that cell actually operated at a higher efficiency than the normal Nafion membrane. This is due to the fact that thin membranes allowed more water to diffuse to the anode side of the fuel cell, thus keeping the cell more evenly hydrated. This membrane may be able to withstand the effects of freeze degradation because of its low bulk water content which would minimize the effects of the internal ice formation.

Di Vona et al. [41] investigated the addition of the same inorganic fillers for the membrane's improvement. They describe similar results as Vengatesan et al., but concluded that there would eventually be porosity problems (i.e. increased membrane ohmic resistance) due to the delamination of the catalyst and GDL layers [41]. Other avenues currently being investigated include the addition of acids such as heteropoly acids, but they tend to leach out during operation. Polymer or organic-inorganic hybrid blends are another plausible solution because these materials allow for advanced control over material properties at the molecular level, thus strengthening the membrane while still maintaining low ion conductivity.

In organic/inorganic polymers, carbon forms the base chain and the inorganics comprise the side groups. These polymers could allow for the precise control of the number of hydrophilic and hydrophobic regions which would optimize proton conductivity, material strength, and morphological stability [36]. 
One of these materials is called polyetheretherketone (PEEK), which when compared to Nafion is less acidic, has a less hydrophobic backbone, allows for wide separation of the $\mathrm{SO} 3 \mathrm{H}$ groups, larger number of narrow channels, and a lower humidity dependence. DI vona concluded after completing a PEEK Nafion performance comparison that PEEK improved the membrane's mechanical properties, but still had a slightly higher resistance to proton transport.

Sgreccia and Licoccia $[42,43]$ found that in order to achieve improvement required. As a result of the sulfonation the mechanical properties were degraded because the acid groups attached to the hydrophobic backbone cannot arrange in separate phase domains (as illustrated in figure 3) as well as the perfluorinated systems with hydrophobic side chains [44]. Since the membrane's mechanical properties have deteriorated the membrane tends to swell and eventually become water soluble and useless as a PEM membrane [45]. A proposed mitigation technique was investigated by using siliated polymers which promise to enhance thermal stability, conductivity, and minimize membrane swelling [42, 43] Sgreccia et al. suggested that the hardening of the polymer could be attributed to the large phenyl-silanol side chains. These side chains would fortify the S-PEEK polymer chains during shearing [42]. Another postulation presented by Sgreccia is that the increase of polymer strength could be related to hydrogen bond interactions between the silanol and sulfonate groups. Both investigations of siliated S-PEEK conclude that there must be a delicate balance between the membrane's mechanical integrity and impedance which is dictated by the amount of membrane hydration.

Another interesting approach to solve the hydration problem was outlined by Ho Jung [46]. SiO2 was added to the anode catalyst layer in attempt to improve the water management. These modifications were conducted on both naturally aspirated (free breathing fuel cell) and the standard forced air cell. Test results showed that both cells which had $\mathrm{SiO} 2$ added to the cathode had 
improved performance through the entire current range [46]. The air blowing cell showed a $26.9 \%$ increase in performance, while the natural air breathing system had a $44.4 \%$ increase. This performance increase has been attributed to the increased hydrophilic properties of the anode caused by the $\mathrm{SiO} 2$ addition.

The membrane is not the only fuel cell component which is in need of a water management scheme. The Gas Diffusion Layer (GDL) and the Micro Porous Layer (MPL) have been known to become flooded, therefore restricting the flow of fuel to the reaction sites. A solution proposed by Nakajima et al. [47] involves the treatment of these two structures with hydrophobic PTFE. It was found that the hydrophobic treatment water accumulates at the electrode and in the flow channel, while decreasing the amount of water present in the GDL layer. Nakajima et al. proposed that the decrease of the performance was due to the accumulated water blocking the transport of oxygen to the electrode [47]. In this case, the hydrophobic treatment of GDL layer simply moved the oxygen transport (i.e. cathodic flooding) problem to another area of the cell.

The last method of membrane alteration involves the dispersion of multiwalled carbon nano-tubes throughout the Nafion membrane [43]. This type of modification has been proposed to aid in the reduction of methanol cross-over in Direct Methanol Fuel Cells (DMFC), but also could improve in the membrane's strength and ion conductivity at low humidity levels. Thomassin et al. found that with the addition of the carbon nano-tubes the methanol permeability was significantly decreased (by approximately $60 \%$ ), while the Young's modulus of the Nafion was increased $160 \%$. The increase of the Young's modulus could help to minimize the membrane degradation that occurs after the internal ice crystallizes. The meshing of Nafion and carbon nano-tube technology has shown promise, but the full potential of this hybridization has yet to be realized. 


\section{Finite element modeling simulation}

Thermal management plays an important role in the optimization of sub zero storage and operation of the cell. Modeling approximations provide an opportunity to gain insight about complex processes occurring within the cell. Mathematical models use fundamental equations to simulate the operation of a fuel cell. This allows for investigation of key processes (i.e. electro-chemical reactions in the catalyst layer, proton mitigation in the semi-permeable membrane, and mass transport in all regions) to be explored and optimized. The thermal, pressure, and humidity maps generated greatly aid design engineer's ability to understand and improve on the current technology. The first fuel cell models were adapted from the battery industry models. These models tended to be one dimensional and inaccurate when compared with the actual results [48$51]$.

Most basic modeling techniques consider the fuel cell stack as a lumped parameter heat transfer problem which uses the exiting coolant temperature to approximate the stack temperature. In order to more accurately model the internal temperature gradient during the transient start up period, a layered experimental model was proposed [11]. The experimental cell would have thermocouples throughout a layered membrane in order to get a better idea of the temperature gradient. As a result of this experiment Sundaresan et al. recommends using an active heating scheme, circulating the cooling loop during warm up, minimizing the thermal mass of the cooling loop, heating of the end plates, and using metal based bipolar plates to facilitate the successful startup of a cell that has been frozen.

The cell's MEA tends to dry out in some areas, while flooded in others suggesting that a one dimensional lumped capacitance model will not provide enough resolution to reveal the condition (temperature and water content) of the MEA. Siegel et al. suggested using a two dimensional model that includes the 
transport of the water, gaseous species, protons, energy, and dissolved water in the membrane. The goal of the model is to describe the operating regimes dominated by mass transport limitations resulting from the transport and formation of water. Siegel stresses that in order to model a membrane, the physical properties of the MEA (porosity of the gas diffusion and catalyst layers, ionic conductivity of the membrane, mass transfer coefficients, reaction surface area, and structural properties) must be accurately measured. Once the model's results were fitted to actual test data, the performance limitations can then be isolated and quantified [48].

An extension of this concept was explored by references [49 and 50] where a three dimensional analysis of the transport and electrochemical reactions were completed. Most three dimensional models incorporate some type of computational fluid dynamic (CFD) code, thus allowing for parallel computing making high resolution steps practical. Most CFD models account for the convective and diffusive transport allowing for predictions of species concentrations. Since the entire membrane structure can be investigated locally, the heat load provided by the electrochemical reaction can be determined accurately. The model developed by Sivertsen et al. solves for the ionic and electric potentials in the electrodes and the membrane, as well as the local activation over-potential in order to predict local current densities. Sivertsen and Djilali [50] concluded that the changing relative influence of ohmic losses and activation over-potential losses drastically alters the current distribution within the model, thus confirming that the local activation potential needs to be considered during modeling efforts. Since the model utilizes three dimensional governing equations, the mass transport limitation of differing flow fields can be evaluated as well [45]. Um and Wang [49] found that at high current densities (greater than $.8 \mathrm{~A} / \mathrm{cm}^{2}$ ), the interdiginated flow field (similar to that of figure 8 ) allowed local current densities to increase by $40 \%$. 

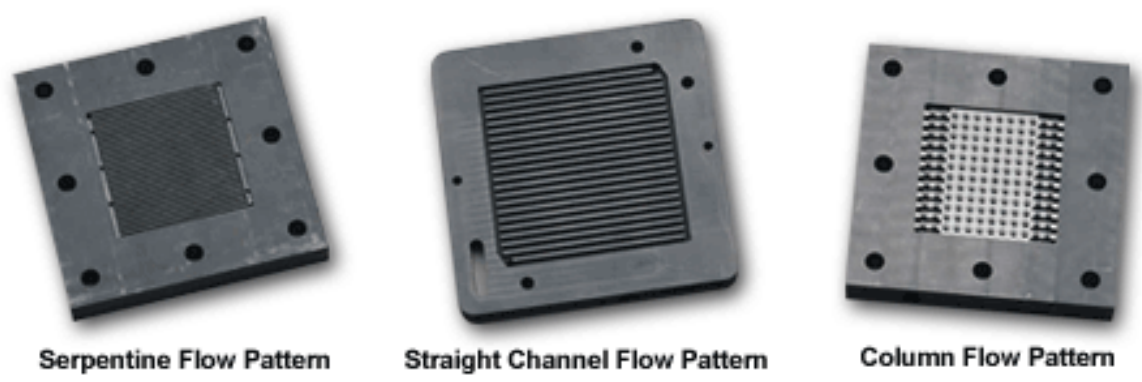

Figure 8: Interdiginated flow patterns

By utilizing one of these three techniques of approximating a cell's operation, authors [51-53] each focused on a different aspect of the membrane in order to elucidate the processes occurring in that specific region. For example, Mishra et al. [51] concentrated on determining the optimal design and operating conditions based on systematic parametric avenues. The design parameters considered for the optimization include the cell's potential, power density, maximum temperature rise, and minimum hydration. The results of the this study conclude that operating temperature, the anode's relative humidity and pressure are critical parameters that must be adjusted to obtain optimum operation [46].

Kulikovsky [52] sought to determine expressions for the membrane's resistance and voltage loss due to the incomplete humidification of the cell. The author determined that both of these parameters depend on the ratio of the mass transport coefficients of the water in the membrane and the GDL backing layer. The simulation accounts for this ratio when determining the effect of the level of hydration upon the membrane resistance and voltage loss. It was determined that if this ratio was less than one, then there exists an optimal current density which minimizes the membrane's resistance [52].

This same concept can be extended to describe the dependence of the cathode's potential on current density. Hsuen [53] validates the one dimensional model approach by accurately determining a cell's performance based on the oxygen depletion within the cathode. Hsuen's investigations prove that all one, 
two and three dimensional models, can accurately estimate the operation of the cell as long as the complexity of the investigation is paired with the appropriate model [53].

In order to simulate the effects of sub-zero start and operation, Sundaresan and Moore state that models must have the ability to map internal heating methods and the effect that the endplate thermal mass has upon the end cells [12]. Although current models do account for the internal and external heating methods, the lumped parameter assumption does not adequately describe the localized effects of these heating strategies. A major evaluation criterion of a heating scheme should include observation of the localized stack temperatures and water content. In addition, the effect that the thermal mass of the endplate has upon the stack's temperature distribution cannot be fully described without a layered model. Sundaresan proposed the use of a layered one dimensional model to quickly and accurately describe a cell's sub-zero operation characteristics. Furthermore, Sundarsen's layered one-dimensional model is of interest since the goal of the model is to evaluate systems for certification of the 2010 Department of Energy's performance criterion.

The model has been designed using Matlab/Simulink software by conducting energy and mass balance equations for each layer of the model. Each layer encompasses all of the pertinent cell processes including: sensible energy flows for the coolant, anode, and cathode gases, water generation and phase changes (vapor, liquid, and ice), stack heat loss to environment, and internal heat generation resulting from electrochemical reactions and ohmic resistances.

The primary result of these considerations is a midpoint temperature of the individual layer as a function of time. The pertinent regions that should be included in the sub-zero model include: the bipolar plates, gas diffusion layers, catalyst support, membrane, and end plate assembly. 
Preliminary results from the layered model simulating differing storage and startup procedures have shown an increased accuracy and ability to predict the effectiveness of a mitigation strategy. For example, during cold storage applications under 12 hours in length at an ambient temperature of $-20^{\circ} \mathrm{C}$, the model, described in [12], predicted that it is energetically favorable to prevent ice formation with resistance heaters ( .05 W per cell internal heat input and $10 \mathrm{~W}$ input at the endplates) instead of trying to thaw out the frozen membrane. In order to correctly model the cold startup situation each cell is assumed to have the same ice mass as the coldest cell in the stack (providing the worst case scenario). Both models clearly show that current mitigation strategies do not provide a viable solution to satisfy the Department of Energy's 2010 goals. 


\section{Chapter 3: Experimental facility and testing procedures}

The test bed was designed to provide the user with control of the parameters deemed necessary to obtain satisfactory experimental results. The following functions were determined to be essential for the operation fuel cell test station: control/monitoring of the ambient temperature, fuel cell temperature, fuel line humidity, contamination, mass flow, and pressure. An automated data acquisition system, a de-ionized water supply, drain for water output, and a power supply to drive all the data acquisition and control elements.

These parameters include thermocouple readings of the fuel cell's anode, cathode, hydrogen fuel line, air fuel line, ambient air temperature, cryogenic freezer temperature and the temperature of the respective gas inside of each humidification bubbler. Other sensors incorporated into this test bed include exhaust gas pressure sensors for both anode and cathode lines, mass flow controllers for both intake lines, humidity sensors for the intake lines, and a fuel cell current and voltage detector. In order to stabilize and control such variables as fuel cell temperature, hydrogen/air stream humidity and temperature active heating elements were installed. These elements are automatically controlled by one or multiple feedback devices described above. 


\title{
Test bed configuration phase: build 1
}

\author{
Purpose
}

The goal of the first build of the fuel cell test bed was to design and implement a testing center that could record important baseline data that would be compared to the performance data in order to determine the extent of cell degradation.

\section{Overview}

This phase of the project is analogous to the prototyping phase of any engineering design. The goal of this build was to explore how well the Labview expansion data acquisition cards could control and acquire the data required to produce the baseline and experimental results. The build 1 test bed design included all of the basic fuel cell system components noted previously. Ideally, the implementation of build 2 would only include the addition of a cryogenic climate chamber used to house the fuel cell while environmental stressing occurs. Of course, nothing is perfect and unfortunately other modifications were needed to optimize the cell's performance while improving the over-all system error. Figures 8, 9, and 10 show build 1's control box and test bed layout. 


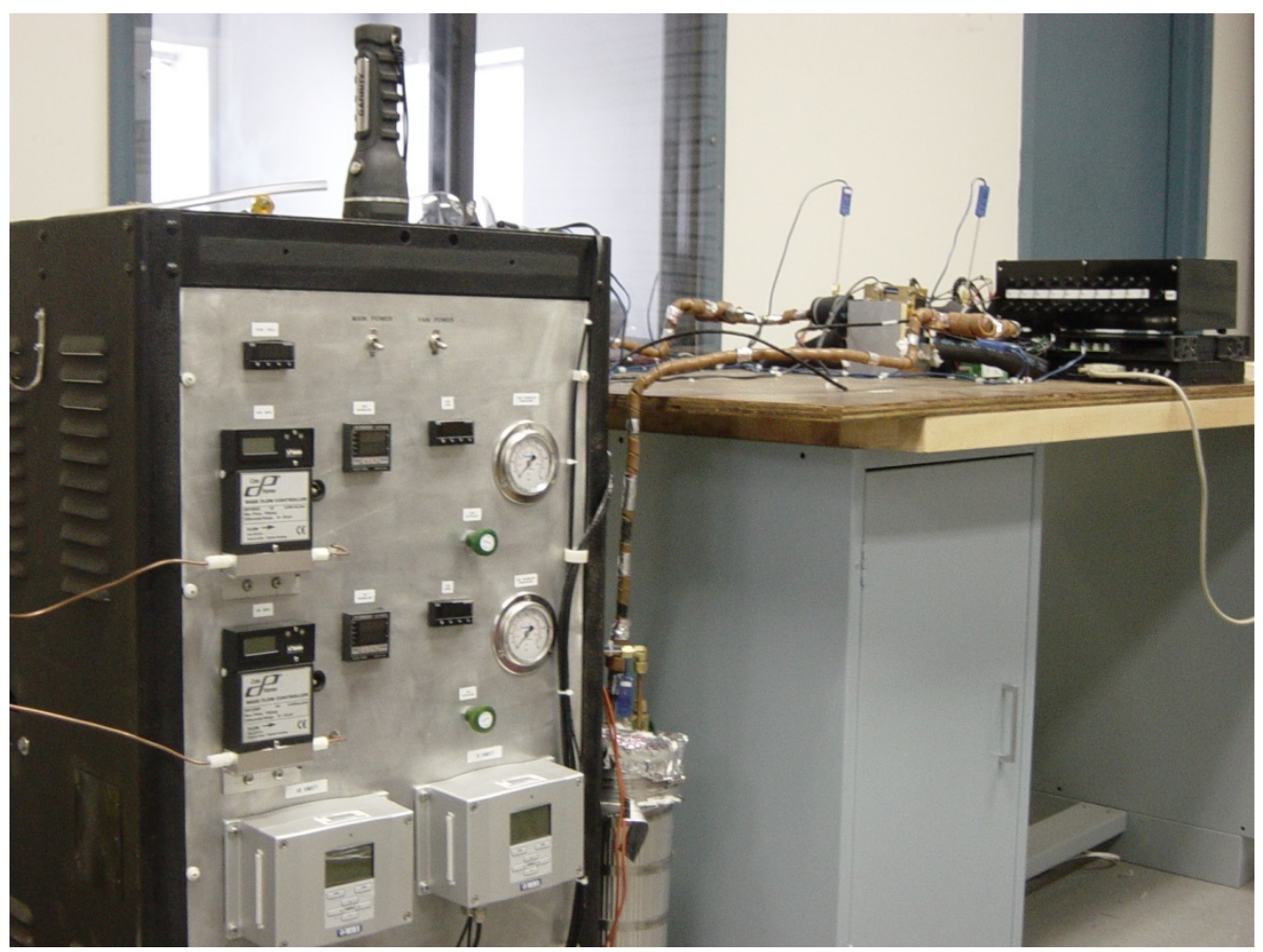

Figure 9: Fuel cell test bed build 1

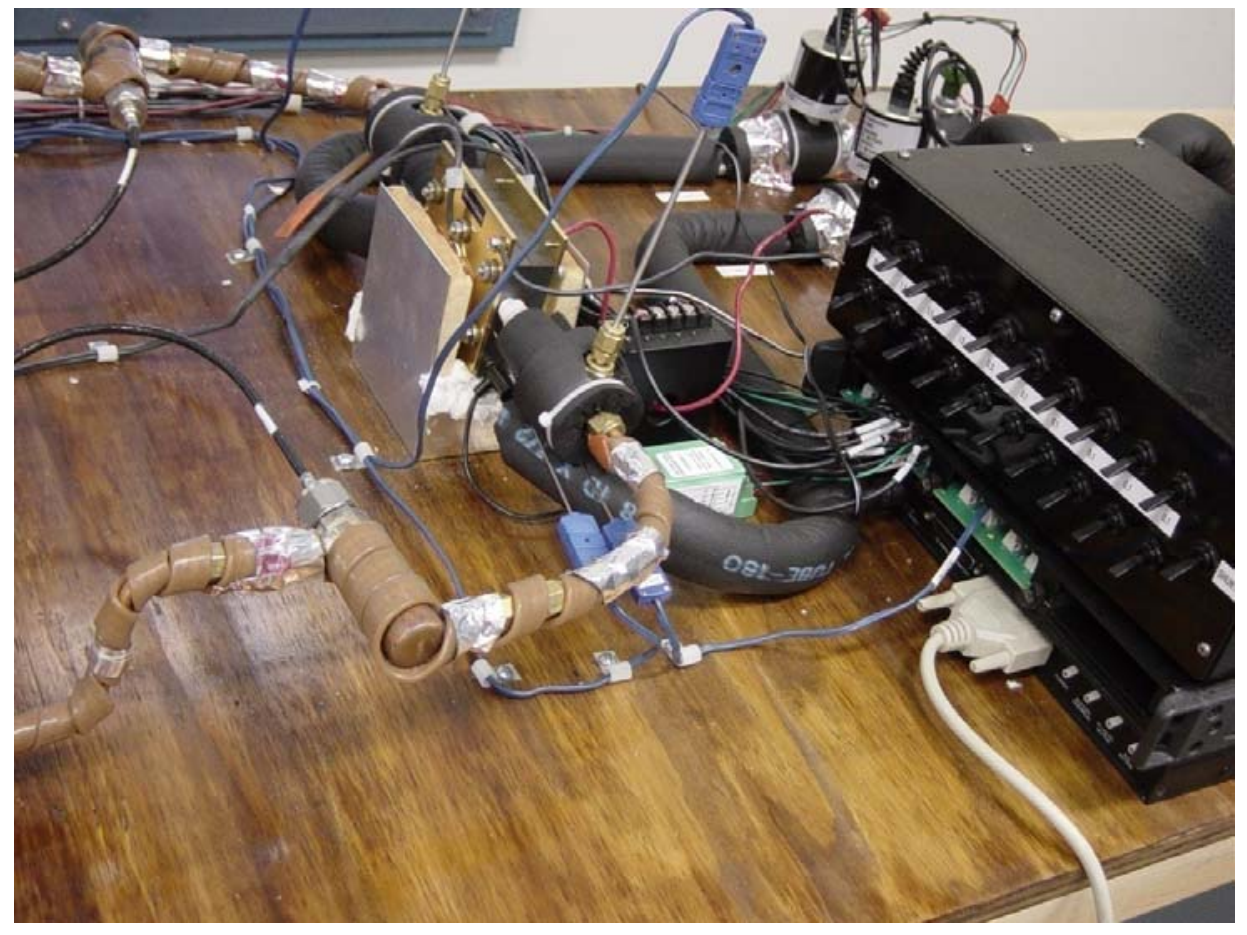

Figure 10: Data acquisition build 1 
A schematic of the test bed layout has been included in Figure 11.

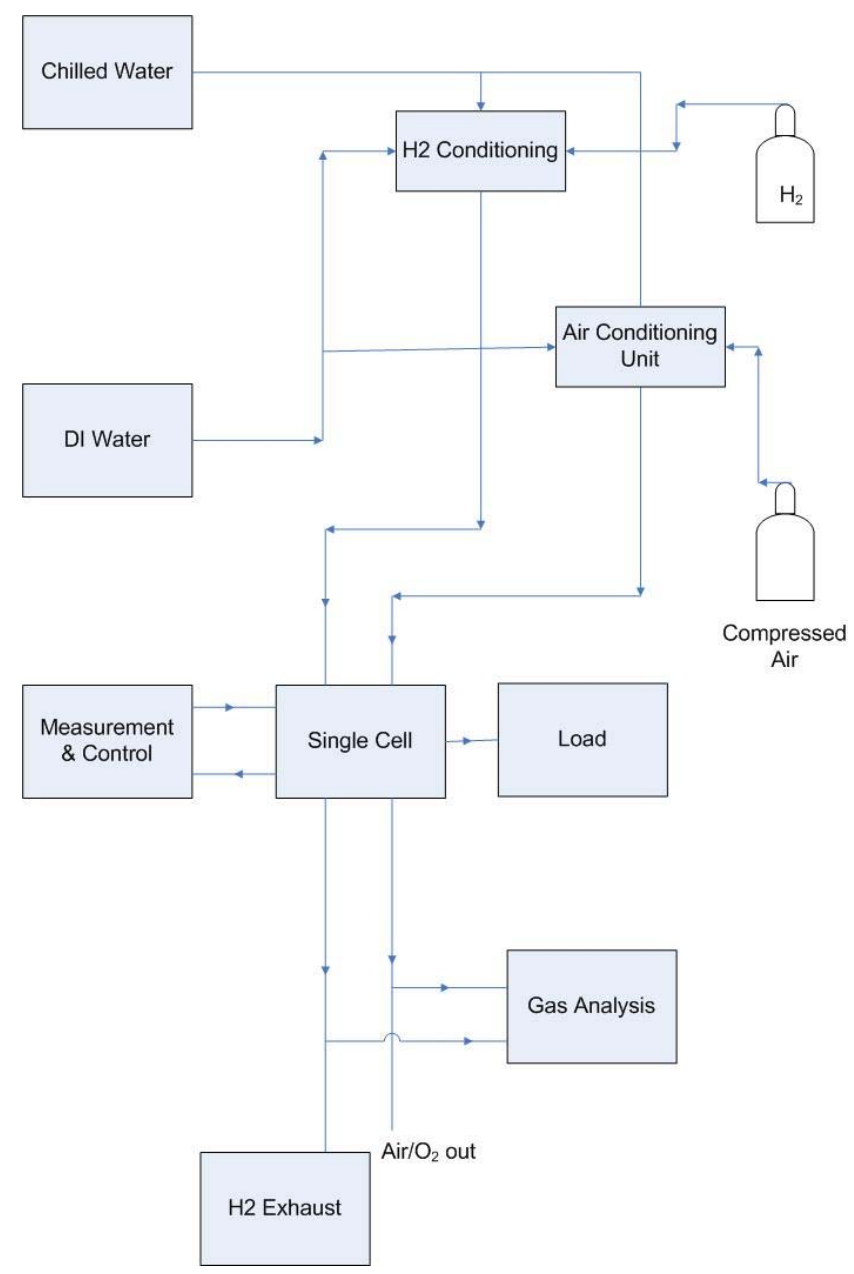

Figure 11: Physical layout of build 1

Data acquisition

The data acquisition system for the fuel cell was developed by Patricia Alexander in the fall of 2005 at the University of Florida. The data acquisition system has been designed using the National Instrument's Lab view program along with I/O Tech's Daq Book 200, a 16 bit parallel port data acquisition device. The DaqBook has been fitted with two expansion cards I/O Tech's DBK/15 general voltage card and DBK/19 a thermocouple acquisition card. This system was designed to acquire all of the required fuel cell related data as well as to 
control the hydrogen and air line temperatures, mass flow rates, humidity, fuel cell temperature, and exhaust line back pressure. This allows the user to simultaneously observe, record, control and manipulate the experimental data in order to obtain the most accurate results. A complete list of all data acquisition devices has been placed in appendix $B$. Figure 12 below is a schematic of the data acquisition system:

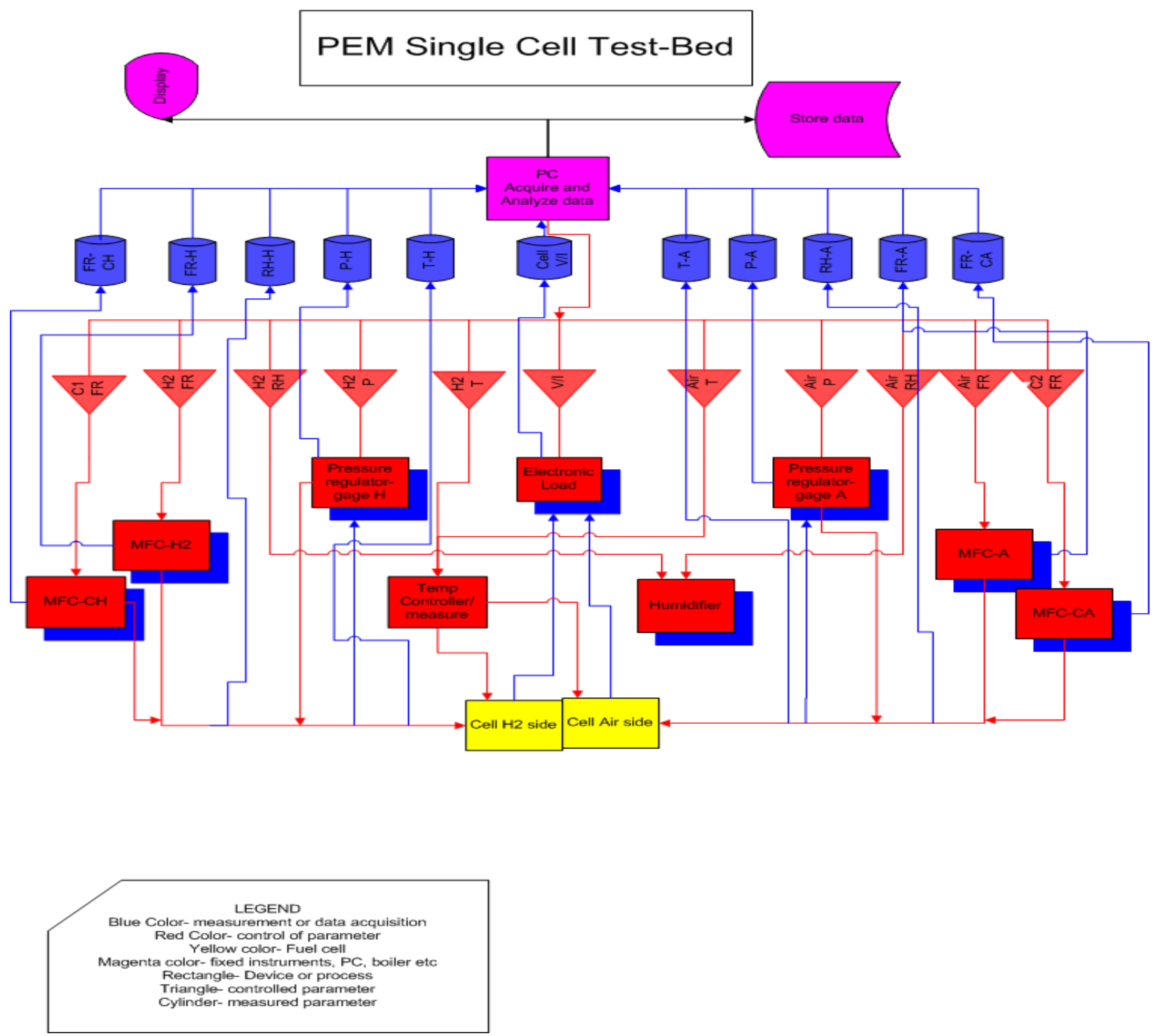

Figure 12: Test bed data acquisition schematic 


\section{Test bed configuration phase: build 2}

\section{Purpose}

The approach of build 2 was to incorporate a climate chamber into the current test bed configuration and implement the required design upgrades as determined necessary. Refinements such as new line heaters, insulation, and gas path routing were integrated into the test bed before cold startup/ operative testing commenced.

\section{Overview}

The second build of the test bed was focused on the design and integration of an environment chamber into build 1's layout. This was accomplished by surveying the current technologies available to satisfy the -40 degrees Celsius temperature requirement, and choosing the most practical system. The two cooling methods explored were mechanical (2-stage compressor system) or direct gas expansion option. First, the mechanical avenue will be briefly discussed in order to provide a better understanding of the final decision. A compound refrigeration system has many advantages such as minimal long duration operating costs, precision temperature control and direct factory implementation. While these points are valid for consideration, it was found that a cryogenic evaporation system was the much cheaper option. There was an approximate $\$ 3,500$ cost differential between the two systems with only a few drawbacks such as less precise temperature control and a longer fabrication time. The cryogenic gas expansion system was chosen because it had a lower initial setup cost and the design was simple enough to fabricate in the lab. 


\section{Cryogenic expansion climate chamber}

Many design considerations were considered before deciding on the current configuration of the cryogenic liquid expansion climate chamber such as external and internal heat loads from the fuel cell and the surrounding environment, size considerations (the fuel cell's dimensions are $5 \mathrm{~cm} \times 5 \mathrm{~cm} \times$ $2 \mathrm{~cm}$ ), chamber door leakage, porting leakage (due to ported holes in the side of the chamber to pass electrical wiring and fuel intake/exhaust lines in to the chamber), and heat exchanger design.

In order to minimize the cooling load the chamber was designed to be as small and thermally insulated as possible. This goal was accomplished by a generous donation from A\&W Refrigeration which included all of the building and insulation materials needed to complete the chamber's infrastructure. The chamber was constructed of 4 inch thick walk-in freezer panels with a thermal Rvalue of approximately 12-14. These panels were cut in order to provide $1 \mathrm{cu}-\mathrm{ft}$ of volume within the chamber. Each panel edge was cut at a 45 degree angle to minimize air infiltration and to ensure even application of the expanding thermal foam. The exterior panel joints were stabilized with extruded aluminum siding and sealed using Hilti CF 116-14 \#314722 expanding foam. This same foam was also used to seal the ported intake/exhaust holes. Next the heat exchanger was constructed of $1 / 4$ inch diameter copper tubing formed into a shape similar to that of figure 13. 


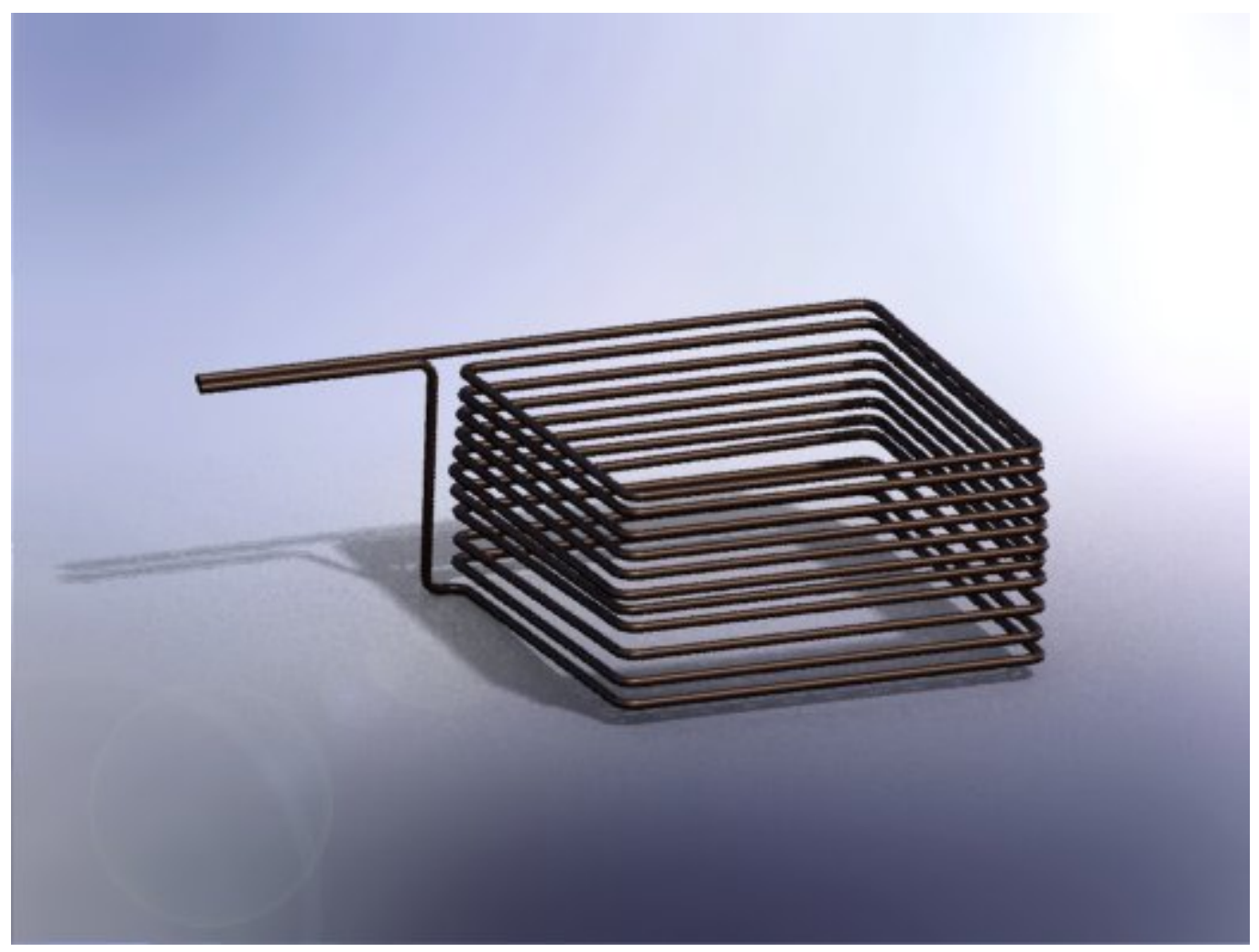

Figure 13: Climate chamber heat exchanger

Liquid nitrogen was chosen as the expandable refrigerant because it was the cheapest cryogenic gas that would fulfill the chamber's low temperature requirement. A Jefferson Valves cryogenic solenoid, catalog number YC1390BT2UCT, was chosen to control the flow of liquid nitrogen as determined by the PID temperature controller. Due to the high velocity of the evaporating gas, a needle valve was installed on the exhaust side of the heat exchanger to maximize the amount of time available for heat transfer to occur. This controller relies on the feedback from a thermocouple inside the chamber to determine the liquid nitrogen flow rate. Figure 14 illustrates the basic construction of the chamber. 

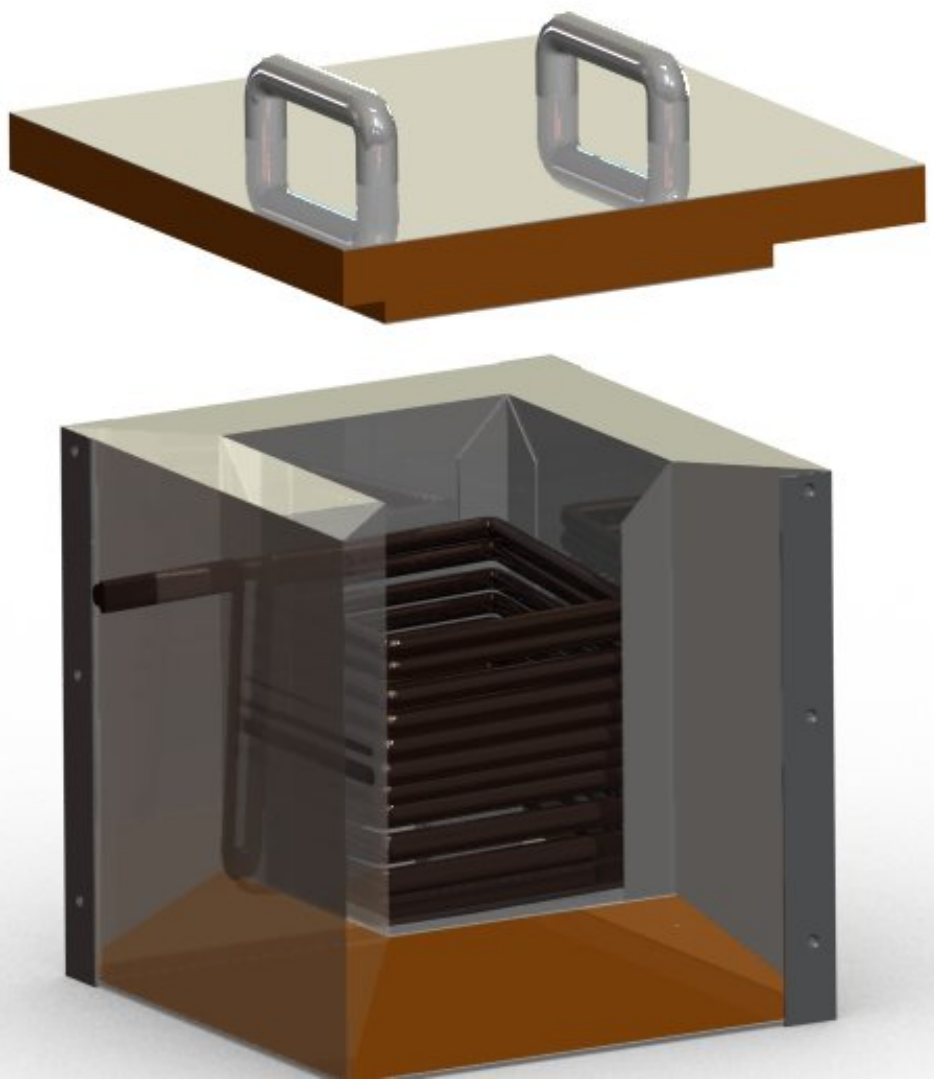

Figure 14: C.A.D. representation of the climate chamber 


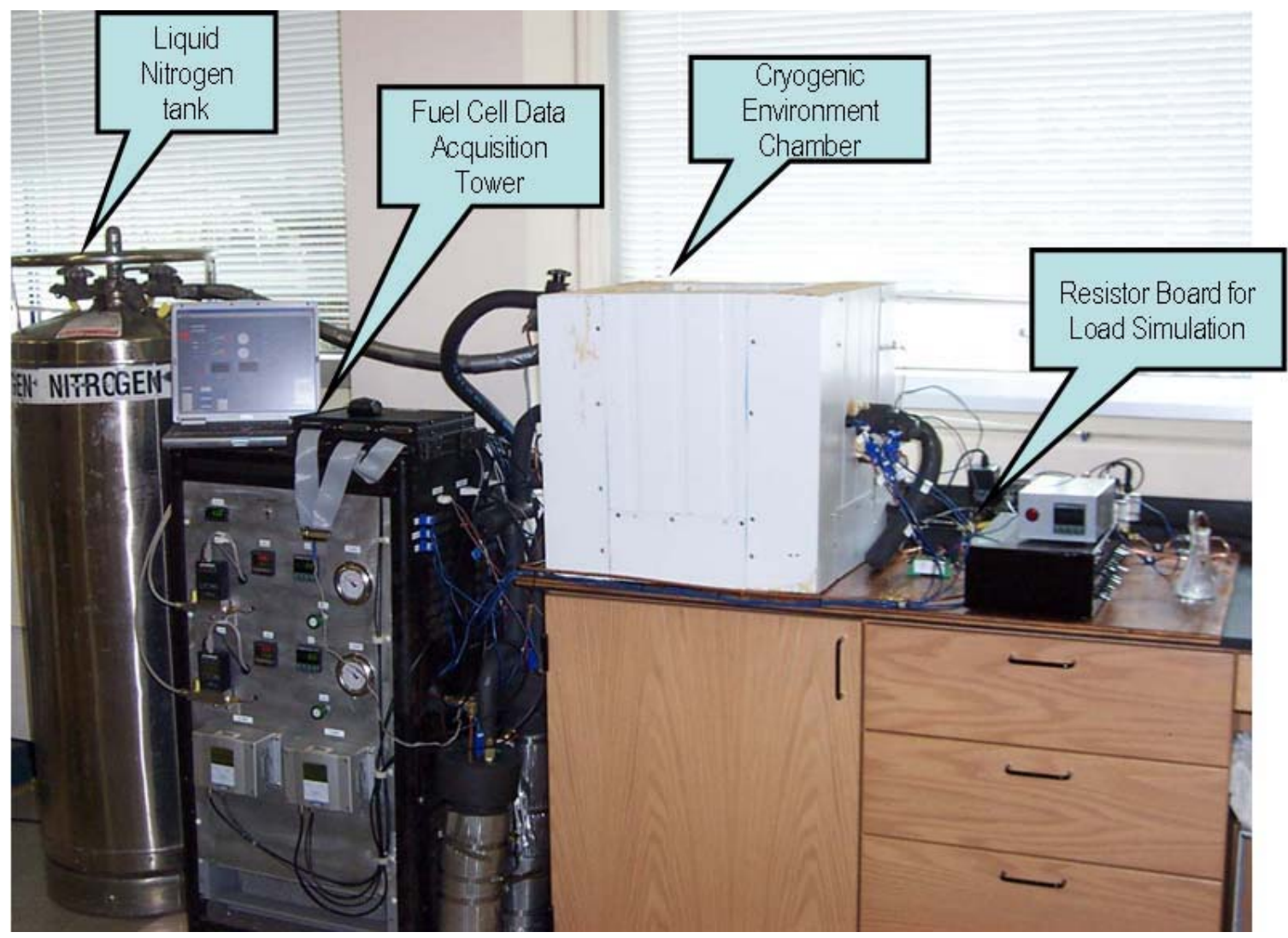

Figure 15: Completed build 2 test bed 


\section{Design upgrades}

In order for the build 2 goals to be accomplished, other modifications to the test bed were required as outlined below:

- The hydrogen and air line heaters and insulation needed replacement as they had become unshielded and a fire hazard.

- The fuel line thermocouples had to be relocated in order to accurately determine the relative humidity in the fuel line.

- The humidity sensor's orientation was adjusted so that water would no longer collect on the probe causing it to short circuit.

After the calibration testing of the build 2 design was completed, three process controllers were identified as being unsuited for their designed task and needed to be replaced. The issues encountered with the CN800 and the CNi32 controllers were due to the lack of ability to control the Proportional, Integral, and Damping (P.I.D.) parameters. These controllers were replaced with Omega model CN9000A which provided greater P.I.D. control and adjustment. Although these controllers functioned properly they still were not the perfect solution because the controllers' manufacturers did not provide the same adjustments for both output channels. This limitation disabled the derivative polling ratio which automatically adjusts the proportional band during large set point deviations, thus minimizing overshoot. This overshoot was minimized manually on the climate chamber by closing the back pressure valve on the heat exchanger to further restrict or even stop the flow until the chamber's internal temperature could equalize. This overshoot does not pose as much of a problem for the line controllers since it only affects the calculated humidity values and not the actual line humidity. The impact of the fuel line temperature (i.e. long start-up time) can be minimized by not allowing any gas to flow through the lines until they have reached the set point temperature. 


\section{Testing procedures}

Baseline tests

The baseline test represents the control data to which the future cold temperature investigations will be compared. Before the fuel cell is exposed to the sub zero temperatures, initial power curves are generated from the recorded data at standard temperature and pressure and at $30 \mathrm{psig}$ fuel line pressure. These power or "polarization" curves will be used to determine the amount of cell degradation experienced during sub zero storage. The loss of efficiency will be quantified by the difference between the experimental and control polarization curves. For the baseline test each membrane was allowed ample time to hydrate and reach full power output before the baseline data will be acquired. The data was recorded as the cell powers down from this maximum level at ten second intervals. In order to accurately represent the polarization curve, the entire power band of the fuel cell was explored. This was accomplished by starting with an open circuit and varying the load from 10 to $.01 \mathrm{ohms}$. This process was repeated a minimum of three times in order to insure proper MEA break-in and hydration. 
Cold storage investigations

In order for the degradation effects to be investigated the test parameters must first be outlined. The cold storage experiments will be evaluating the performance loss caused by internal ice formation resulting from low temperature storage. The following procedure was followed for each test in order to ensure repeatability and test integrity. First, the cell was "broken in" according to the manufacturer's specifications and a base line test was completed as outlined above. Next, one of the three variable parameters was chosen to be explored and a goal was defined. For example, to determine the effects that the hydration state prior to freezing has upon the performance, the MEA was subjected to a dehydration period in which the fuel gases were humidified to the experimental value and allowed to flow through the cell at $250 \mathrm{ml} / \mathrm{min}$ for ten minutes. After the dehydration period, the cell was properly shut down, and the climate chamber was properly adjusted for the correct subzero temperature. The cell was allowed enough time to reach equilibrium with the climate chamber before the freeze/thaw time was recorded. The cold storage tests are unique in that they focus on the shutdown regimes and their effect on the cell's operation. The cell's water content during shutdown is very important because of the effect that residual water has upon MEA degradation, so this parameter was investigated by varying the dehumidification level during the shutdown procedure. 
The actual time of the cold storage is of particular interest since the water in the fuel cell reacts differently depending on its location within the cell. Longer duration freeze times may be required to solidify the water in these regions of the cell. Finally, the start-up time/procedures were evaluated to determine the proper way to recover the cell from the extreme temperatures as quickly as possible.

Methodology

To isolate the performance degradation caused by internal ice formation from the numerous other causes of performance loss (i.e. impurity contamination, low water content, insufficient fuel flow) a simple yet focused procedure must be developed. The performance loss of the cell was extrapolated from the polarization curves before and after each freeze/thaw cycle. To characterize the cold storage degradation, multiple M.E.A.'s of similar thickness, platinum content and fabrication technique were investigated.

In order to determine the effect that membrane hydration has upon the cold storage degradation both the GDL and Nafion membrane pore size were determined via a B.E.T. porosity scanner. Prior to exposing the membrane to a subzero environment, the physical structure and pore size was quantified using a scanning Hitatchi S800 electron microscope, energy dispersive x-ray spectroscopy, and a B.E.T. porosity scanner. Further information regarding these instruments can be located in appendix B. This allows for quantification of the relative pore size as well as visual inspection of the pore structure. Storage effects were investigated with the membrane at $90 \%, 80 \%, 70 \%, 60 \%$, and $50 \%$ relative humidity at a temperature of 60 degrees Celsius. Once the baseline power curves were obtained the test station was shutdown according to the operating instructions. Next the climate chamber was adjusted to the correct 
experimental set point $\left(0^{\circ} \mathrm{C},-10^{\circ} \mathrm{C},-20^{\circ} \mathrm{C},-40^{\circ} \mathrm{C}\right)$ and allowed ample time to equilibrate. The freezer was allowed to operate until the internal temperature of the fuel cell had stabilized at the set point temperature for one hour. The freezer was then turned off and the cell was allowed to return to the ambient temperature by the process of natural convection. At this point the membrane's power output is quantified as discussed previously, and then the membrane is ready to begin the next freeze/thaw test at the next colder temperature. It should be noted that the $60 \%$ and $70 \%$ relative humidity cold storage tests were each conducted with new membranes, however, due to the lack of degradation the same membrane was used for the $70 \%, 80 \%$, and $90 \%$ runs.

In order to better quantify the amount of degradation caused by the membrane's water content, the amount of time of the freeze/thaw cycles had to be increased in order to cause a measurable degradation. It was determined that a twenty four hour freeze/thaw duration would be better suited to cause the expected membrane degradation. This investigation was conducted in a similar fashion as outlined above, but instead of varying the temperature of freeze/thaw cycle only the humidity altered. The coldest temperature previously investigated (- $40 \mathrm{C})$ will be utilized for all NM4 membrane tests.

It should be noted that due to the sample size restrictions of the S.E.M. and BET scanner the physical quantification of the measured degradation was conducted at the membrane's end of life and not after each experiment. Thus, any physical degradation identified by these techniques is the result of an entire set of freeze/thaw cycles and can not be attributed to any particular set of variable combinations. 
Investigated membrane electrode assembly

The M.E.A. used to quantify the freeze/thaw degradation was purchased from www.fuelcell.com. This model of the M.E.A. chosen is FC25-MEA, which has an area of $25 \mathrm{~cm}^{\wedge} 2$ and a platinum content of $1 \mathrm{mg} / \mathrm{cm}^{\wedge} 2$ or $(20 \% \mathrm{wt} \mathrm{Pt} / \mathrm{C})$. All of Electrochem's membranes have been fabricated with proprietary manufacturing processes that use up to $30 \%$ Teflon in the gas diffusion and catalyst layers. This M.E.A. also utilizes a hydrophobic carbon paper upon which the catalyst and proprietary coatings are applied and subsequently hot pressed in to a Nafion membrane [54]. 


\section{Chapter 4: Results}

\section{Cold storage investigation}

The goal of this research was to obtain a general idea of how resilient a P.E.M. fuel cell membrane is at varying climate conditions. This task was accomplished by storing the cell at different temperatures and varying the humidity as outlined in the methodology section. The results show that a P.E.M. fuel cell can be frozen and thawed without catastrophic destruction to the membrane. In fact, the cell showed very little degradation during certain storage conditions.

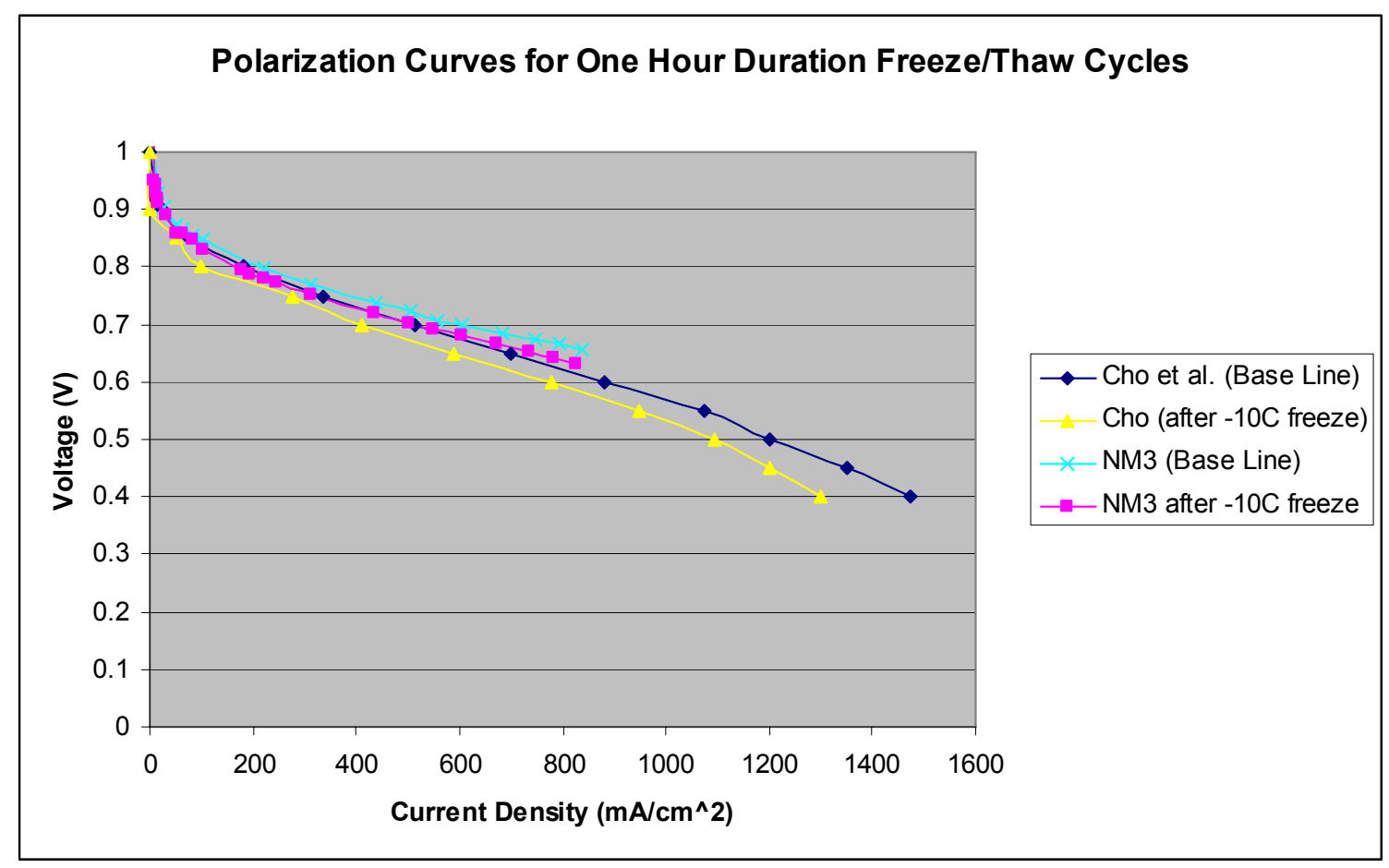

Figure 16: Polarization curve comparison 
The results presented in figure 16 compare the NM3 one hour freeze/thaw cycles to similar results observed by Cho et al. [22]. Similarities between the polarization curves can be seen even though the experimental procedures and membranes differ. Some differences should be noted as well; for example, Cho et al. [22] chose to utilize a one hour freeze thaw duration from which he observed significant power losses after the cell was thawed.

The NM3 results for the freeze/thaw duration of one hour show a greater resilience to the ice degradation. It should also be observed that mode of degradation experienced by each cell is very similar. According the polarization graph, both membranes had increased ohmic resistance and flooding probability, while the activation energies stayed fairly constant.

It can be seen in figure 17 that the cell did not degrade significantly as the membrane was exposed to a one hour freeze/thaw cycle. This membrane was dehydrated for ten minutes with $70 \%$ relative humidity gas before freezing.

Figures 17 through 35 illustrate the Electrochem membrane's operational map after being exposed to several freeze thaw cycle at various temperatures and degrees of dehydration. 


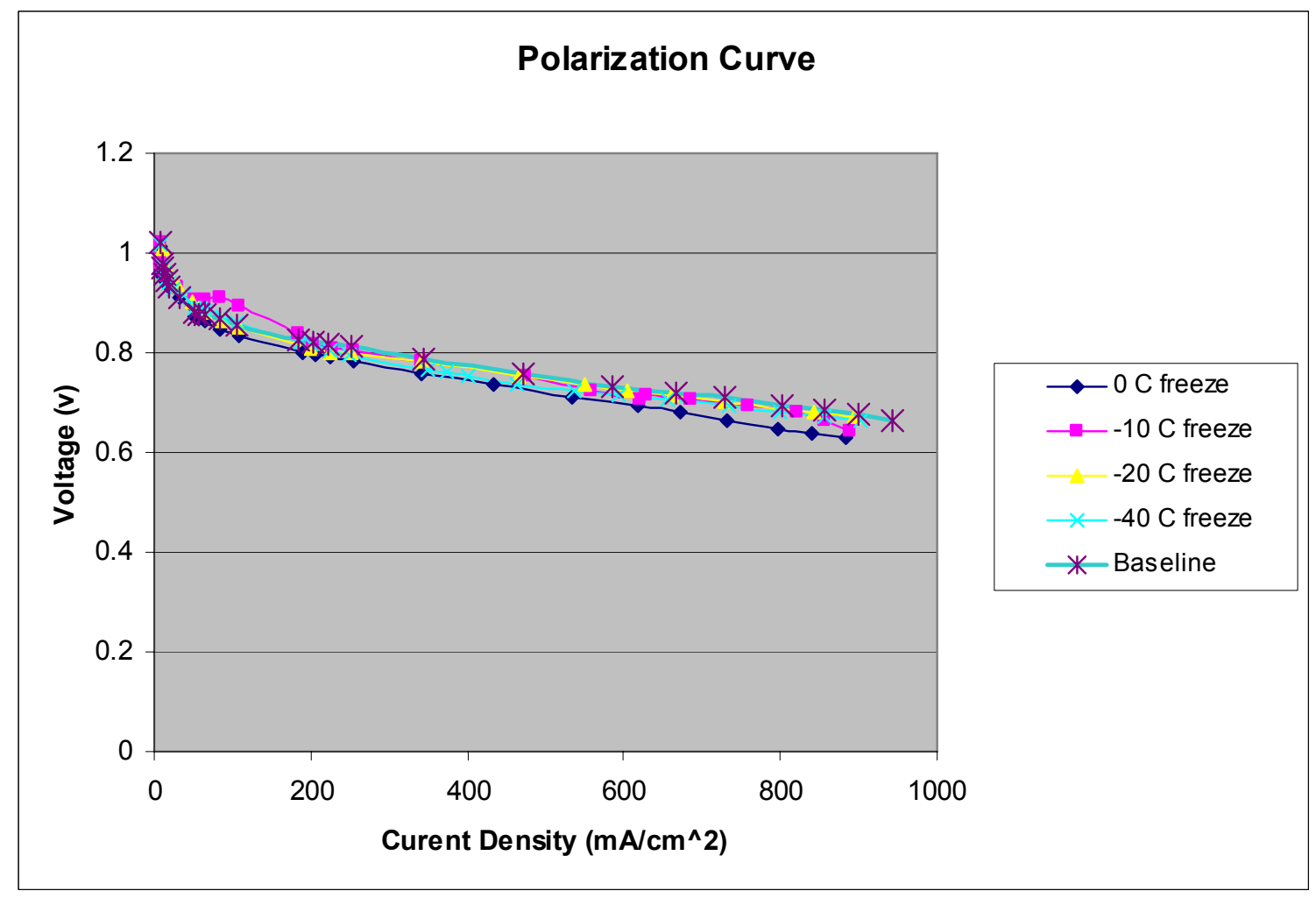

Figure 17: One hour freeze/thaw cycle investigation - polarization graph $60 \%$ relative humidity 


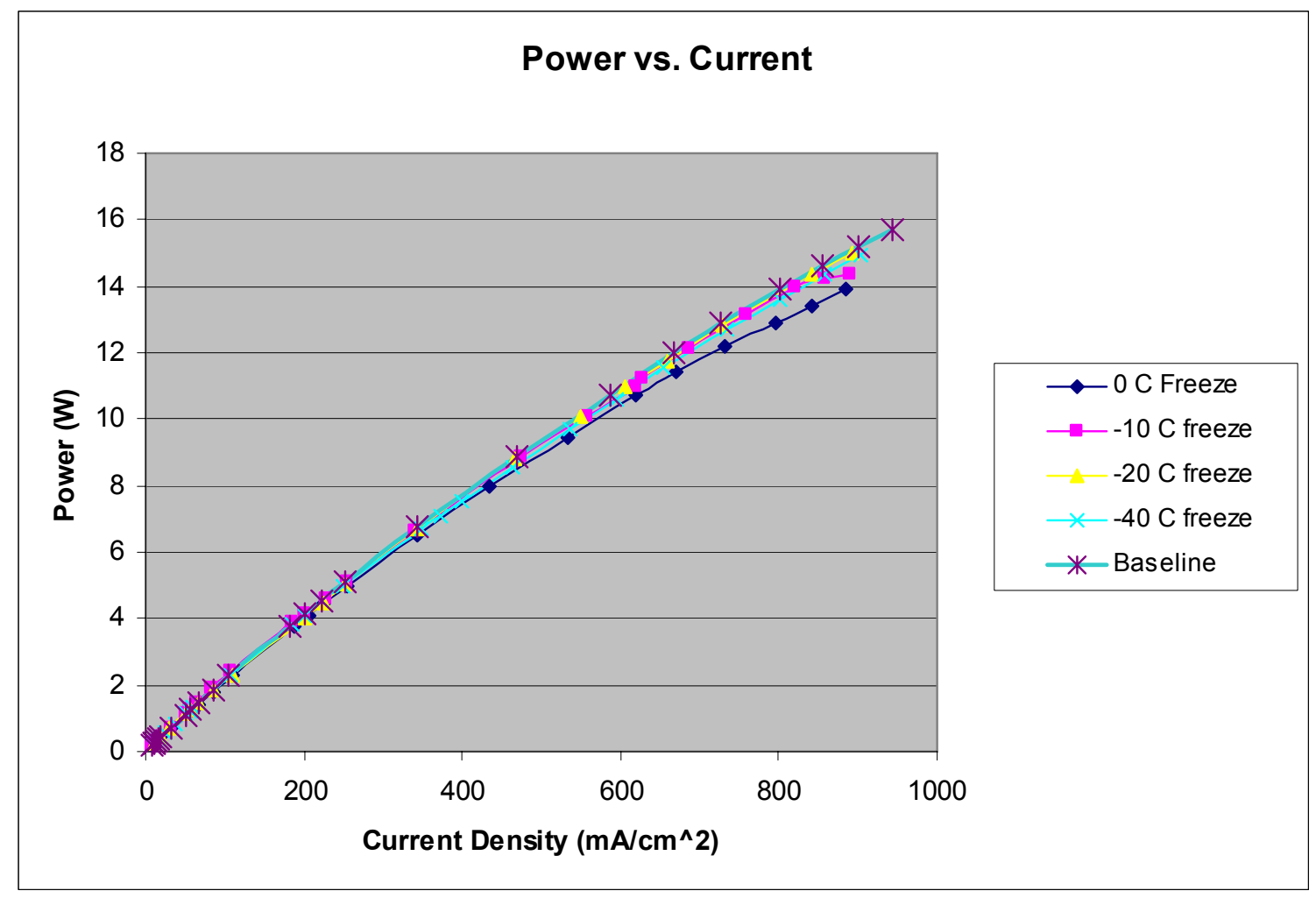

Figure 18: One hour freeze/thaw cycle investigation - power v. current graph $60 \%$ relative humidity 


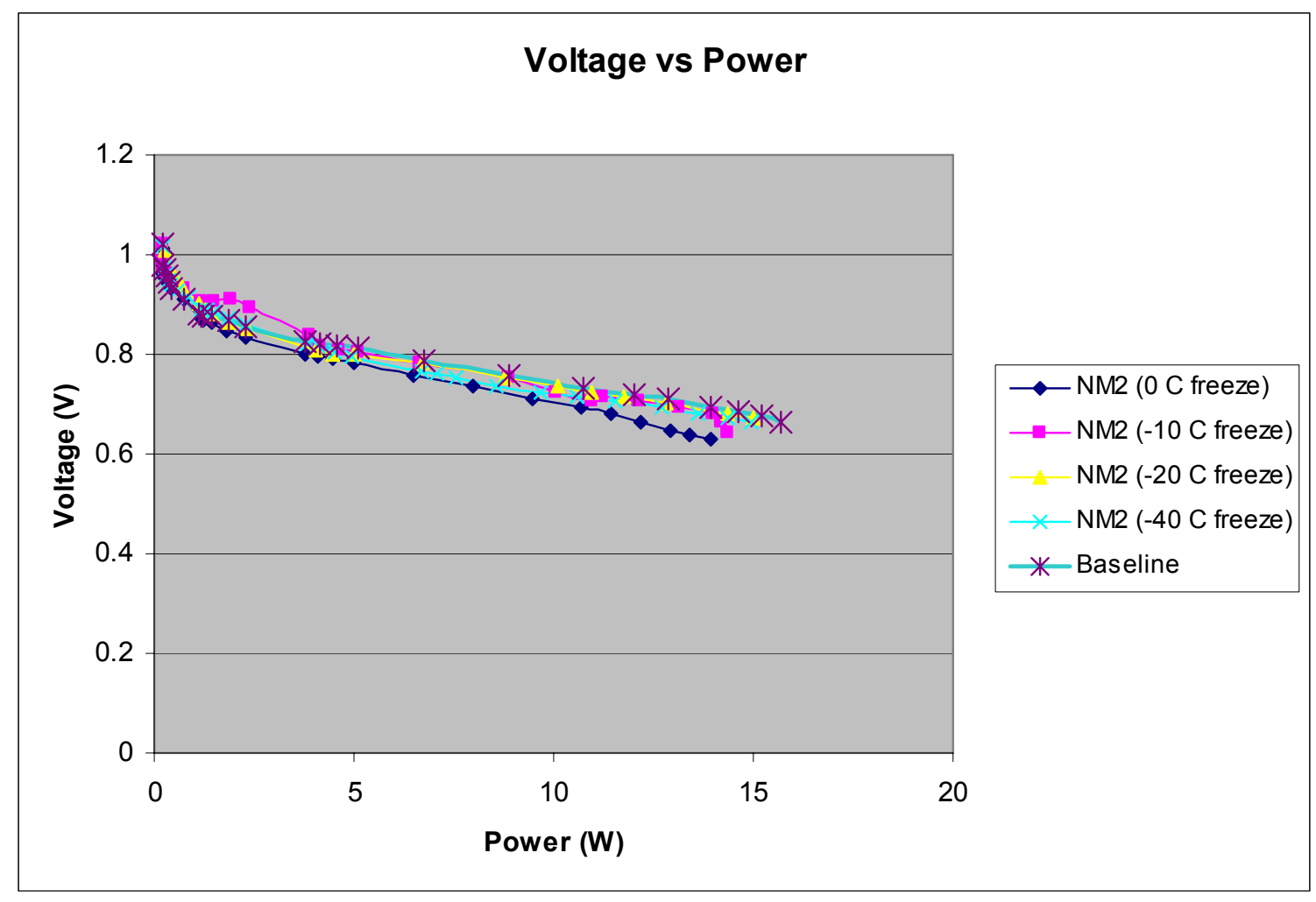

Figure 19: One hour freeze/thaw cycle investigation - voltage v. power graph $60 \%$ relative humidity

Figure 19 illustrates that there is very little degradation of this particular P.E.M. fuel cell membrane after it experienced several freeze/thaw cycles for a duration of one hour. The fuel cell was placed in the subzero climate chamber and allowed to equilibrate to the set point temperature for one hour before the duration cycle time was started.

If the $60 \%$ dehumidified test run is compared with the $70 \%$ case presented in figure 20 , it can be postulated that the amount of dehydration has a negligible effect on the performance for this storage duration. 


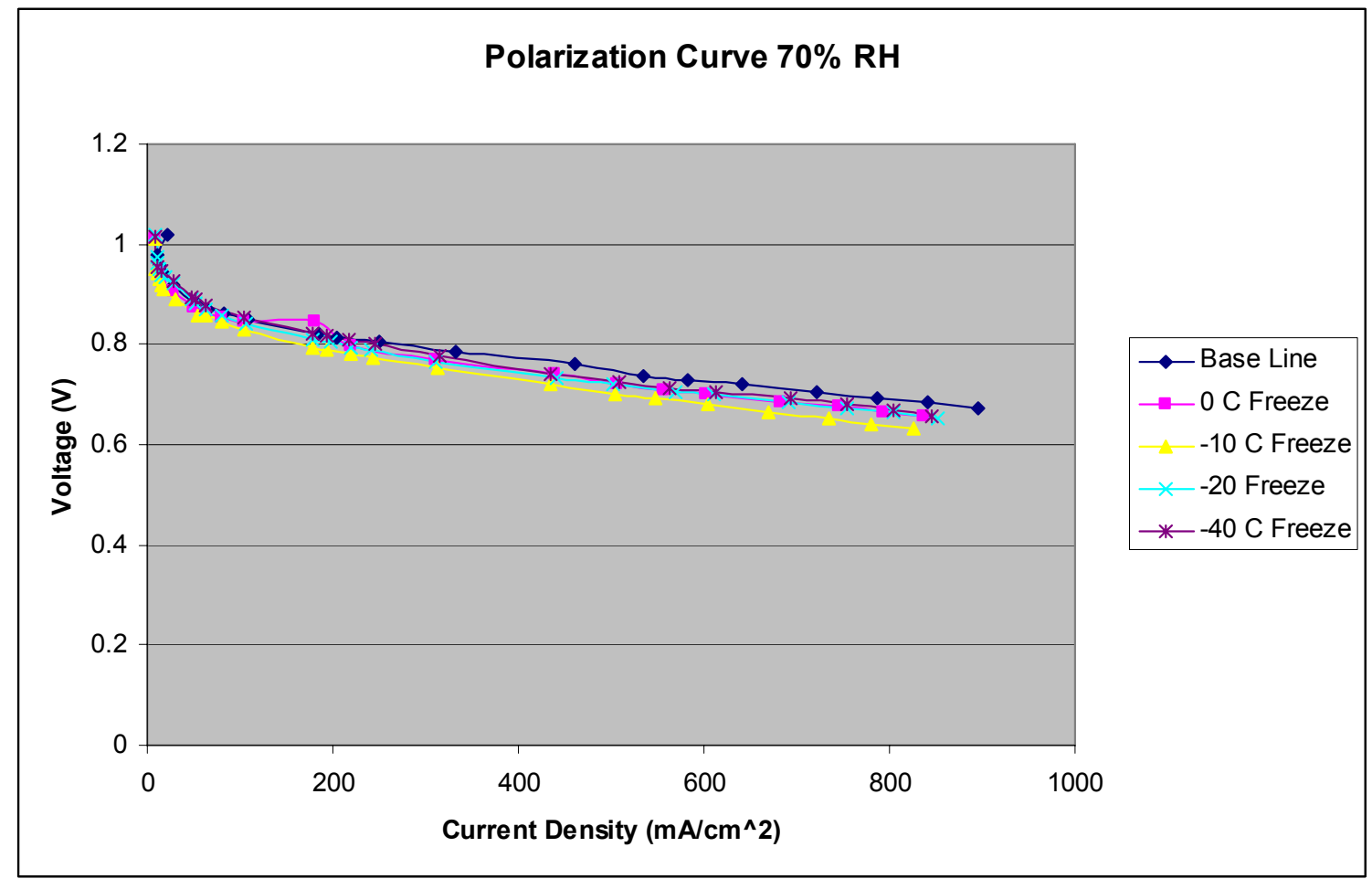

Figure 20: One hour freeze/thaw cycle investigation - polarization graph $70 \%$ relative humidity 


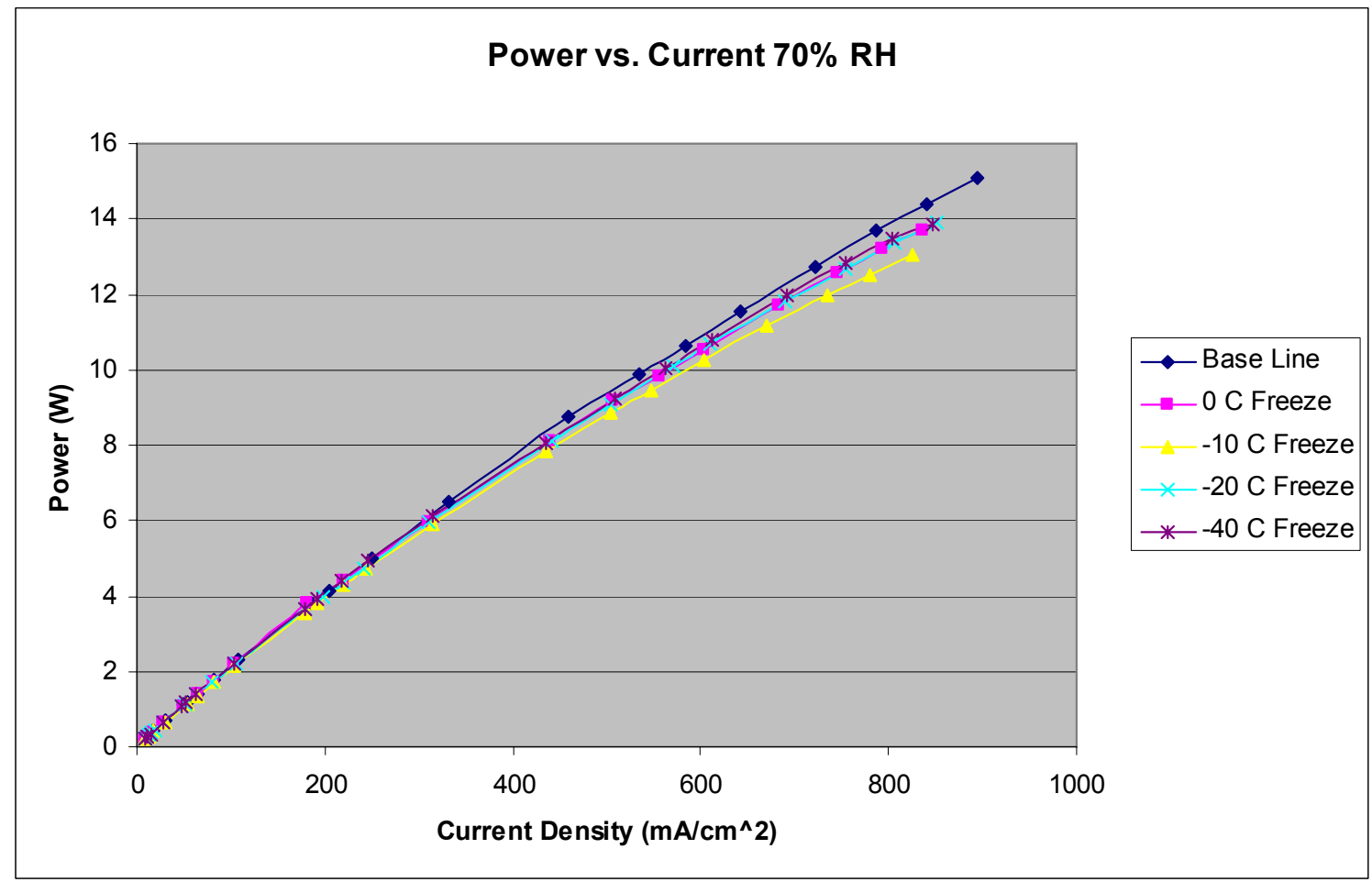

Figure 21: One hour freeze/thaw cycle investigation - power v. current graph $70 \%$ relative humidity 


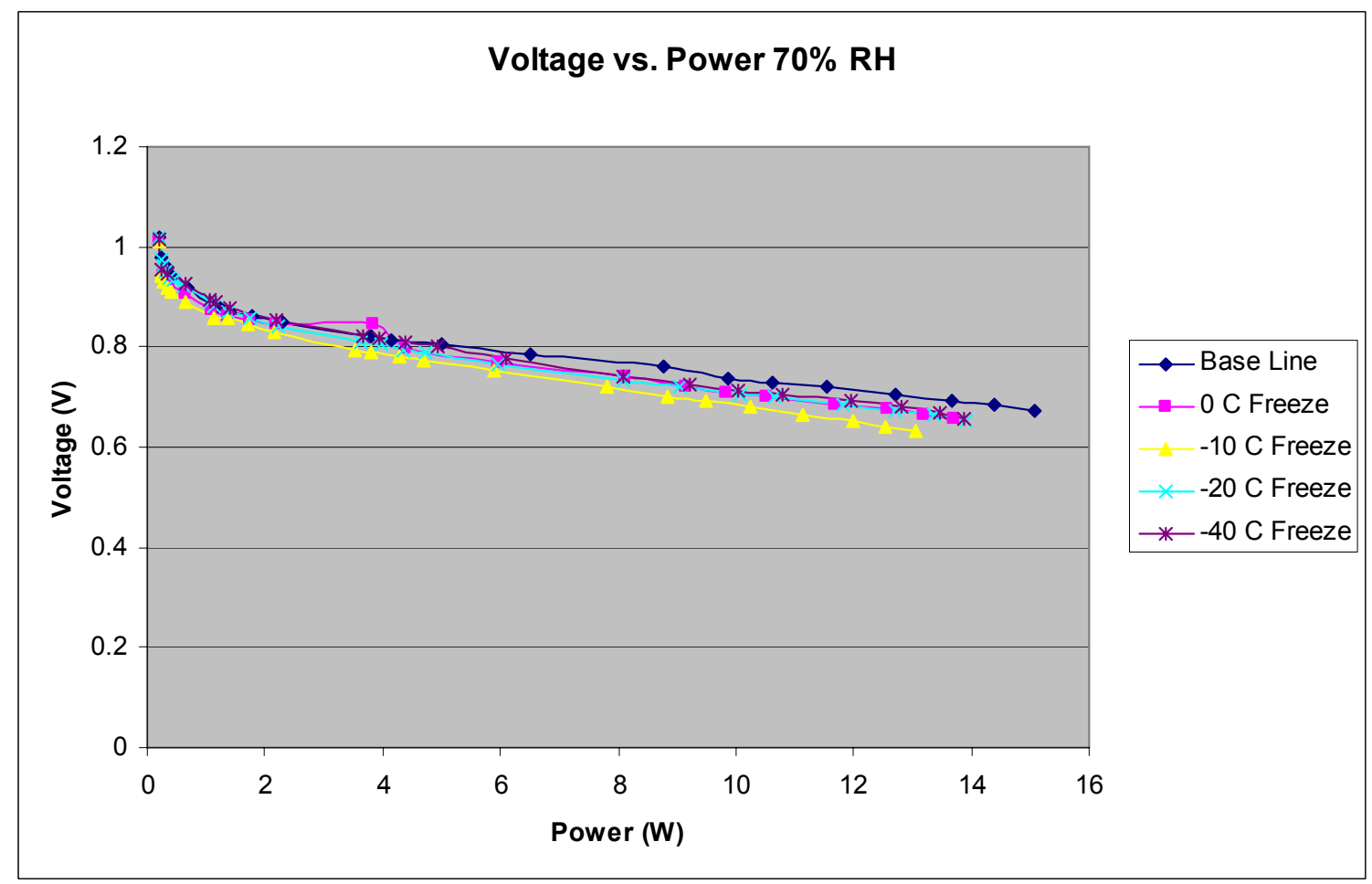

Figure 22: One hour freeze/thaw cycle investigation - voltage v. power graph $70 \%$ relative humidity

The insignificance of the dehydration can be confirmed by the following cold storage data for the $80 \%$ relative humidity case. The conclusion from these experiments is that the water content and temperature of the subzero storage had little effect on the performance of the cell with a one hour freeze cycle duration. 


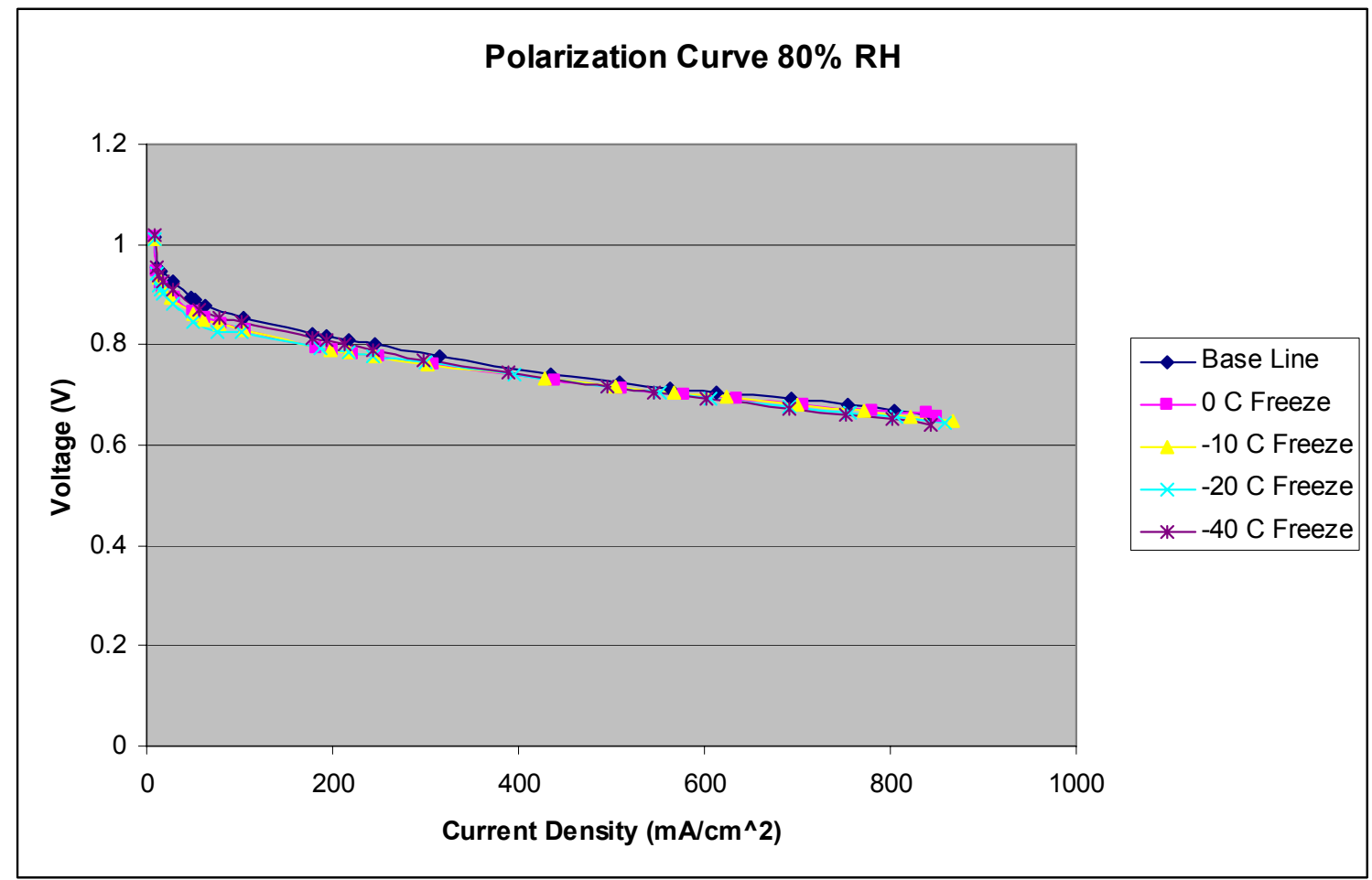

Figure 23: One hour freeze/thaw cycle investigation - polarization graph $80 \%$ relative humidity 


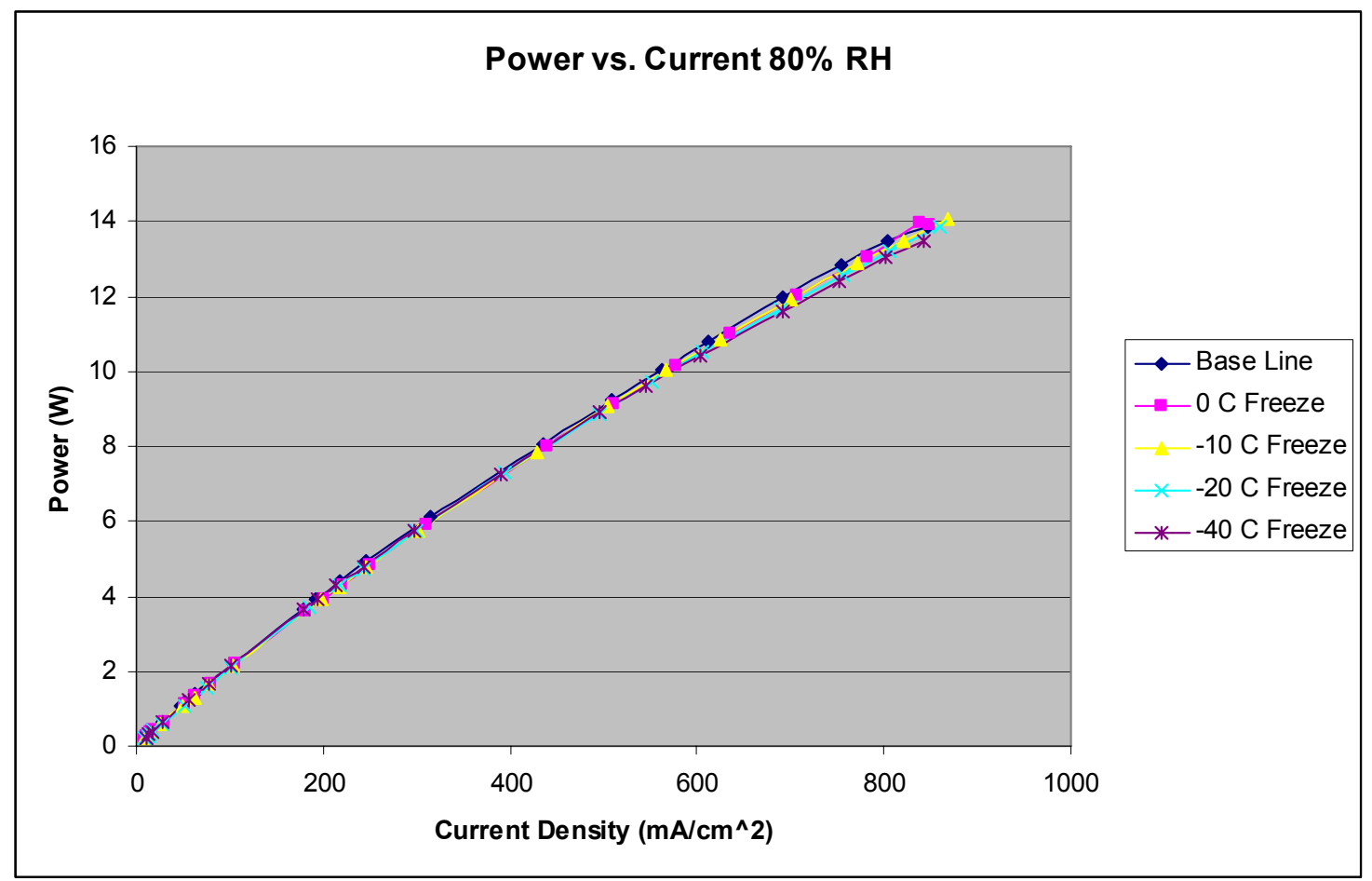

Figure 24: One hour freeze/thaw cycle investigation - power v. current graph $80 \%$ relative humidity 


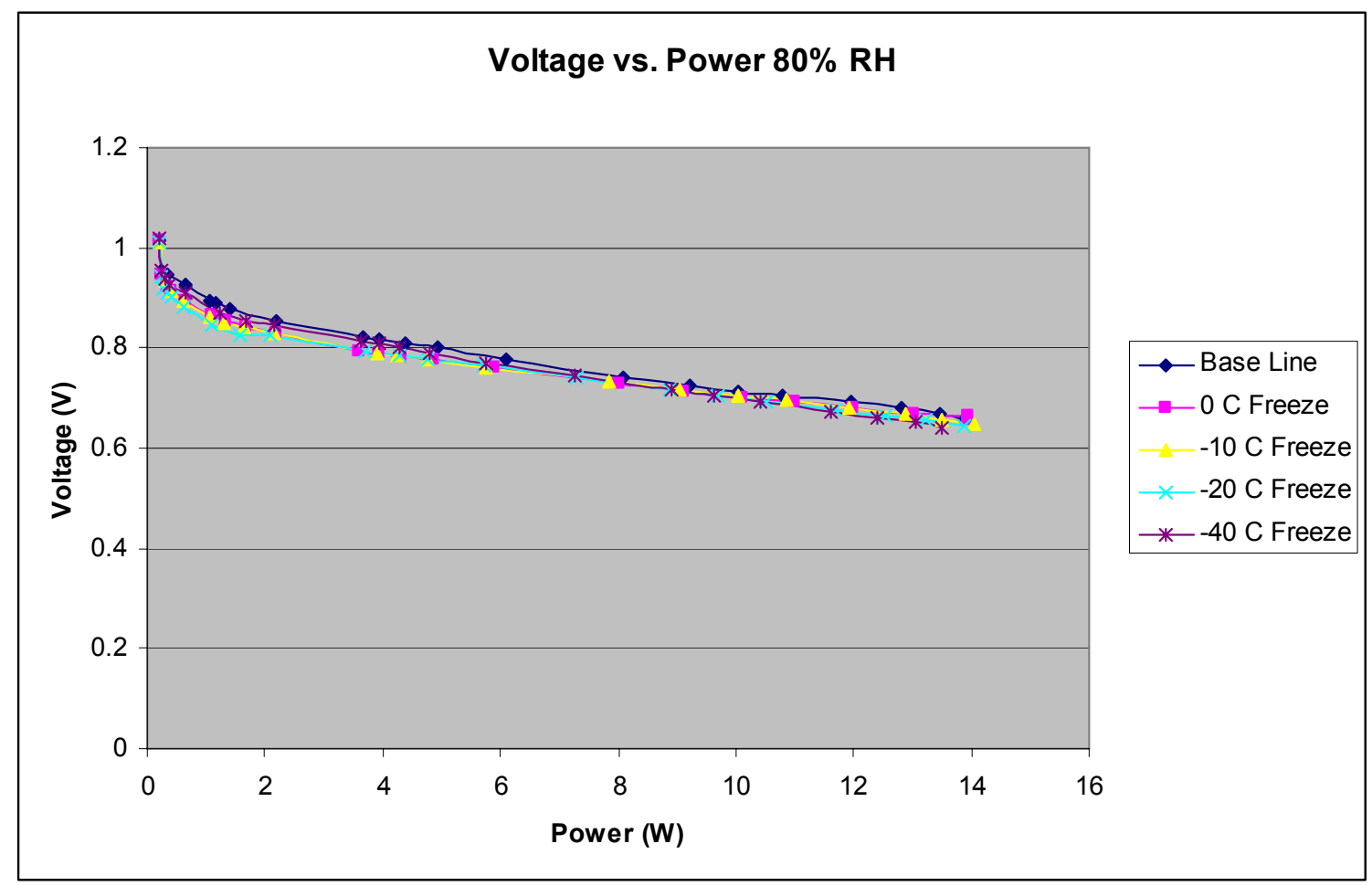

Figure 25: One hour freeze/thaw cycle investigation - voltage v. power graph $80 \%$ relative humidity

Due to the membrane's resilience to freeze/thaw degradation, the duration was extended to intensify the degradation in order to better indentify the physical consequences. This investigation involves freezing a fully humidified membrane $(80+\%)$ to -40 degrees Celsius for varying amounts of time. The results of these runs have been illustrated in figures 26,27 , and 28 . 


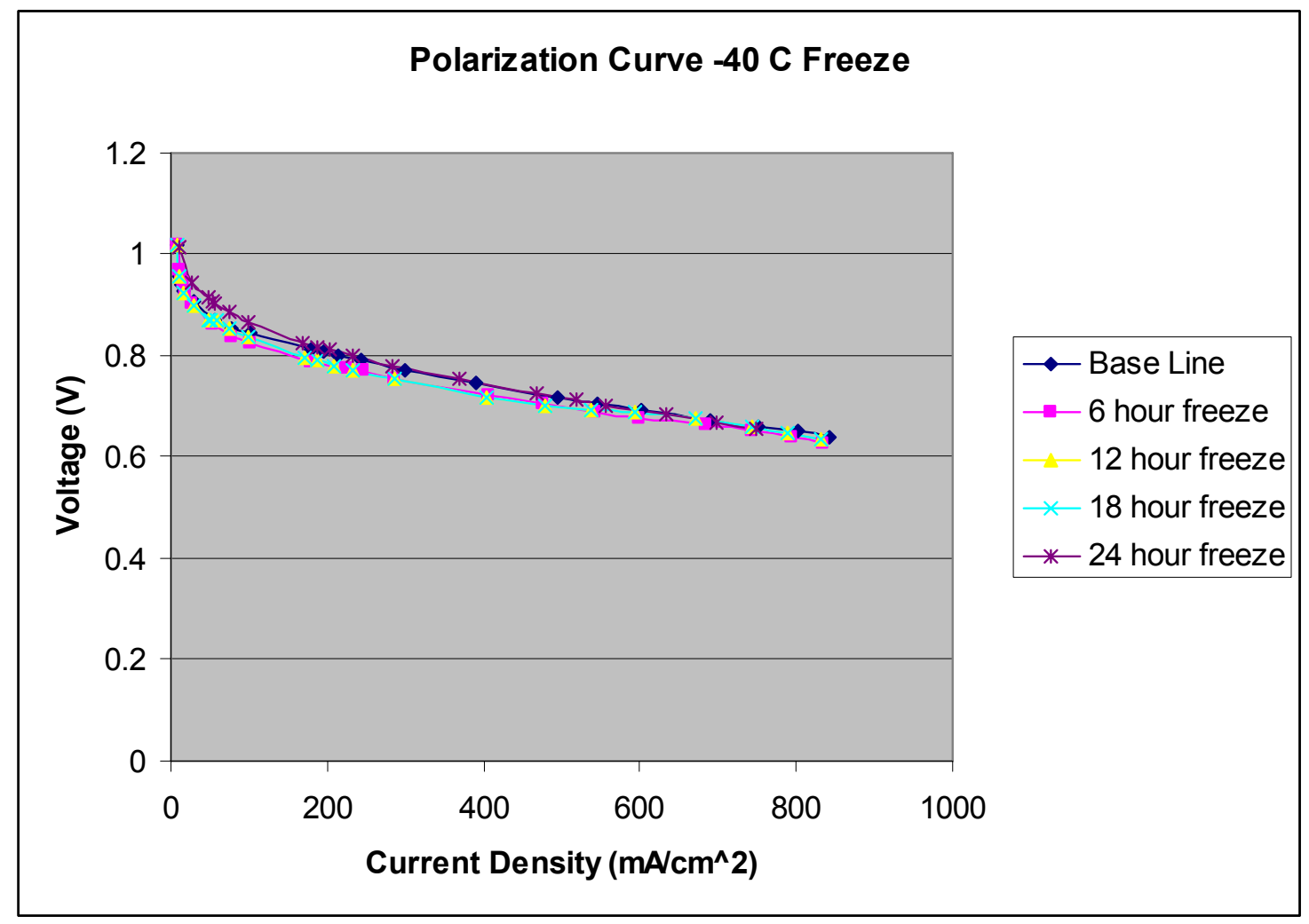

Figure 26: Freeze/thaw cycle duration investigation - polarization graph 


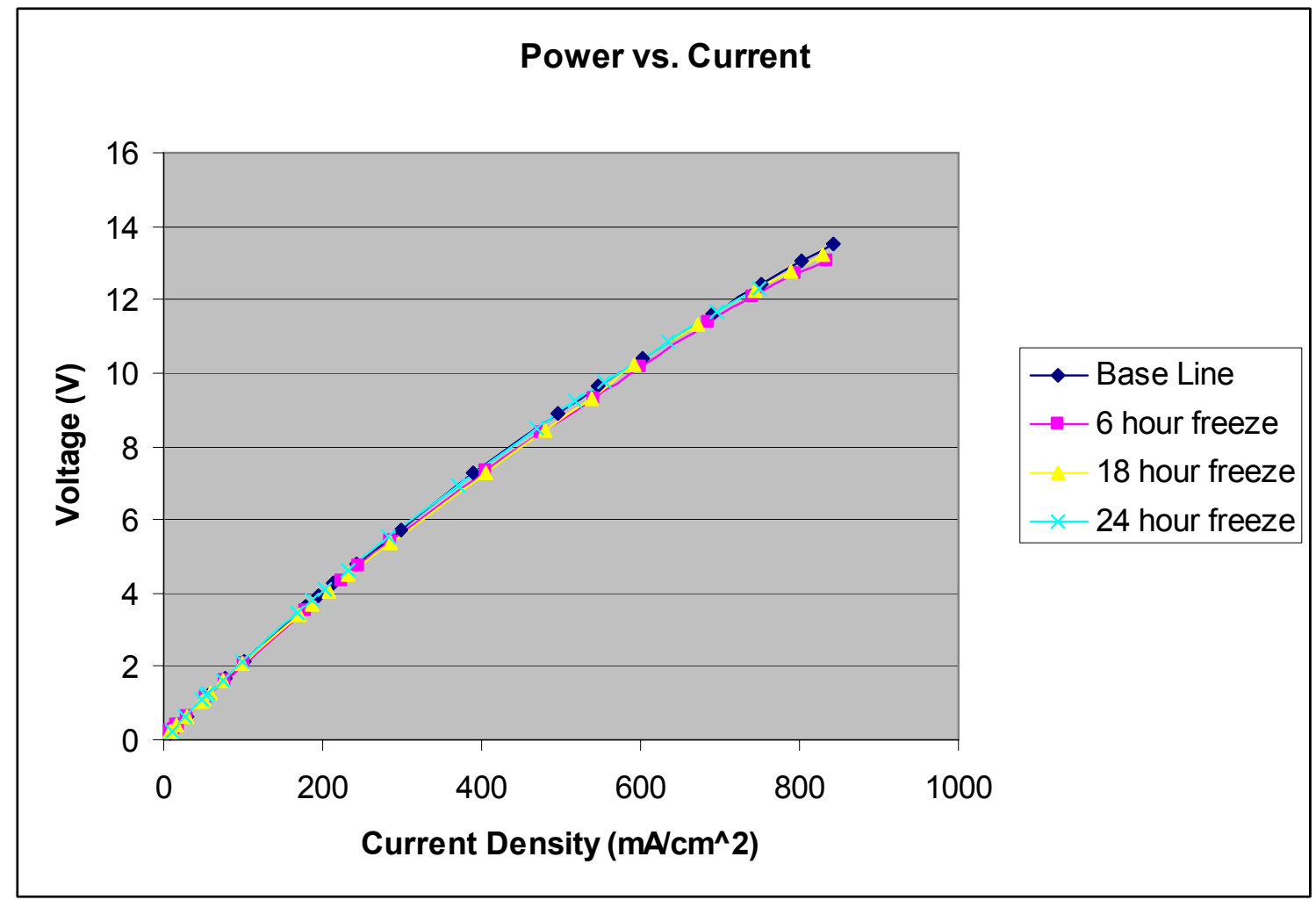

Figure 27: Freeze/thaw cycle duration investigation - power v. current graph 


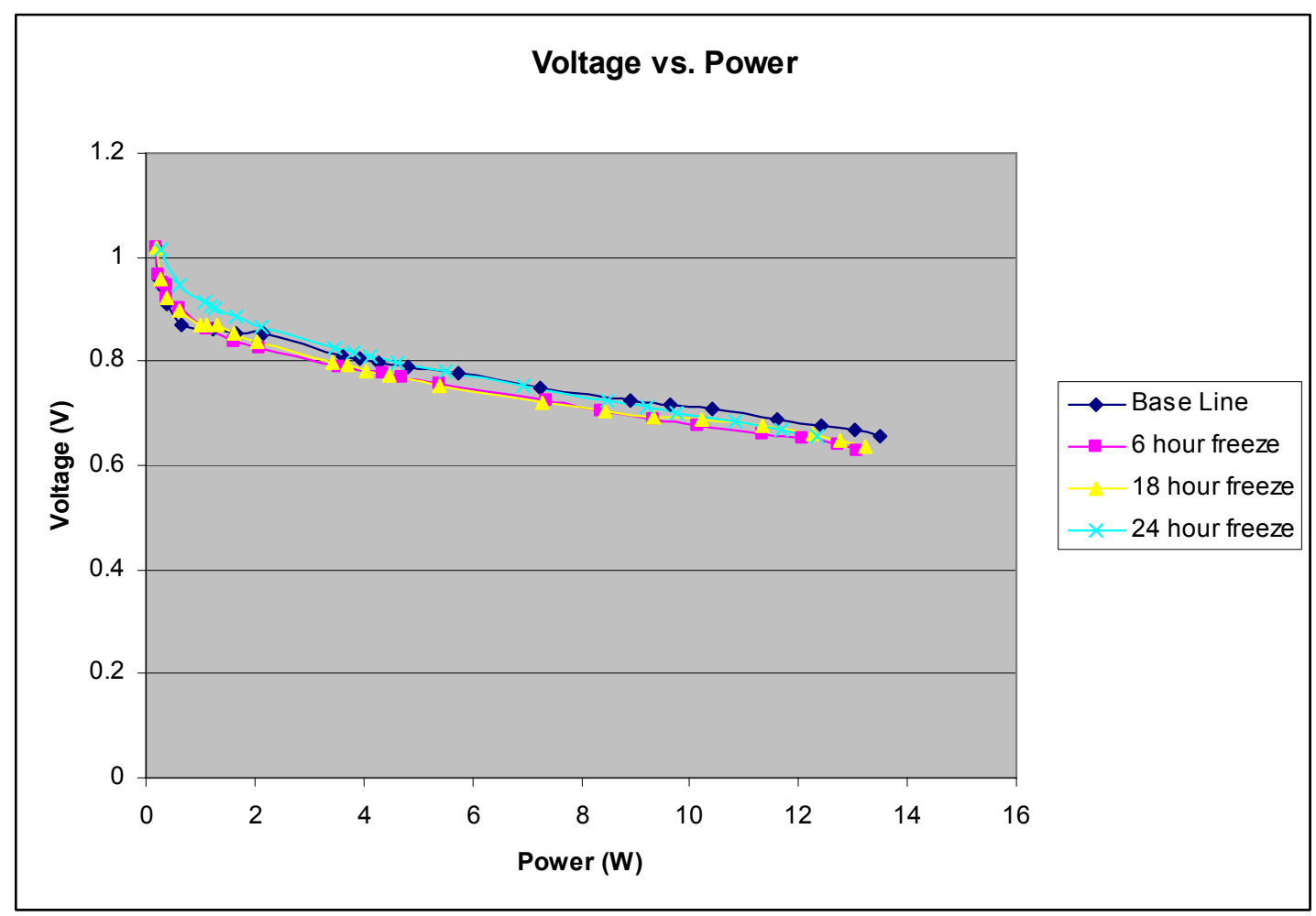

Figure 28: Freeze/thaw cycle duration investigation - voltage v. power graph

The graphs above demonstrate that although the curve of the power map is similar, the maximum power output has been reduced. This can be best illustrated by figure 29 which plots the same data as figure 26 , but modified slightly to better magnify the performance loss. 


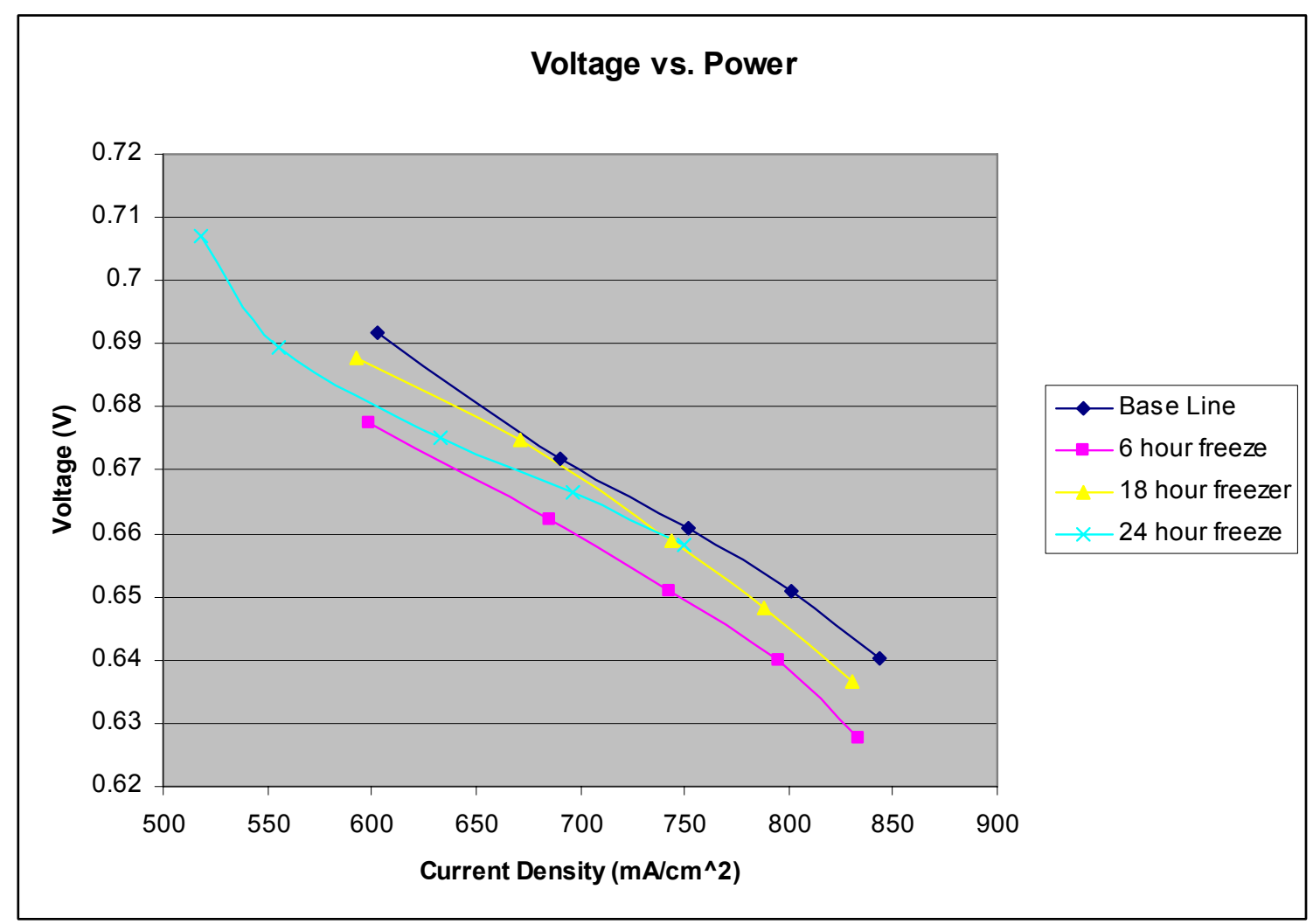

Figure 29: Freeze/thaw cycle duration investigation - voltage v. power (high load)

It can now be seen from figure 29 above that the cell's power output is affected as each freeze/thaw cycle is conducted for longer durations of time. Since this particular membrane had previously experienced twelve, one hour, freeze/thaw cycles $(70 \%, 80 \%$ and $90 \%$ relative humidity tests) before the beginning of this experiment, and very little degradation was previously recorded therefore it can be assumed that the duration of the freeze thaw cycle is a critical parameter for the facilitation of power degradation.

To determine the effect that the humidity has upon the membrane's degradation a twenty four hour freeze/thaw cycle will be utilized in order to properly explore the low temperature operational range of this membrane. 
The results from the twenty four hour freeze/thaw cycles were similar to the previous freeze/thaw investigations; in that there was an initial degradation from the base line along with minimal performance loss from the subsequent cycles. This is illustrated in figures 30,31 , and 32 .

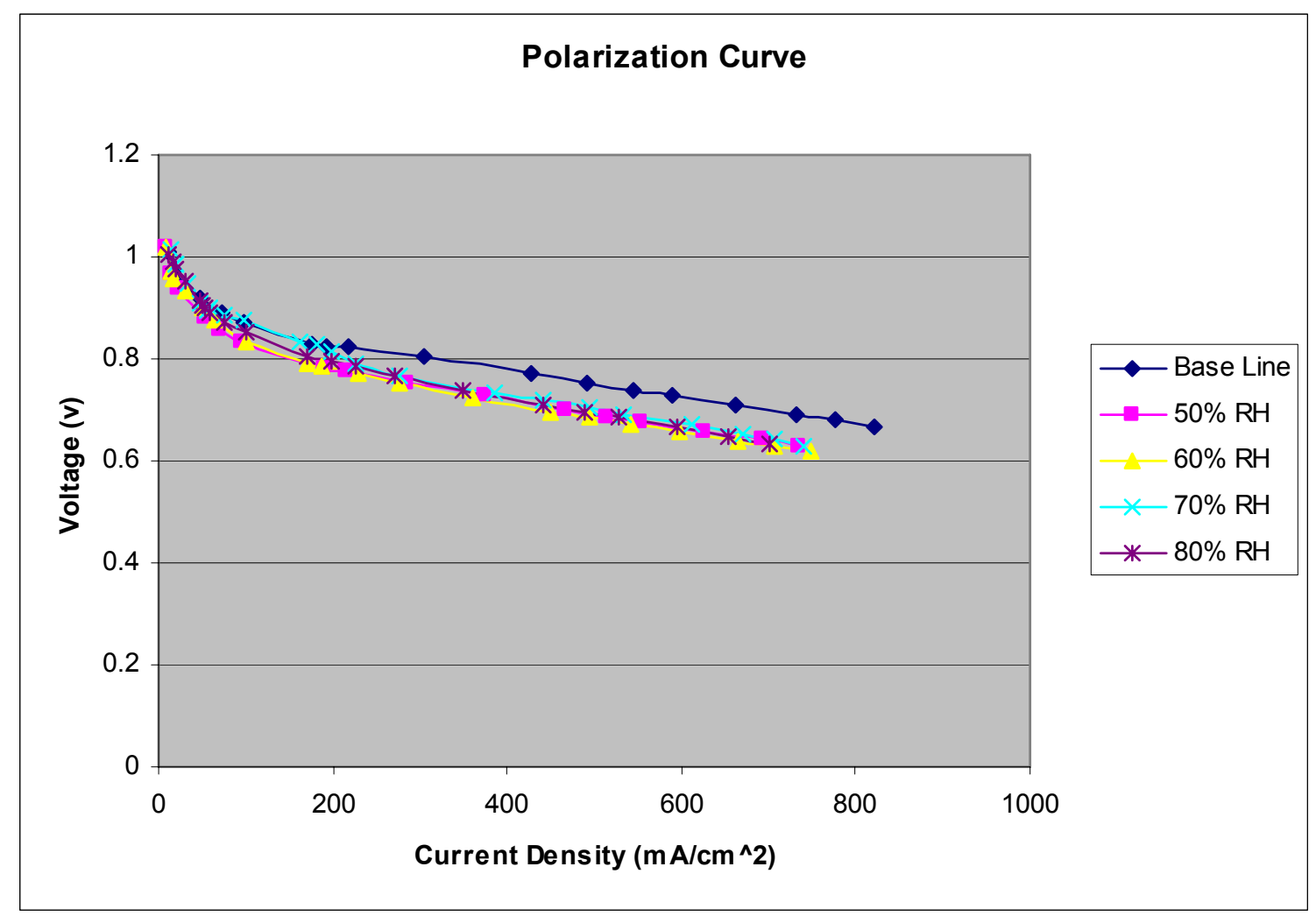

Figure 30: Twenty four hour freeze/thaw cycle - polarization graph

Figure 30 shows that in contrast with the previous NM3 membrane, the NM4 membrane has produced noticeable losses for the entire operational range of the cell. This is significant because the NM3 membrane only produced limited losses near full power operation point. One plausible explanation is the separation of any of the four critical transport areas (i.e. between the GDL and MPL layers, and between the MPL and Nafion layers.) Since the membrane is symmetric about its center, both the cathode and anode have similar interfaces. An increase in the ohmic resistance would explain why the entire power curve was affected. The delamination of these components would decrease the 
membrane's ion conductivity over the entire operational range, thus restricting the power output as seen in figure 30 .

The degradation effects can be confirmed by the following polarization curve illustration.

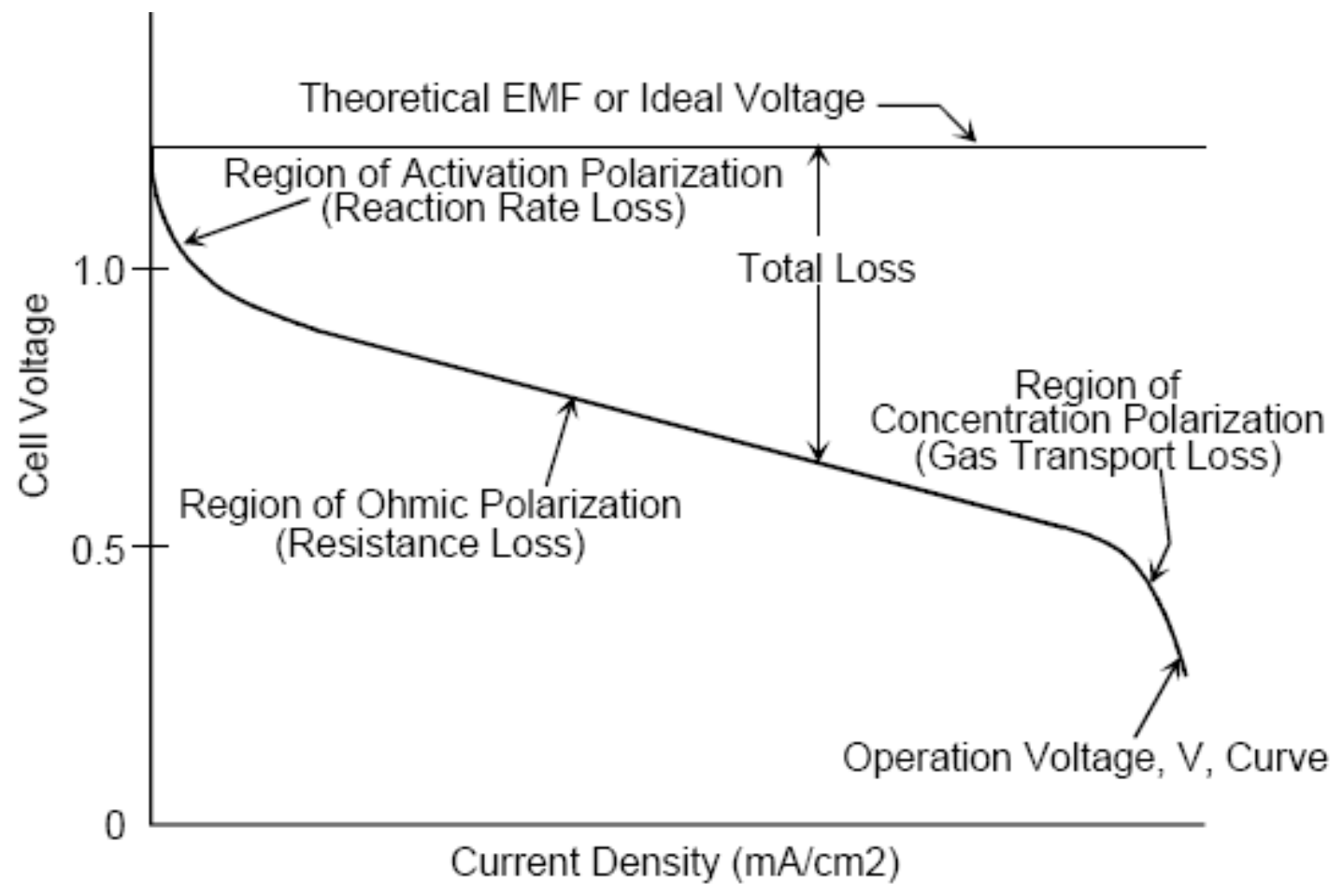

Figure 31: Polarization graph tutorial

Figure 31 describes how use the polarization curve to help identify three types of possible degradation namely activation, ohmic and concentration losses. Each type is identified on one specific region of the graph. By utilizing figure 31, the first mode of degradation could be attributed to an increase in cell's resistance which occurs because of reduced ionic conductivity through electrolyte and electrode. Physically the ohmic resistance could have increased because of the destruction of interconnecting ionic channels, or the separation of the GDL, MPL, and Nafion layers as mentioned above [55]. This ohmic resistance loss is quantified by the Area Specific Resistance (ASR) which has units of $\mathrm{ohm} * \mathrm{~cm}^{2}$ and is a function of membrane's design, material selection, 
manufacturing technique, and operating conditions. This parameter can be determined using the slope of the linear portion of the polarization curve as shown in figure 31 or more accurately by impedance spectroscopy.

If the ASR of the baseline polarization curve is compared to the subsequent curves a slight increase in the slope can be seen, but the difference between the slopes is too small to quantify as shown in figure 32 below.

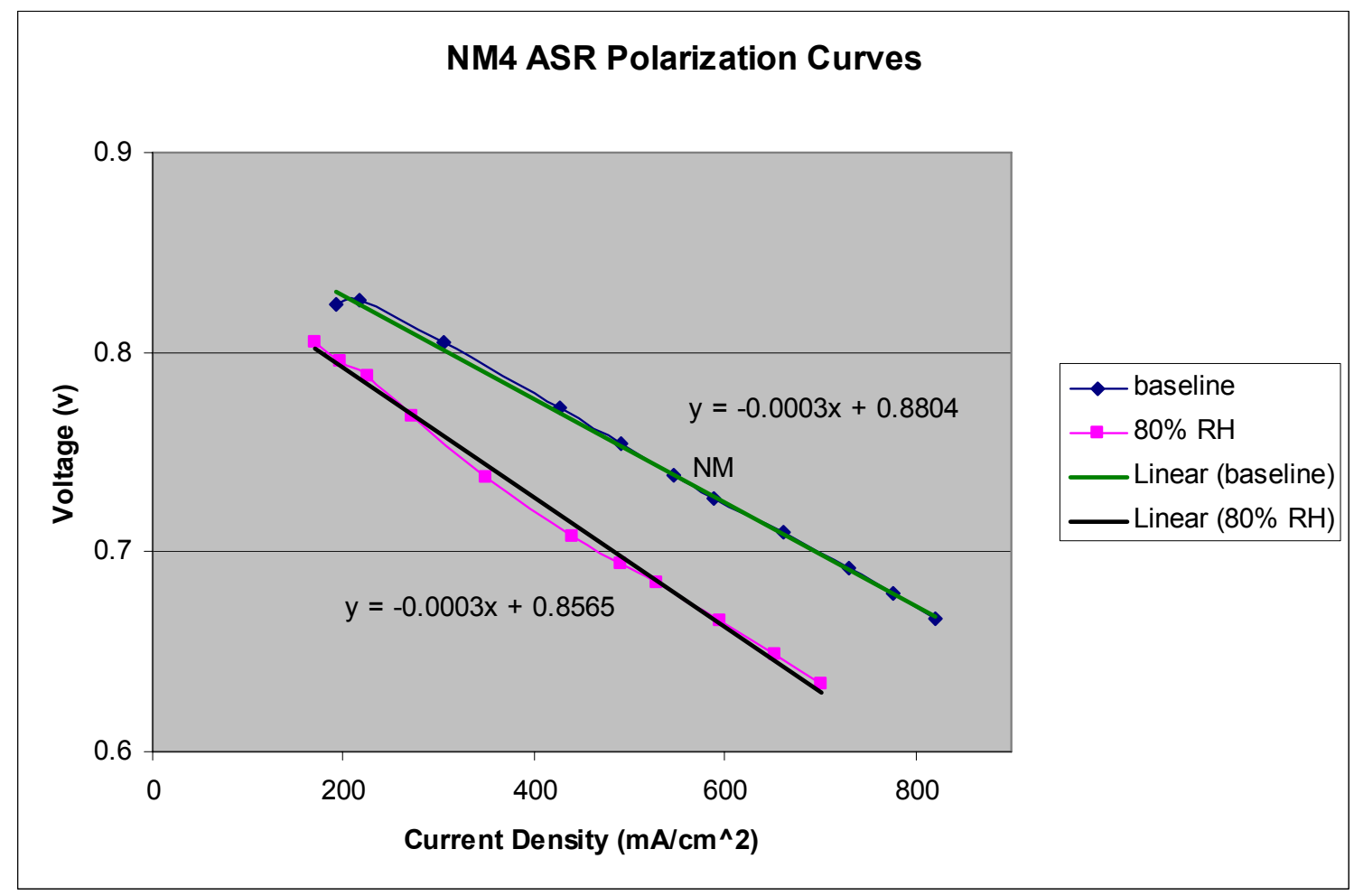

Figure 32: Post twenty four hour freeze/thaw cycle - area specific resistance

After the initial freeze thaw degradation from the baseline power curve the membrane continued to follow the same voltage/current relationship for each subsequent cycle. It cannot be assumed that the cell did not experience some type of degradation during these cycles. 


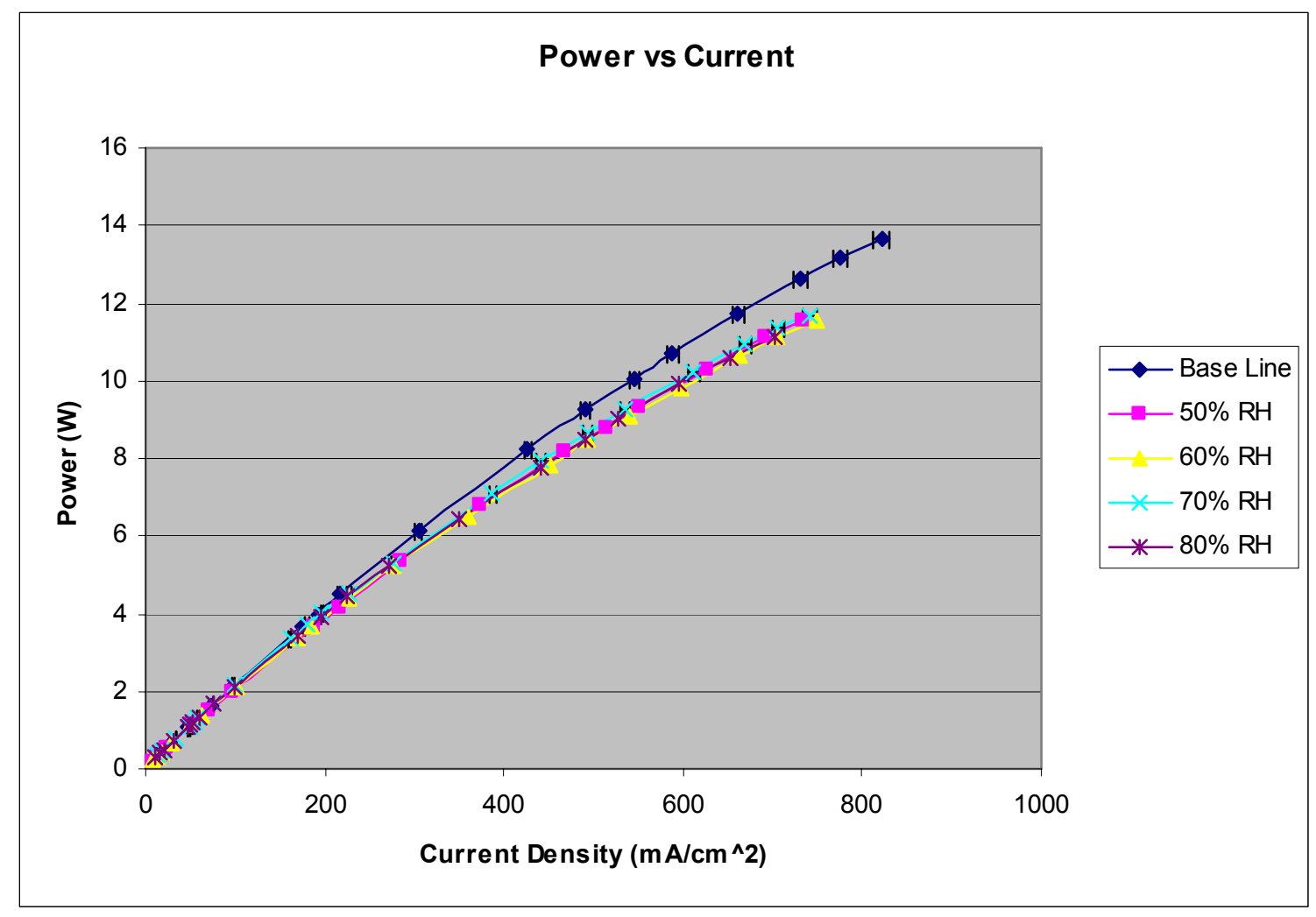

Figure 33: NM4 power v. current

In fact, figure 33 illustrates that the cell does experience the same type of power degradation as seen in the NM3 membrane. It can be seen that the $80 \%$ humidity run had a $5 \%$ decrease in current and power output when compared to the previous $70 \%$ test run. This type of degradation can be related to the mass transport losses which occur at high current densities due to the dilution of the fuel by the products produced at the cathode. This increased dilution could be caused by GDL, MPL and Nafion pore enlargement which would reduce the layers' hydrophobic properties and allow water vapor to flood the electrode. The potential difference which is produced by the change in concentration has been formulated by United States' Department of Energy [55]. Two forms of this equation have been presented below. The first form is the potential difference in terms of the species concentrations, and the second is related to the current and limiting current. 


$$
\Delta E=\eta_{\text {conc }}=\frac{R T}{n F} \ln \frac{C_{S}}{C_{B}}
$$

Where

- $\Delta E$ represents the potential difference produced by the concentration change

- $\eta_{\text {Conc }}$ represents the losses caused by the loss constituent concentration

- $\mathrm{R}$ represents the total cell resistance including electronic, ionic, and contact sources

- $\mathrm{T}$ represents the Temperature of the Cell

- $\mathrm{n}$ represents the number of electrons participating in the reaction

- F represents Faraday's constant: 96,487 coulombs/g-mole electron

- $C_{B}$ represents the bulk species concentration

- Cs represents the surface concentration

by using a Fick's law relation the equation becomes

$$
\eta_{\text {conc }}=\frac{R T}{n F} \operatorname{Ln}\left(1-\frac{i}{i_{l}}\right)
$$

- i represents the rate of mass transport to and electrode surface

- $i_{L}$ represents the limiting current of the maximum rate of which the reactant can be supplied to the electrode

By comparing the maximum current produced after the $80 \%$ relative humidity freeze to the base line value; the change in the potential was determined to be $.029 \mathrm{~V}$. This value can be compared to the actual potential difference calculated by subtracting the voltage at maximum power of the $80 \%$ relative humidity case from the control membrane's voltage at maximum power. This difference was calculated to be $.666-.6337=.0323 \mathrm{~V}$. The experimental values compared well with the theoretical formula well with an error of approximately $10 \%$. 


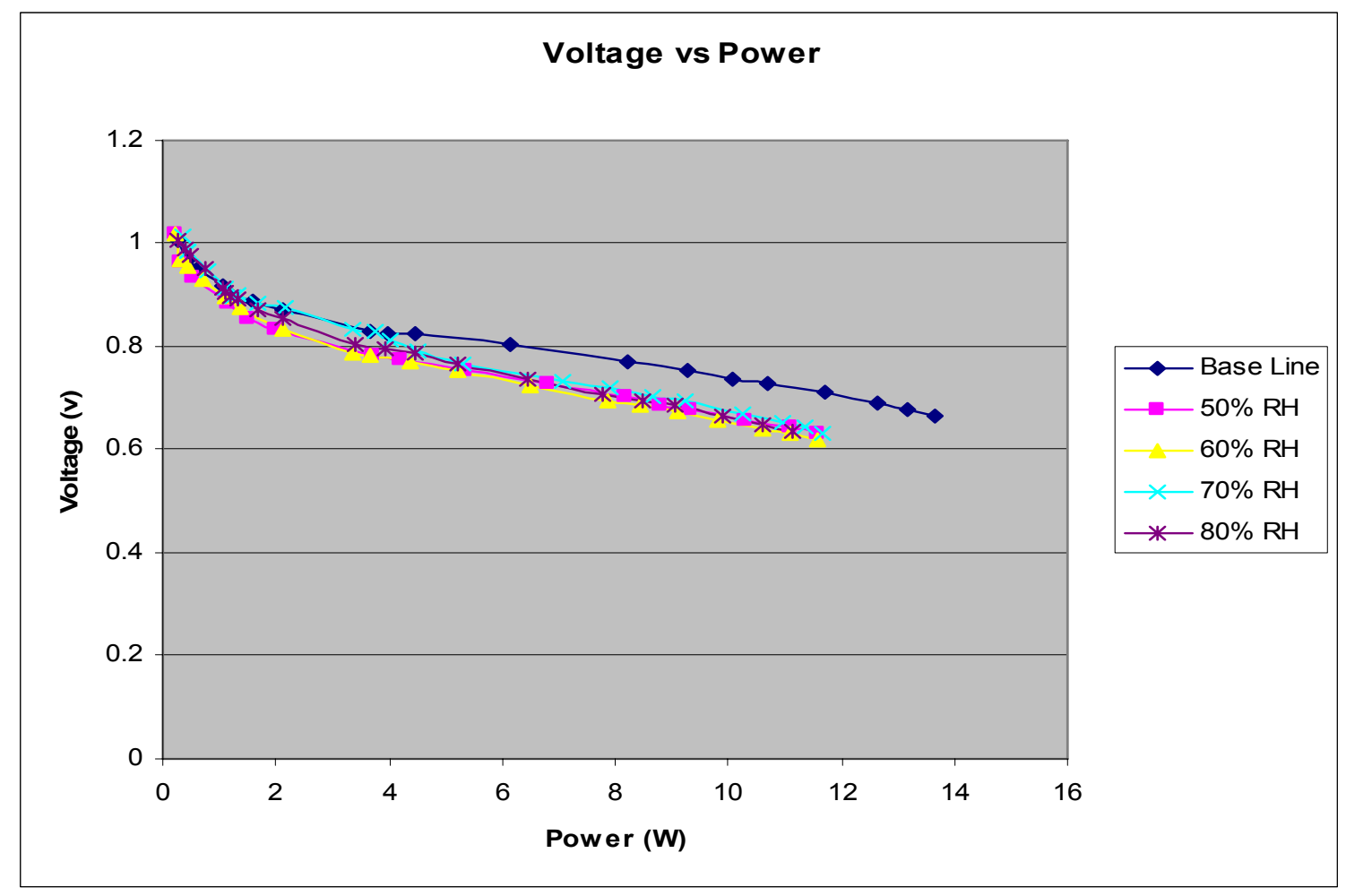

Figure 34: Twenty four hour freeze/thaw cycle - voltage v. power graph

It should be noted that similar degradation losses were not experienced between the $50 \%-60 \%$, and $60 \%-70 \%$ test runs. This suggests that the dehumidification of the membrane had a mitigating effect on the cell's power loss, but just not as pronounced as reported by Hou [21]. The membrane's fabrication method and proprietary hydrophobic treatments are probably responsible for this performance. 


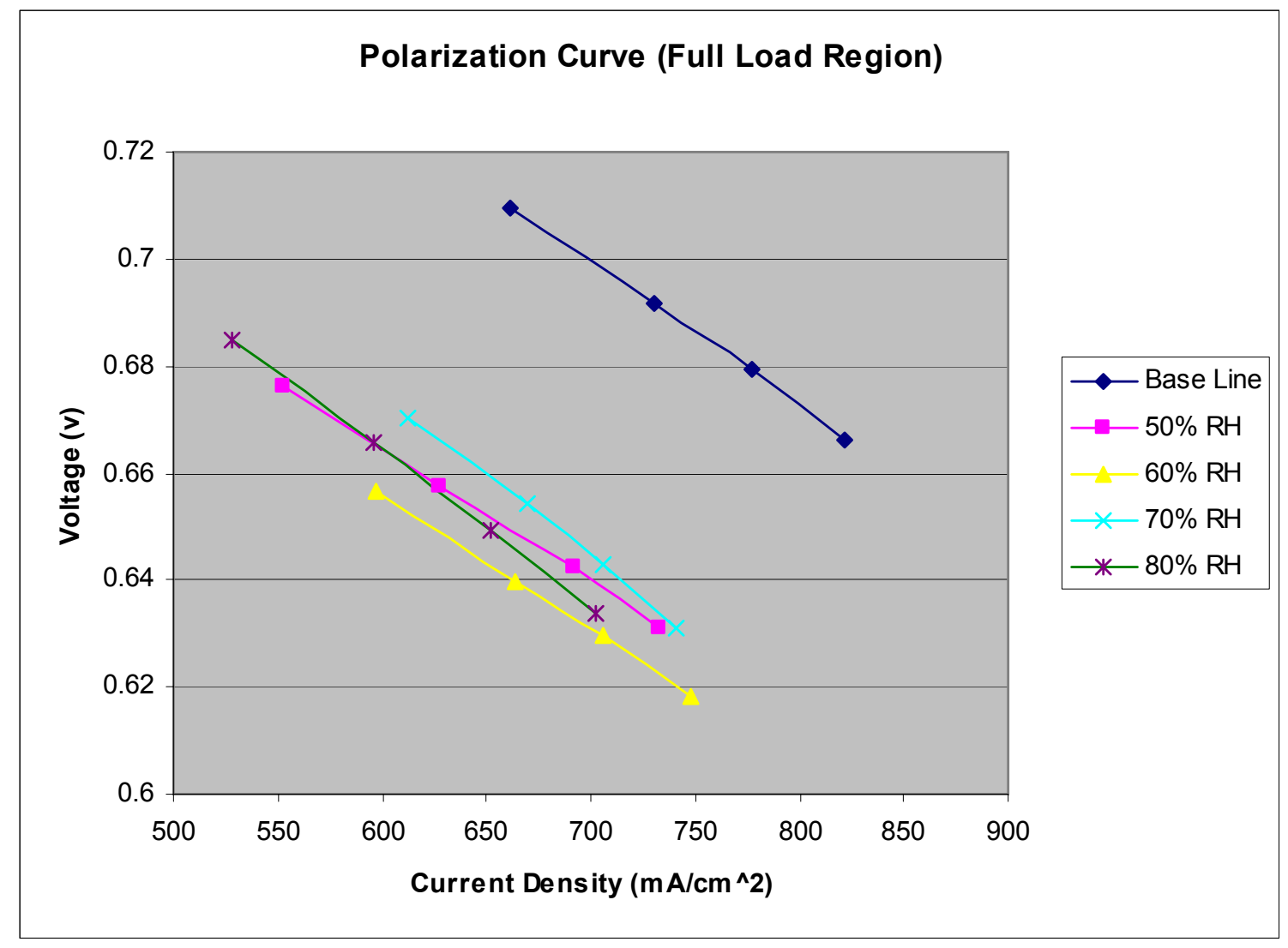

Figure 35: Twenty four hour freeze/thaw cycle - polarization graph (full load region) 


\section{B.E.T. investigations}

To identify the affect that the ice formation has upon the pore size, volume, and membrane surface area a B.E.T. porosity scanner was utilized. A complete description of scientific principles employed with this type of analysis has been included in appendix $C$. The porosity scanner determines the surface area of both meso-porous and micro-porous structures by measuring the nitrogen physisorption of the material.

Figure 36 compares the presented results to that of Cho et al. [22] This graph illustrates the pore volume plotted against the pore diameter as calculated by the Horvath - Kututhar method [58] for a particular membrane before and after the experimental freeze/thaw cycles. Both investigations observed enlargement of the pore volume after the thermal cycles. It can be seen that the Electrochem membrane has a smaller initial pore size, but a larger pore volume when compared with Cho et al.'s membrane. 


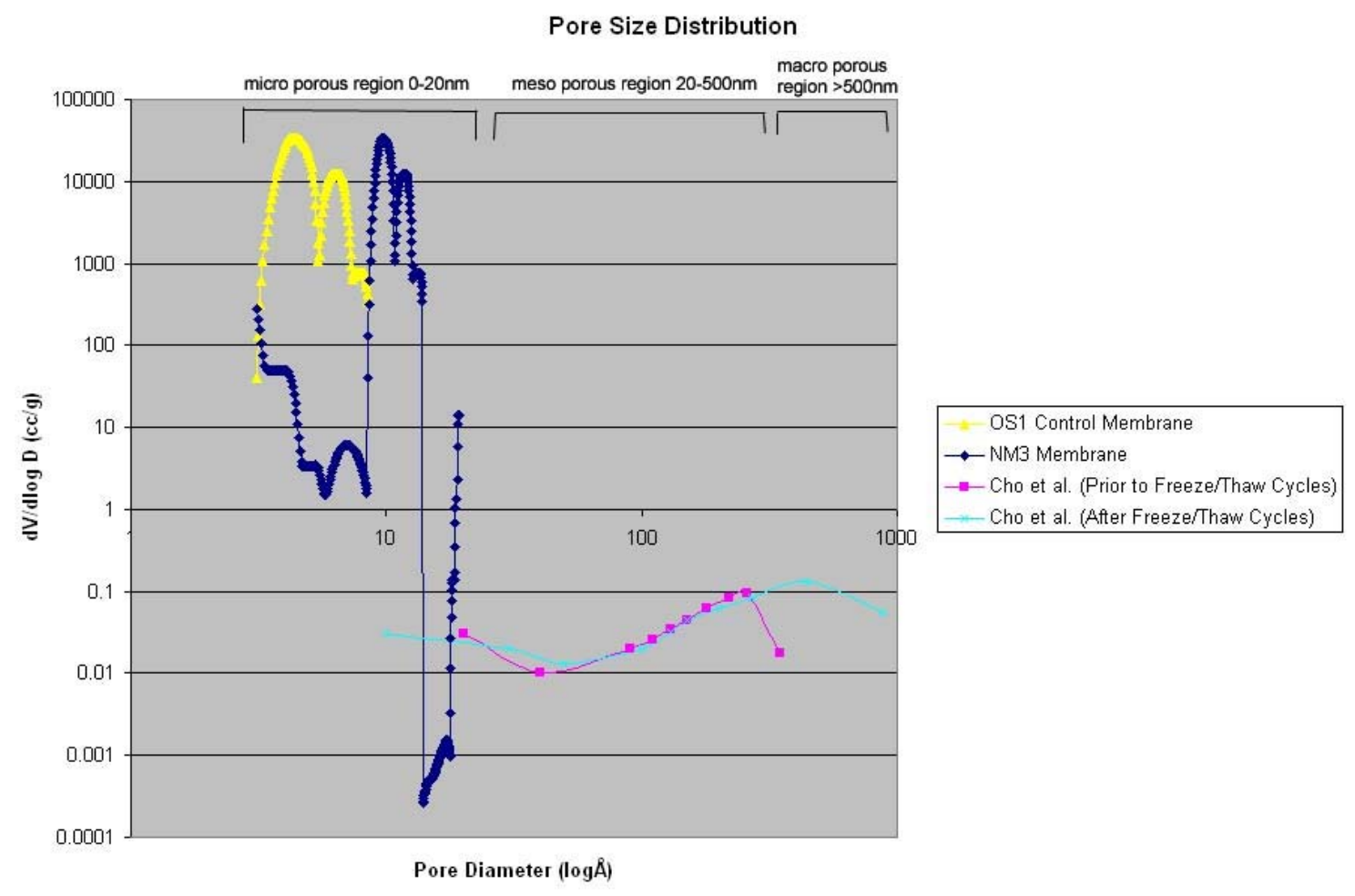

Figure 36: Pore size distribution

The surface area, pore diameter and volume were characterized for an unfrozen membrane (OS1), the $60 \%$ de-humidified membrane (NM2), the membrane used for the $70 \%, 80 \%$, and preliminary 24 hour investigations (NM3), and a reference membrane which was frozen in standard freezer at 0 degrees Celsius for approximately for 14 days (REF1). The results from these investigations have been outlined below in figures 37 and 38 . 


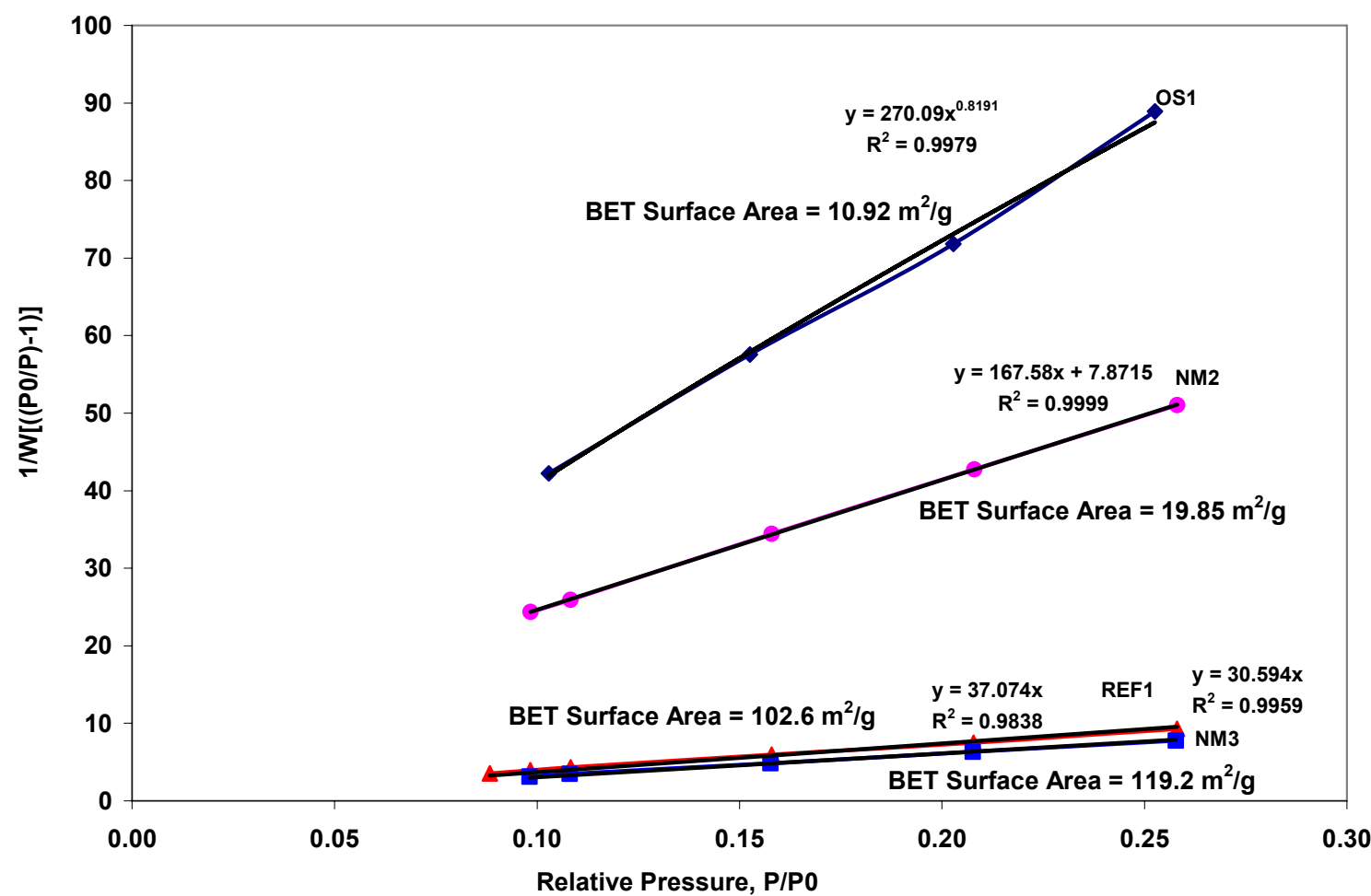

Figure 37: Surface area: adsorbed nitrogen v. relative pressure 


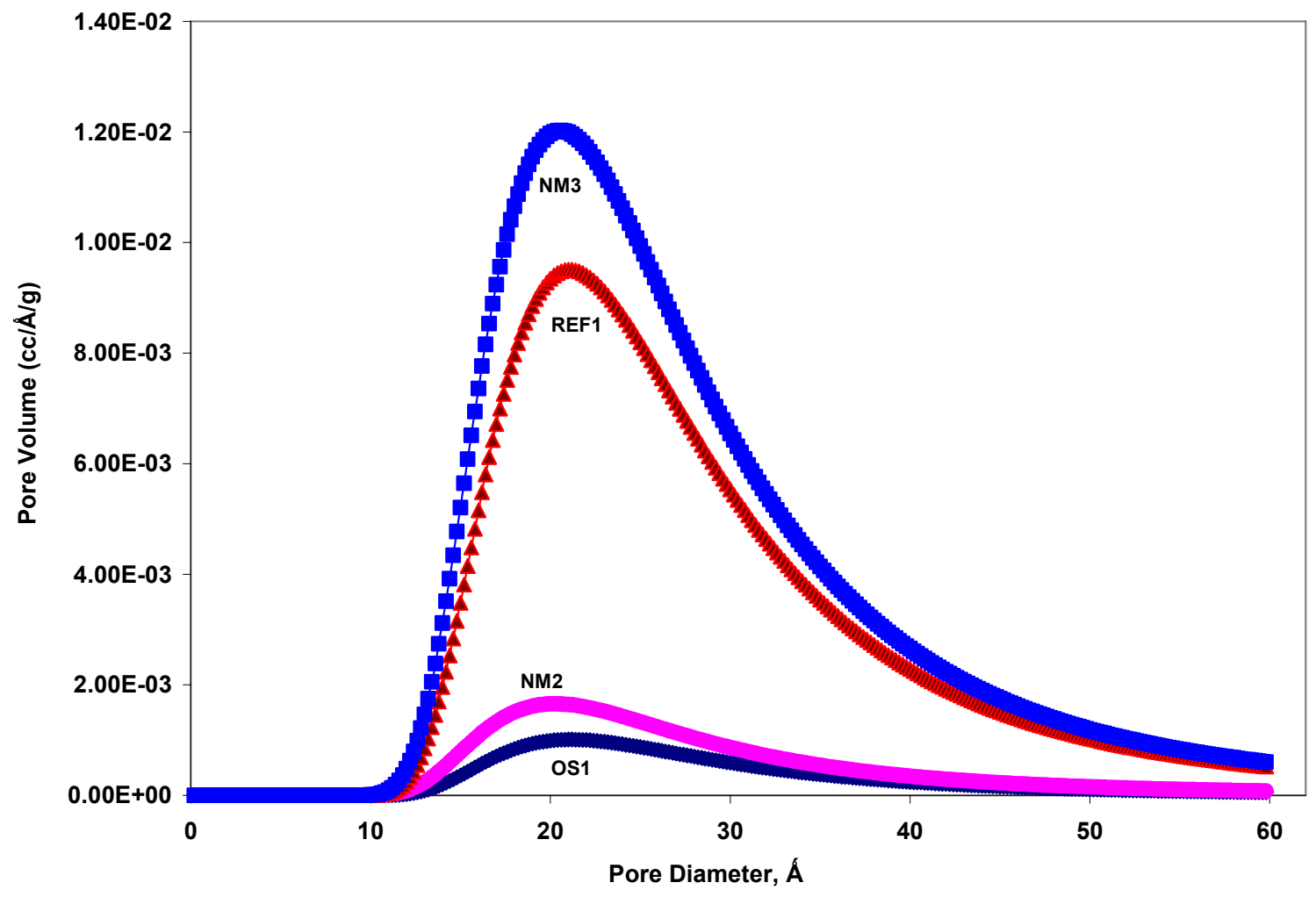

Figure 38: Pore volume v. pore diameter 
Figure 37 illustrates that as the duration of subzero exposure increases the amount of nitrogen that is physisorbed decreases, thus indicating an increase of membrane surface area. It was extrapolated from the figure 37 that the surface area increased by an order of magnitude from the OS1 to the NM3 tests. It should be noted that an increase of the surface area does not imply that an increase of the active surface area (regions where the catalyst, hydrogen and oxygen are present) was measured. In fact, the exact opposite is true since an increase of the surface area would indicate an increase of the pore size or volume, therefore decreasing the active surface area. These results agree with the performance data acquired from the samples, in that, if the sample had shown larger performance losses, then it also experienced large increases in pore volume and surface area. A similar relationship is true for the control and NM2 samples; smaller performance loss - smaller pore volume and surface area increases. Therefore the performance loss must have a direct correlation with the membrane's pore volume and surface area increases.

Figure 38 shows the pore volume in relation to the pore diameter as calculated by the DA method [58]. These results show that the pore size did not increase by any appreciable amount; therefore the majority of the physical destruction must have occurred within the pore structures. The destruction can be quantified by analyzing the pore volume variations of different membranes. It can be seen that the pore volume increased by a factor of 10 between OS1 and NM3 cases.

This does present a slight contradiction with the results obtained from the HK method, but the literature [58] says that the DA method may not describe all samples properly. Specifically it noted that if the sample had larger amounts of active carbon may map erroneous results. It should be understood that HK method provides an accurate analysis for this particular application. 


\section{S.E.M. investigations}

A Hitachi Scanning Electron Microscope was utilized to correlate the recorded power loss to certain structural anomalies such as layer delamination or separation. Due to the sample size limitations, the optical investigation of the membrane was conducted after the membrane's performance data had been collected. Each sample had similar preparation procedures which included:

- Cut a $1 \times 2 \mathrm{~cm}^{2}$ rectangle from the parent sample using a new industrial razor blade.

- Place the rectangular sample into a climate chamber for 1 hour at $90^{\circ} \mathrm{C}$ to remove as much water as possible, before degrading the Nafion layer.

- Sputter approximately $15 \mathrm{~nm}$ of gold on to the surface using a Hummer ${ }^{\mathrm{TM}}$ sputter coater.

- Ground the sample to the sample holder using a piece of conductive copper tape.

The membranes that were investigated include the control membrane OS1, NM3, and NM4. 
First, the cross sectional view was analyzed for any apparent separation or tearing of the individual layers. Figure 39 illustrates a typical polymer electrolyte membrane. The image has been annotated to indicate the approximate thickness of each of the layers of assembly.

- Gas Diffusion Layer 120 $\mathrm{\mu m}$

- Micro Porous Layer 100 $\mu \mathrm{m}$

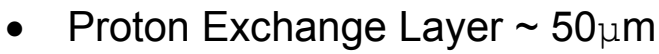

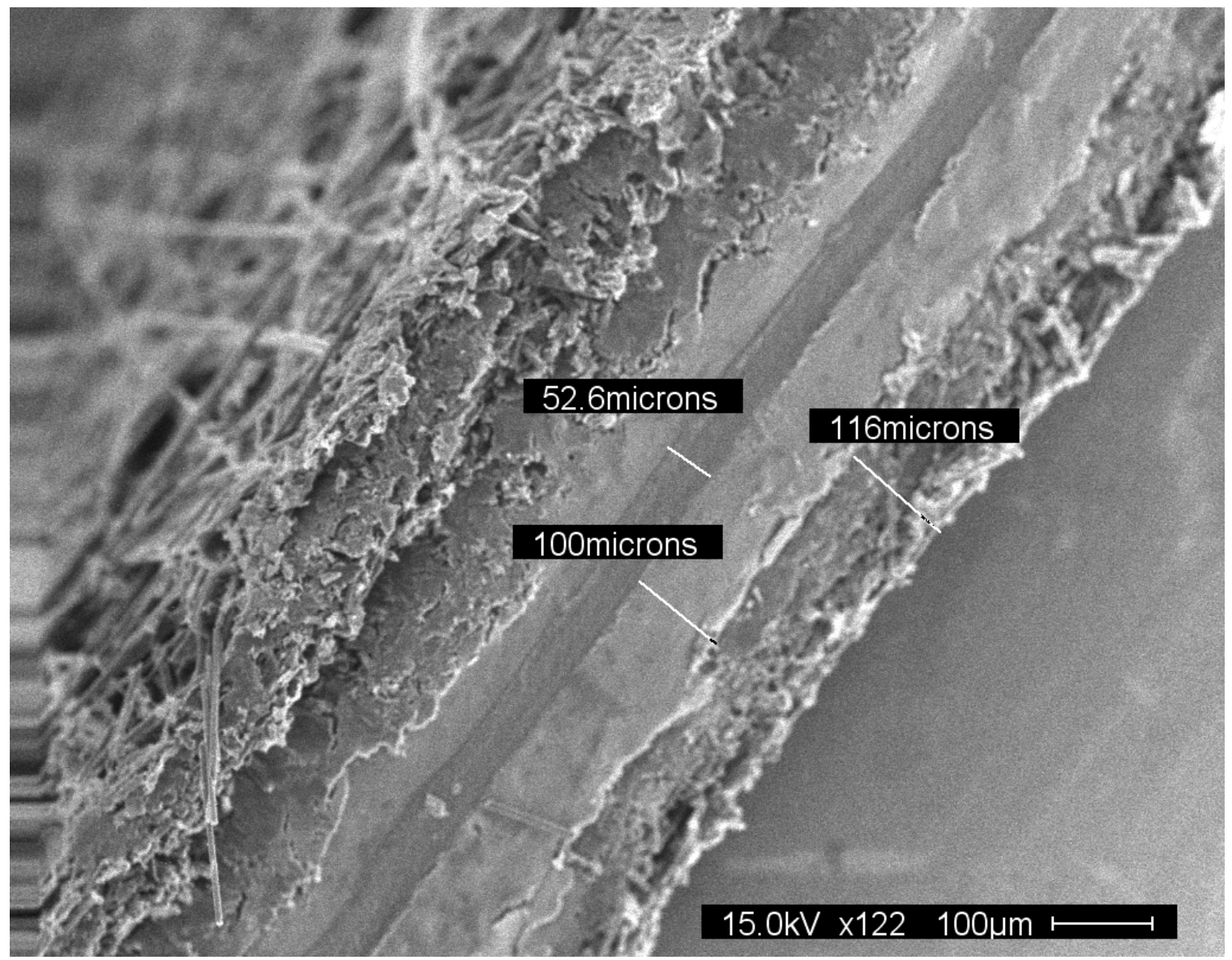

Figure 39: Proton exchange membrane cross-section 
When figure 39 was investigated at a higher magnification, it was apparent that some amount of delamination occurred between the layers of the M.E.A. The results of this investigation can be summarized by the meso-porous section below.

Meso-porous investigations

Figure 40 below shows the interface between the micro-porous (catalyst) and proton exchange (Nafion) layers of an unfrozen membrane. At 1100x magnification there is no apparent gap or tearing of the interface.

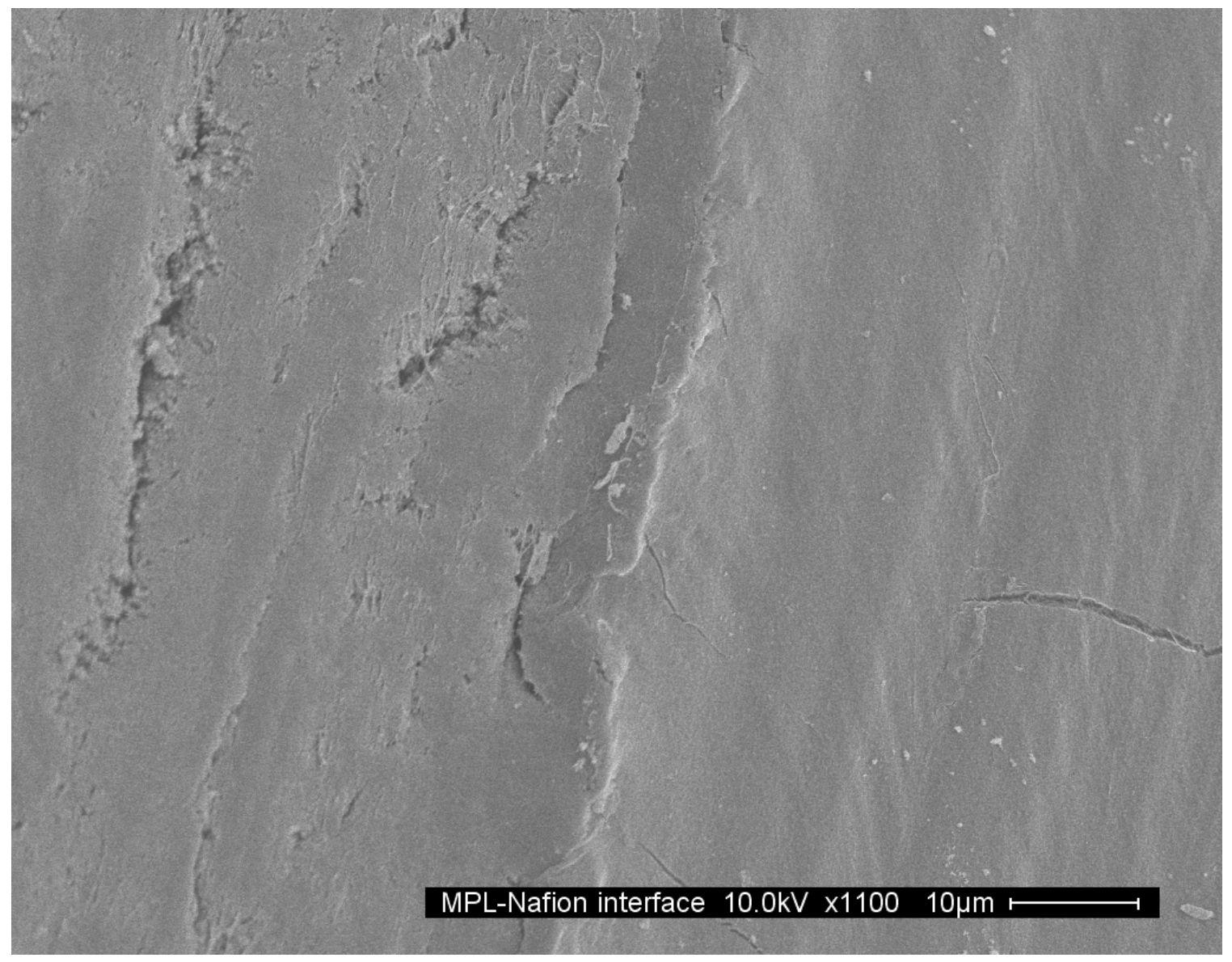

Figure 40: Control (OS1) proton exchange - M.P.L. interface x1100 


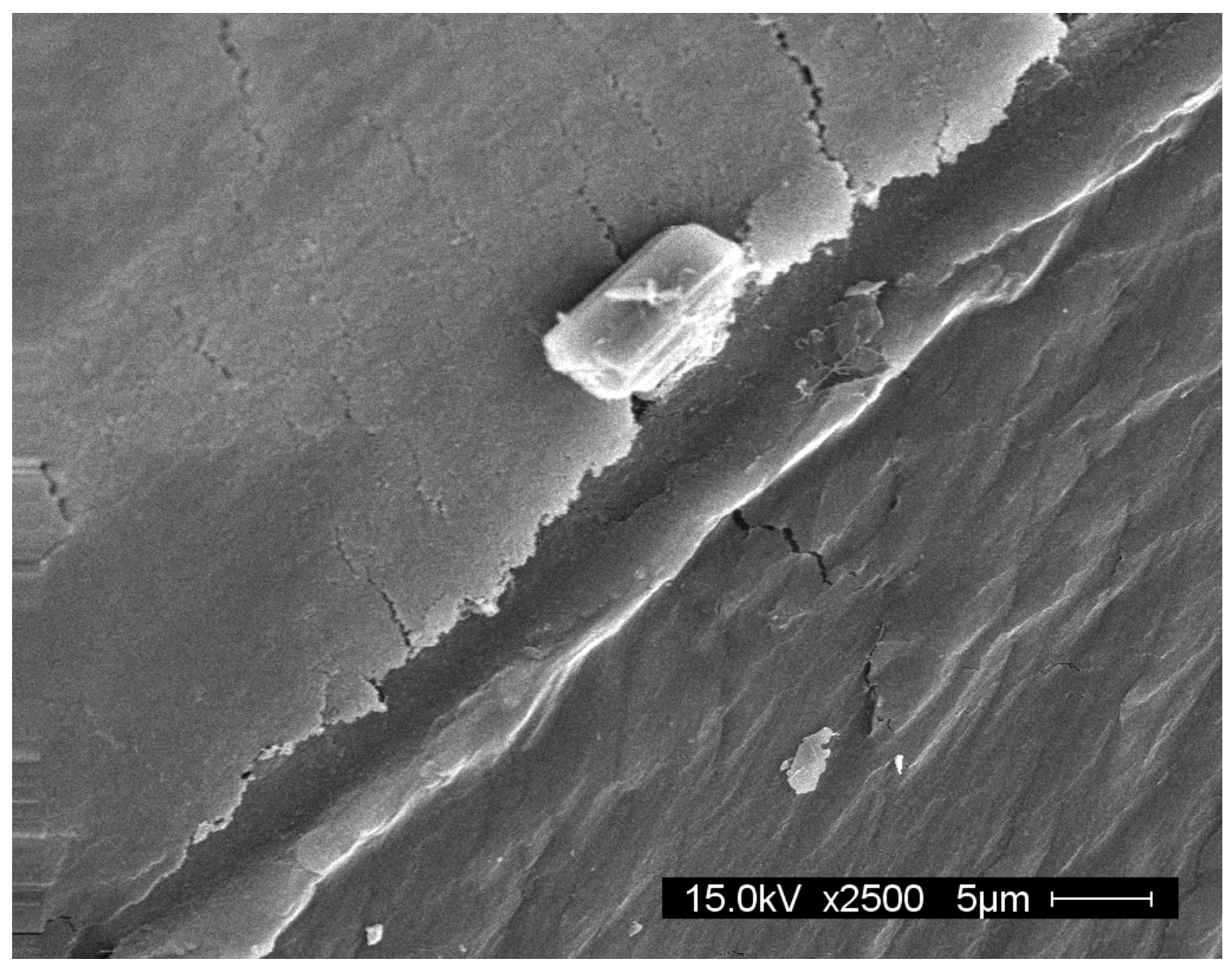

Figure 41: NM3 proton exchange - M.P.L. interface $x 2500$

Figure 41 depicts the same interface in the NM3 membrane which experienced approximately 20 freeze/thaw cycles. This image shows a more pronounced division between the two layers. 


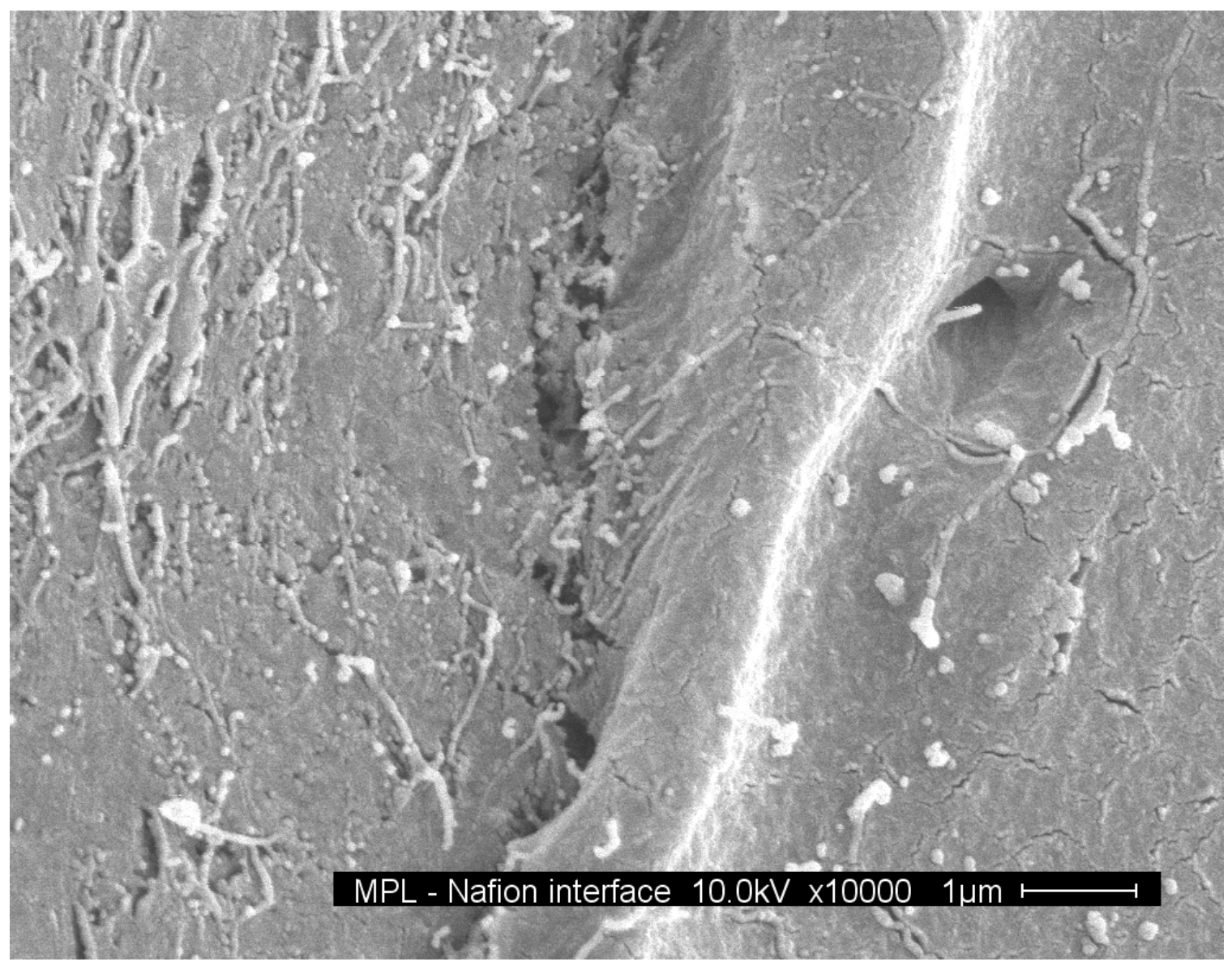

Figure 42: Control (OS1) proton exchange - M.P.L. interface x10,000

Figure 42 shows the control membrane's interface at 10,000x magnification. A relatively smooth transition is still seen between the layers even at this magnification. 


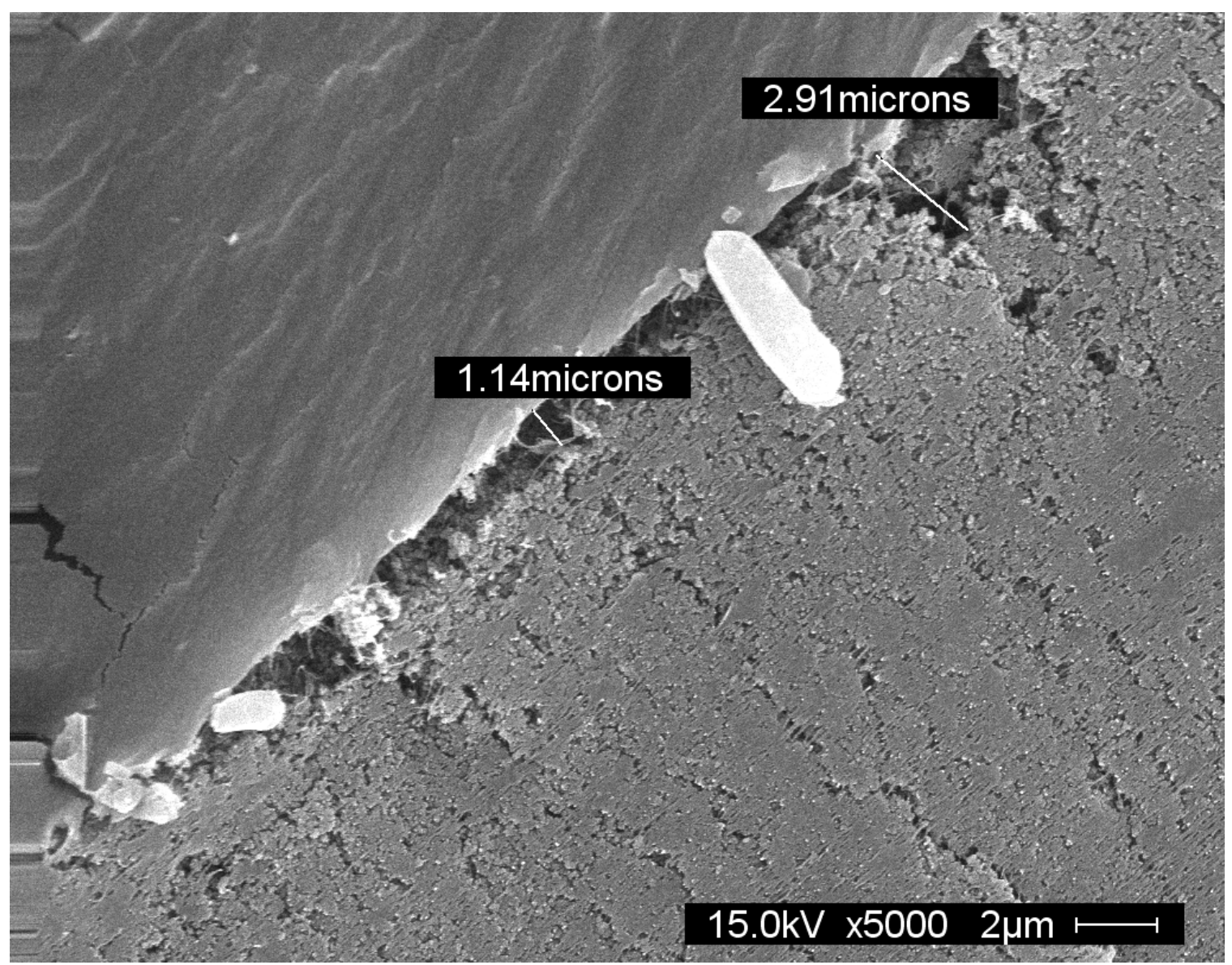

Figure 43: NM3 proton exchange - M.P.L. interface $x 5,000$

In contrast, figure 43 shows a distinct channel dividing the two layers at half the magnification. This channel would be enough to increase the ohmic proton exchange resistance of the membrane.

By increasing the magnification yet further the approximate size of the fore mentioned channel can be determined in both the control and experimental samples. 
Figure 44 below shows the control membrane at 70,000x magnification. At this magnification level the approximate channel gap of the interface is measured with the Edax Genesis software. The approximate size of the channel is .283 microns with an uncertainty of $+/-15 \mathrm{~nm}$.

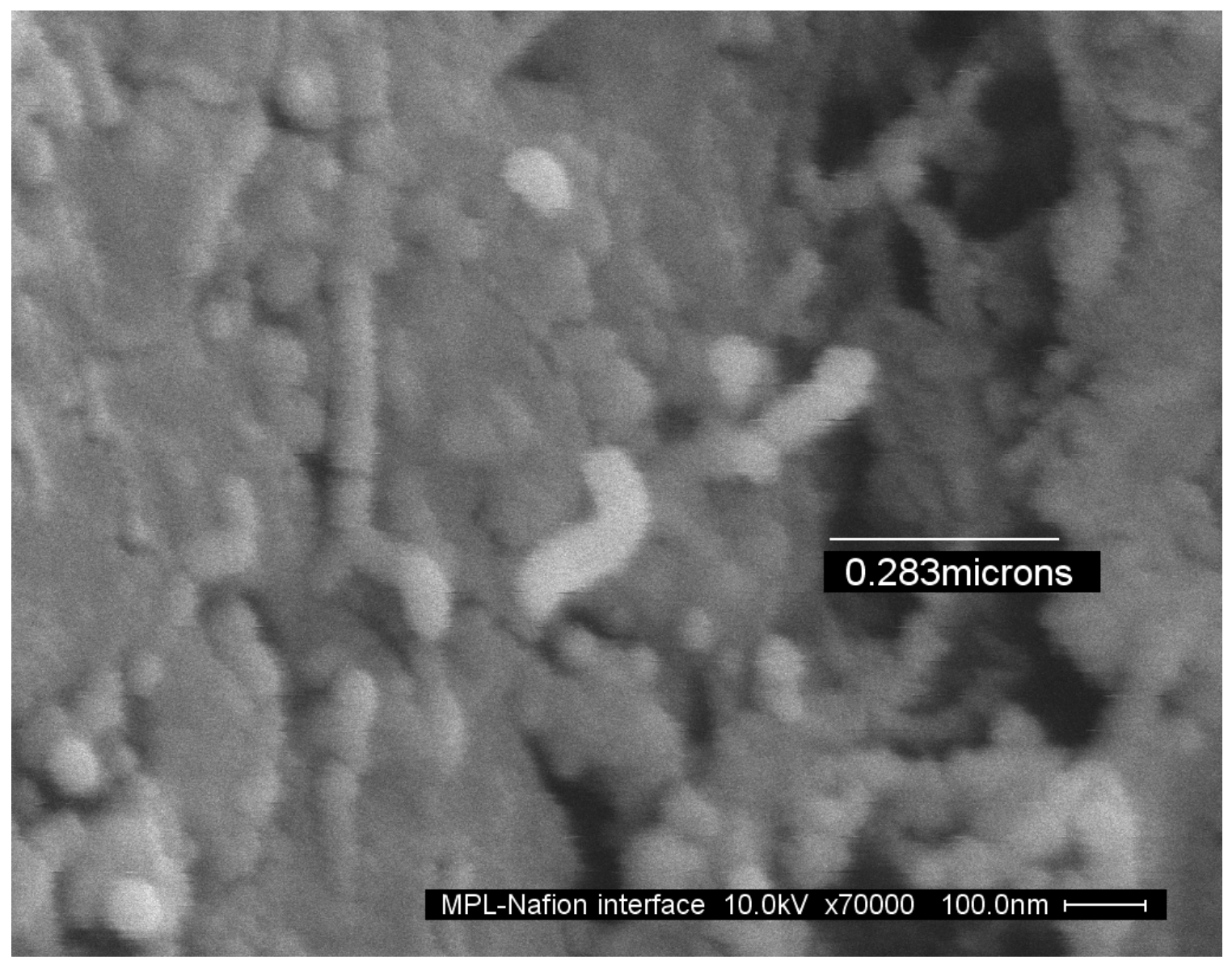

Figure 44: Control (OS1) proton exchange - M.P.L. interface x70,000

Figure 45 shows the captured image of the NM3 membrane after being physically strained by internal ice formation. The effects of this strain are evident by the few stay strands of the polymer that still cling to the proton exchange layer. It can be seen from the picture that the approximate size of the channel is 1.35 microns, almost an order of magnitude larger than the control sample. The associated error with this measurement would be $+/-67 \mathrm{~nm}$. 


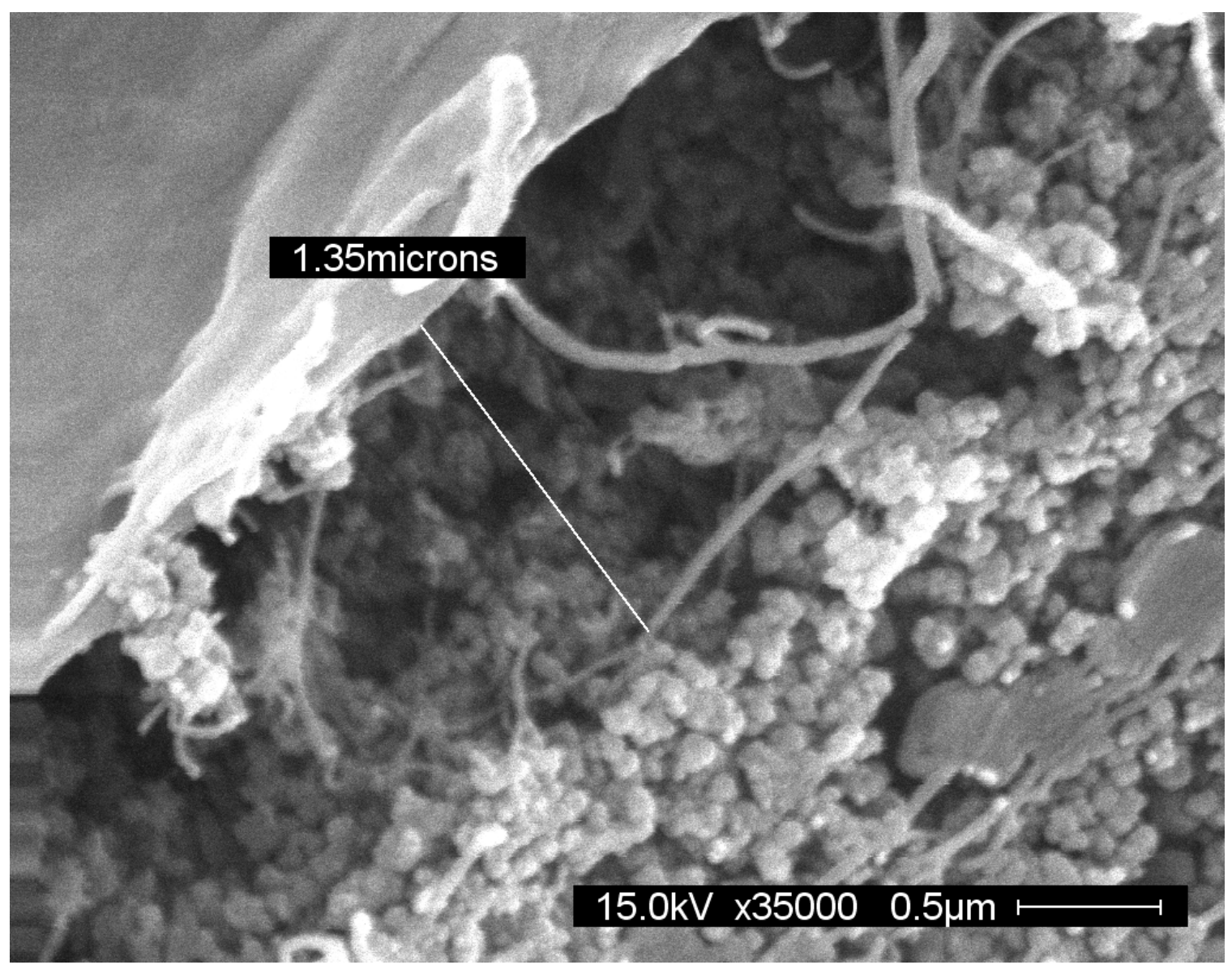

Figure 45: Proton exchange - M.P.L. interface $\times 35,000$

After the micro-porous layers were investigated, the effects of the ice formation on the G.D.L. structure quantified.

Gas diffusion layer investigations

The gas diffusion layer has been identified as a possible cause of the post - freeze cathodic flooding. One possible explanation of this flooding is the enlargement of the macro and micro matrix of the structure. 
Figure 46 illustrates the G.D.L. layer's macro pore matrix which is comprised of larger macro pores connected with a fine micro-porous weave as shown in figure 47.

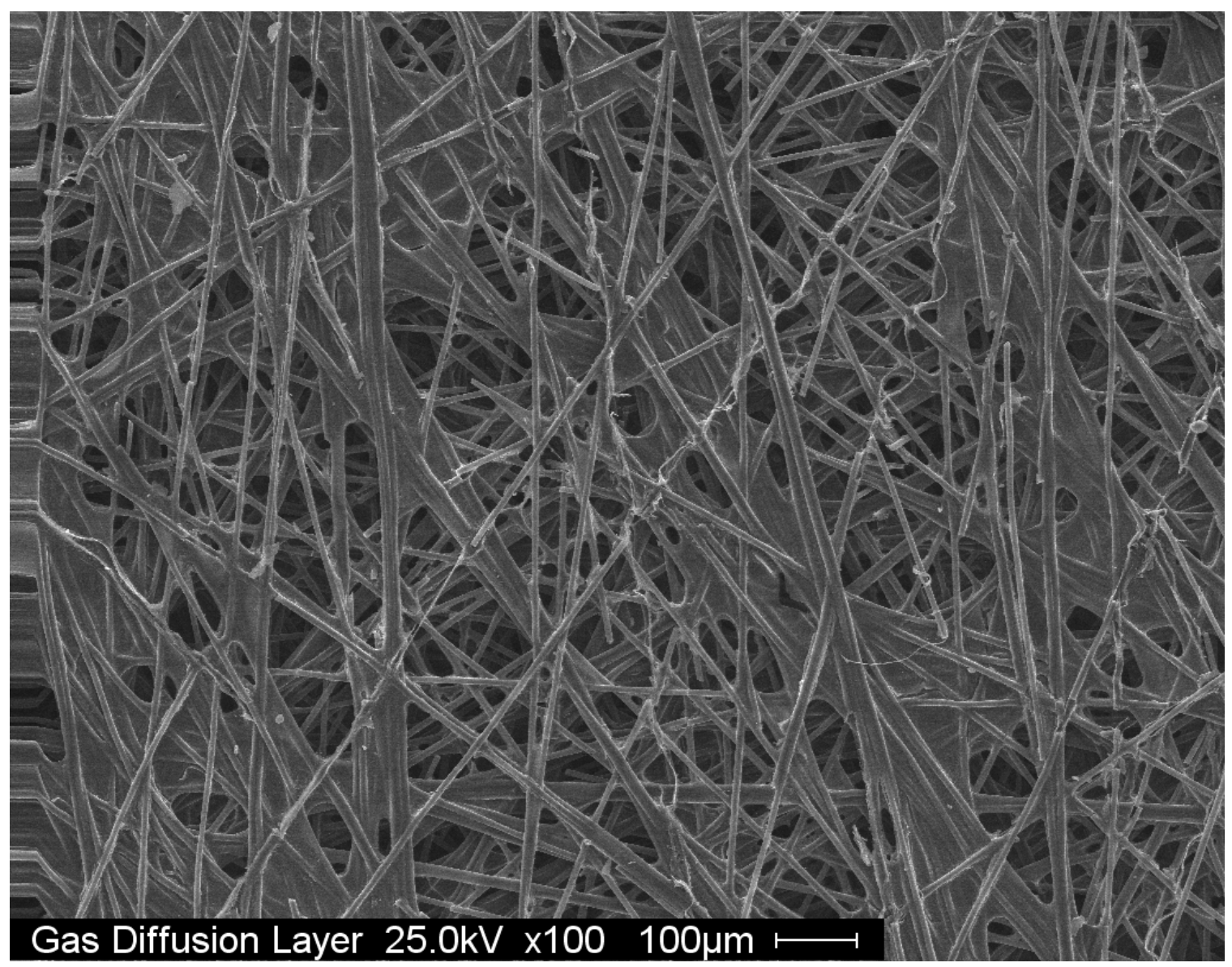

Figure 46: Control (OS1) gas diffusion layer x100 


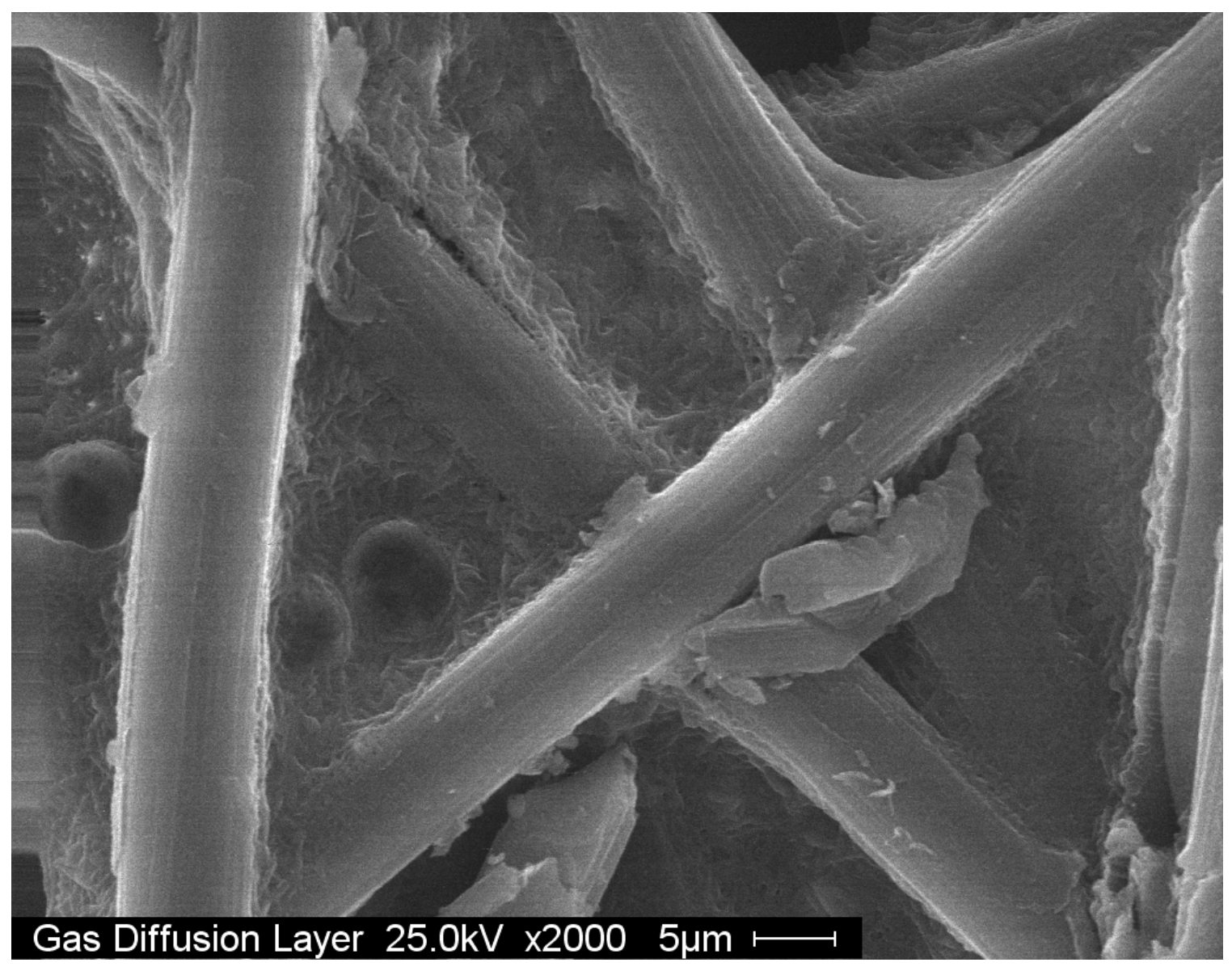

Figure 47: Control (OS1) gas diffusion layer x2000 


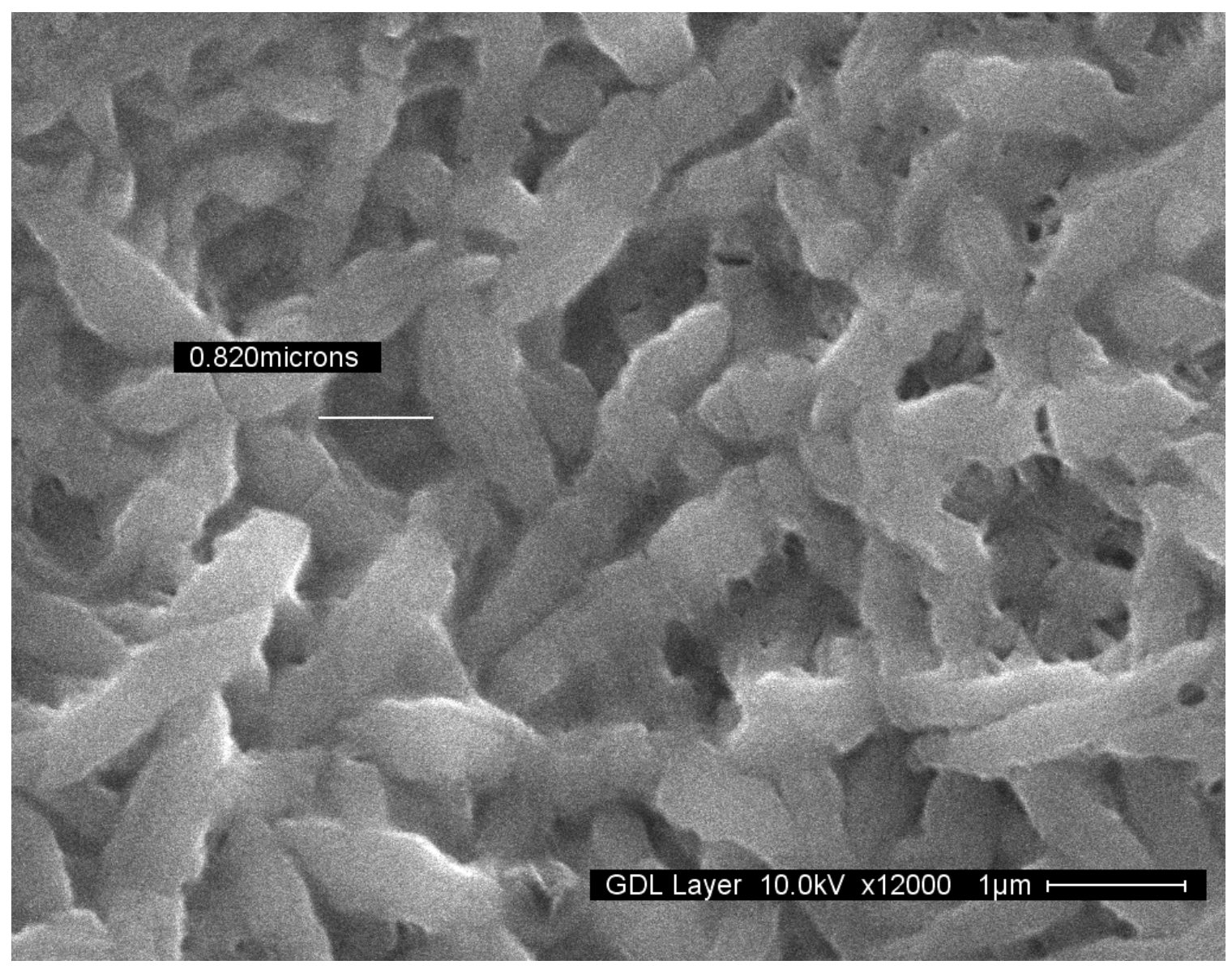

Figure 48: Control (OS1) gas diffusion layer $\times 12,000$

It can be seen from figures 49 and 50 , that there is little degradation to the structure of this layer. The pore size and shape of the G.D.L layer remains unaffected by the ice as it crystallizes. 
Gas Diffusion Layers

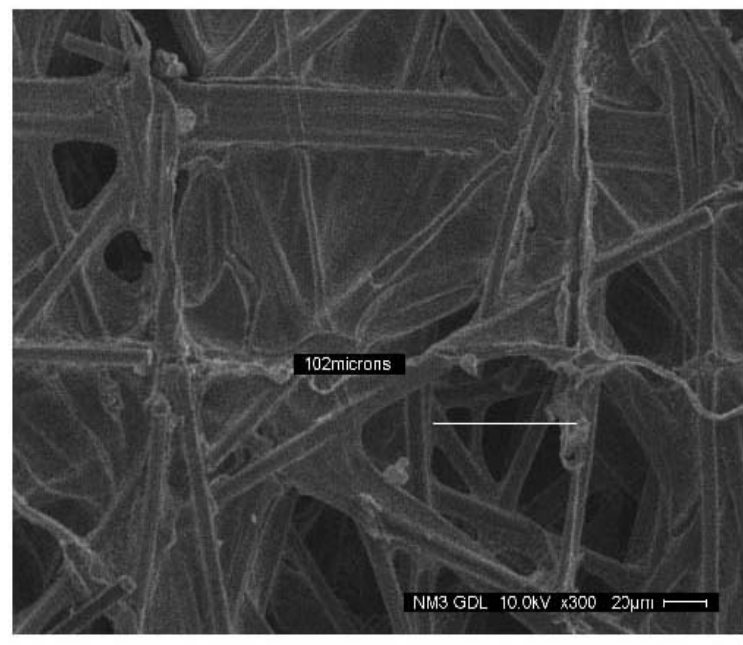

NM3

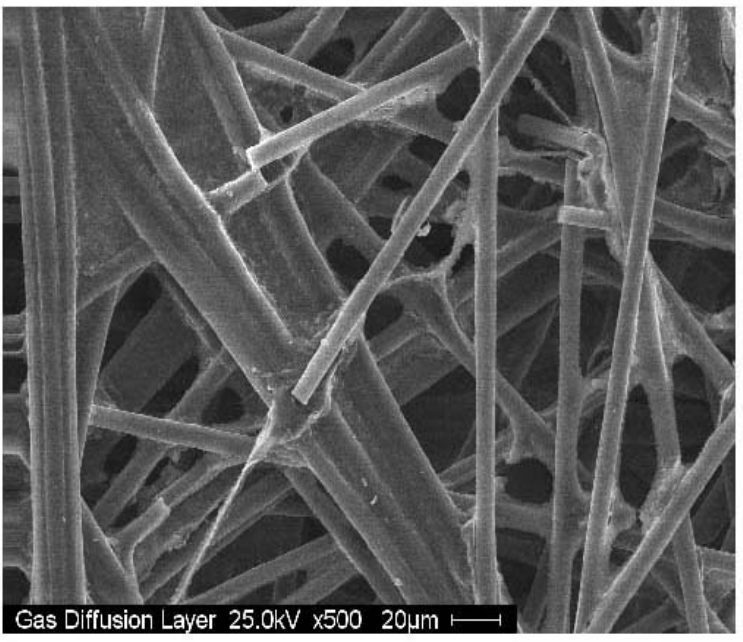

Control

Figure 49: Comparison of NM3 and control (OS1) G.D.L. layers (macro sized)

GDL Meso-Porous Structure Comparison

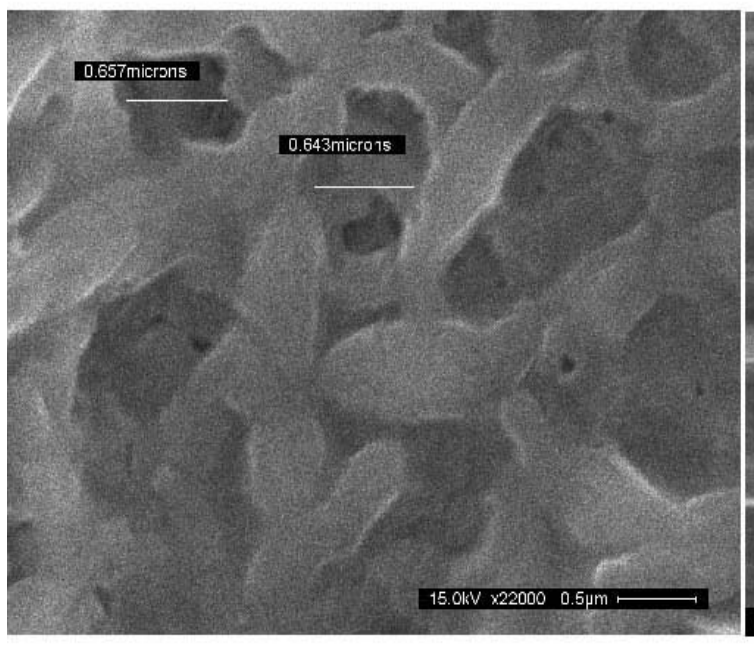

NM3

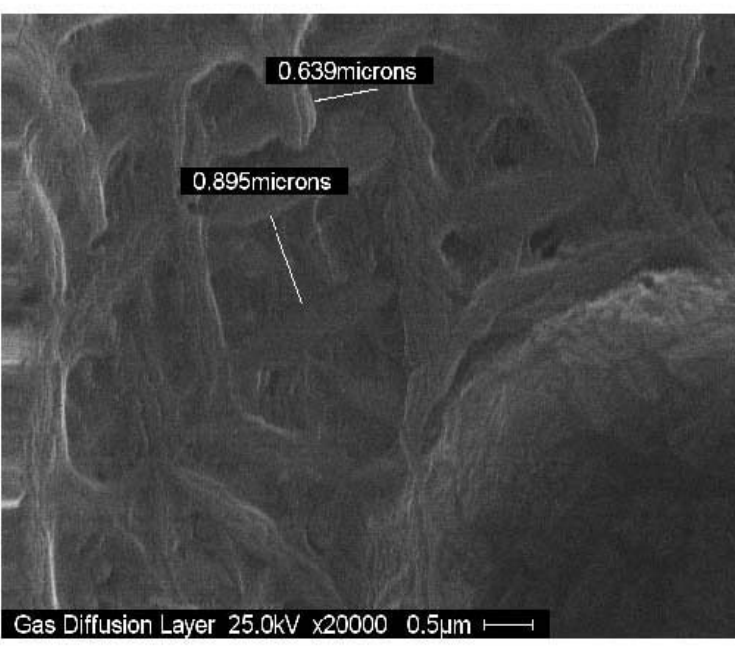

Control

Figure 50: Comparison of NM3 and control (OS1) G.D.L. layers (micro sized) 


\section{Chapter 5: Conclusions}

\section{One hour freeze/thaw cycle investigations}

Based on the results presented in the preceding section, it was

determined that a one hour freeze/thaw cycle was not long enough to show the anticipated degradation in this particular membrane. Therefore, no conclusion can be made about the effects that the cell's water content has upon the membrane.

Superficially this experiment seems like a failure, but it did provide some valuable insights which helped to properly quantify the causes of the degradation. For example, it cannot be assumed that there was not any degradation; in fact the degradation observed was actually due to the dilution of fuel gases at the cathode. This power loss may be caused by delamination of additives designed to maintain the delicate water balance needed to operate at maximum power. 


\section{Extended duration investigations}

These experiments were conducted to explore the power loss of the membrane as it is exposed to longer subzero climate durations. From these results it was clear that another investigation similar to the one hour investigation, but longer in duration was needed. Although the membrane used in these investigations showed more power loss than previously obtained, the full extent could not be understood because of the effects of the previous fifteen freeze/thaw cycles.

\section{Twenty-four hour freeze/thaw duration investigations}

Based on the results from the extended duration testing, a new membrane was broken in and utilized to explore the effects of the membranes hydration level on the cell's degradation after a twenty four hour freeze/thaw cycle time. The only difference between the one hour and twenty four hour investigations is that the twenty four hour tests were all conducted at a temperature of -40 Celsius to isolate the hydration effects. The membrane was found to degrade not only near the maximum power region, but along the whole power curve as well. According the Fuel Cell Handbook [55] there are multiple modes of degradation occurring simultaneously i.e. delamination of the membranes, and the enlargement/ or destruction of the meso-porous structures. From this investigation it is evident that the time of the subzero storage is a critical parameter in determining how much degradation will be experienced by the membrane. 


\section{B.E.T. investigations}

These tests were conducted to analyze the micro and meso-porous structures for apparent destruction and/or enlargement. After comparing the physisorbtion of nitrogen between several samples, it was clear that the internal ice formation affected the membrane's delicate pore structures. The B.E.T. determined that the samples which had experienced large numbers of freeze/thaw cycles, or had experienced long subzero climate exposure had the average pore volume and active surface area increased by a factor of 10 . Being in agreement with the performance results, a relationship can be established between the increase of the membrane's pore volume and the observed performance losses.

\section{S.E.M. - optical investigation}

Delamination

By analyzing the experimental membranes with the electron microscope, possible causes of the performance loss were observed. First, separation of the membrane electrode assembly layers was captured on the NM3 membrane. A clear distinction can be made between the control and experimental sample as seen figures 40 and 41 . Again this delamination is further apparent after comparing figures 42 and 43 . The line tool has identified a clear physical tearing or separation of these particular layers which increased the channel by a factor of 4.3. 
G.D.L. micro-structure

Another interesting finding was that micro-porous weave that is used to hold the larger carbon chains to the matrix was unaffected by the repeated freeze/thaw cycles. This can be confirmed after analyzing figures 49 and 50 . This is notable because it proves that not all of the porous structures of the membrane are negatively affected by the freeze/thaw cycles. The most plausible explanation for this lack of degradation pertains to the application of the hydrophobic coatings to the Gas Diffusion Layer. 


\section{References}

1. Department of Energy (Editor), U.S., Hydrogen, Fuel Cells \& Infrastructure Technologies Program, Washington, D.C. 2003.

2. Chalk, S.G. and J.F. Miller, Key challenges and recent progress in batteries, fuel cells, and hydrogen storage for clean energy systems. Journal of Power Sources, 2006. 159(1): p. 73-80.

3. Larminie, J., Fuel Cell Systems explained. 2nd ed. West Sussex: John Wiley \& Sons Ltd, 2003.

4. Oszcipok, M., et al., Portable proton exchange membrane fuel-cell systems for outdoor applications. Journal of Power Sources, 2006. 157(2): p. 666-673.

5. Yan, Q., et al., Effect of sub-freezing temperatures on a PEM fuel cell performance, startup and fuel cell components. Journal of Power Sources, 2006. 160(2): p. 1242-1250.

6. Scheiba, F., et al., Electron microscopy techniques for the analysis of the polymer electrolyte distribution in proton exchange membrane fuel cells. Journal of Power Sources, 2008. 177(2): p. 273-280.

7. Heitner-Wirguin, C., Recent advances in perfluorinated ionomer membranes: structure, properties and applications. Journal of Membrane Science, 1996. 120(1): p. 1-33. 
8. Giddey, S., F.T. Ciacchi, and S.P.S. Badwal, Design, assembly and operation of polymer electrolyte membrane fuel cell stacks to $1 \mathrm{kWe}$ capacity. Journal of Power Sources, 2004. 125(2): p. 155-165.

9. Hou, J., et al., Analysis of PEMFC freeze degradation at -20 [degree signjC after gas purging. Journal of Power Sources, 2006. 162(1): p. 513520.

10. Hottinen, T., O. Himanen, and P. Lund, Performance of planar freebreathing PEMFC at temperatures below freezing. Journal of Power Sources, 2006. 154(1): p. 86-94.

11. Ishikawa, Y., et al., Behavior of water below the freezing point in PEFCs. Journal of Power Sources, 2007. 163(2): p. 708-712.

12. Sundaresan, M. and R.M. Moore, Polymer electrolyte fuel cell stack thermal model to evaluate sub-freezing startup. Journal of Power Sources, 2005. 145(2): p. 534-545.

13. Hou, J., et al., Investigation of resided water effects on PEM fuel cell after cold start. International Journal of Hydrogen Energy, 2007. 32(17): p. 4503-4509.

14. Shichiri, T. and Y. Araki, Nucleation mechanism of ice crystals under electrical effect. Journal of Crystal Growth, 1986. 78(3): p. 502-508.

15. Cappadonia, M., J.W. Erning, and U. Stimming, Proton conduction of Nafion(R) 117 membrane between $140 \mathrm{~K}$ and room temperature. Journal of Electroanalytical Chemistry, 1994. 376(1-2): p. 189-193. 
16. Saito, M., et al., Mechanisms of proton transport in alcohol-penetrated perfluorosulfonated ionomer membranes for fuel cells. Solid State lonics, 2007. 178(7-10): p. 539-545.

17. Datta, B.K., G. Velayutham, and A.P. Goud, Fuel cell power source for a cold region. Journal of Power Sources, 2002. 106(1-2): p. 370-376.

18. Watanabe, M., M. Tomikawa, and S. Motoo, Experimental analysis of the reaction layer structure in a gas diffusion electrode. Journal of Electroanalytical Chemistry, 1985. 195(1): p. 81-93.

19. Guo, Q. and Z. Qi, Effect of freeze-thaw cycles on the properties and performance of membrane-electrode assemblies. Journal of Power Sources, 2006. 160(2): p. 1269-1274.

20. Kim, S. and M.M. Mench, Physical degradation of membrane electrode assemblies undergoing freeze/thaw cycling: Micro-structure effects. Journal of Power Sources, 2007. 174(1): p. 206-220.

21. Hou, J., et al., Electrochemical impedance investigation of proton exchange membrane fuel cells experienced subzero temperature. Journal of Power Sources, 2007. 171(2): p. 610-616.

22. E. Cho, J.K., H. Ha, S. Hong, Fuel Cell Applications. Electrochemical Society, 2003: p. A1667-A1670.

23. K. Weisbrod, J.H., J. Tafoya, R. Borup, M. Inbody, 2000 Fuel Cell Seminar Preview. Fuel Cells Bulletin, 2000. 3(25): p. 3. 
24. Zhang, S., et al., Effects of Freeze/Thaw Cycles and Gas Purging Method on Polymer Electrolyte Membrane Fuel Cells. Chinese Journal of Chemical Engineering, 2006. 14(6): p. 802-805.

25. Mathias, M.F., Roth, J., Fleming, J.,Lehnert,W., Vielstich,W., Gastegier,H., Lamm, A., Handbook of Fuel Cells: Fundamentals, Technology and Applications. Vol. 3. 2003: Wiley.

26. Wood, D.L., Xie, J., Pacheco, S.D., Davey, J.R., Borup, R.L., Garzon, F. Atanassov, P. Durability Issues of the PEMFC GDL and MEA Under Steady-State and Drive-Cycle Operating Conditions. in Fuel Cell Seminar. 2004. San Antonio, TX.

27. Frisk, J., Hicks, M., Radoslav, A.T., Boand, W.M., Schmoeckel, A.K., Kurkowski, M.J. How 3M Developed a New GDL Construction for Improved Oxidative Stability. in Fuel Cell Seminar. 2004. San Antonio, TX.

28. Kangasniemi, K.H., Condit, D.A., Jarvi, T.D., , Characterization of vulcan electro -chemically oxidized under simulated PEM fuel cell conditions. Journal of Electroanalytical Chemistry, 2004. 151.

29. Williams, M.V., H.R. Kunz, and J.M. Fenton, Operation of Nafion(R)-based PEM fuel cells with no external humidification: influence of operating conditions and gas diffusion layers. Journal of Power Sources, 2004. 135(1-2): p. 122-134.

30. Lee, C. and W. Merida, Gas diffusion layer durability under steady-state and freezing conditions. Journal of Power Sources, 2007. 164(1): p. 141153. 
31. Reiser, C.A., Battery boosted rapid startup of frozen fuel cell. 2004, UTC fuel cells LLC.

32. Wheeler, T.F.F.D.J., Start up of a frozen fuel cell. 2000, Internation Fuel Cell Corporation: United States of America.

33. Vengatesan, S., et al., Operation of a proton-exchange membrane fuel cell under non-humidified conditions using thin cast Nafion membranes with different gas-diffusion media. Journal of Power Sources, 2006. 156(2): p. 294-299.

34. Palan, V., J.W.S. Shepard, and K.A. Williams, Removal of excess product water in a PEM fuel cell stack by vibrational and acoustical methods. Journal of Power Sources, 2006. 161(2): p. 1116-1125.

35. Wang, H., et al., Effects of reverse voltage and subzero startup on the membrane electrode assembly of a PEMFC. Journal of Power Sources, 2007. 165(1): p. 287-292.

36. Olsommer, R.J.A.W.T.U.L.A.B.A.P.G.B.C., Method and apparatus for preventing water in a fuel cell from freezing during storage. 2004, UTC fuel cells LLC.

37. Sun, S., et al., Catalytic hydrogen/oxygen reaction assisted the proton exchange membrane fuel cell (PEMFC) startup at subzero temperature. Journal of Power Sources, 2008. 177(1): p. 137-141.

38. Hickner, M.A., et al., Alternative Polymer Systems for Proton Exchange Membranes (PEMs). Chem. Rev., 2004. 104(10): p. 4587-4612. 
39. Martwiset, S., et al., Intrinsically conducting polymers and copolymers containing triazole moieties. Solid State lonics, 2007. 178(23-24): p. 13981403.

40. Vengatesan, S., et al., Operation of a proton exchange membrane fuel cell under non-humidified conditions using a membrane-electrode assemblies with composite membrane and electrode. Journal of Power Sources, 2007. 167(2): p. 325-329.

41. Di Vona, M.L., et al., Hybrid materials for polymer electrolyte membrane fuel cells: Water uptake, mechanical and transport properties. Journal of Membrane Science, 2007. 304(1-2): p. 76-81.

42. Sgreccia, E., et al., Mechanical properties of hybrid proton conducting polymer blends based on sulfonated polyetheretherketones. Journal of Power Sources. In Press, Corrected Proof: p. 81.

43. Licoccia, S., et al., SPPSU-based hybrid proton conducting polymeric electrolytes for intermediate temperature PEMFCs. Journal of Power Sources, 2007. 167(1): p. 79-83.

44. Alberti, G., R. Narducci, and M. Sganappa, Effects of hydrothermal/thermal treatments on the water-uptake of Nafion membranes and relations with changes of conformation, counter-elastic force and tensile modulus of the matrix. Journal of Power Sources. In Press, Corrected Proof.

45. Kreuer, K.D., On the development of proton conducting polymer membranes for hydrogen and methanol fuel cells. Journal of Membrane Science, 2001. 185(1): p. 29-39. 
46. Ho Jung, U., et al., Improvement of water management in air-breathing and air-blowing PEMFC at low temperature using hydrophilic silica nanoparticles. International Journal of Hydrogen Energy, 2007. 32(17): p. 44594465.

47. Nakajima, H., T. Konomi, and T. Kitahara, Direct water balance analysis on a polymer electrolyte fuel cell (PEFC): Effects of hydrophobic treatment and micro-porous layer addition to the gas diffusion layer of a PEFC on its performance during a simulated start-up operation. Journal of Power Sources, 2007. 171(2): p. 457-463.

48. Siegel, N.P., et al., A two-dimensional computational model of a PEMFC with liquid water transport. Journal of Power Sources, 2004. 128(2): $p$. 173-184.

49. Um, S. and C.Y. Wang, Three-dimensional analysis of transport and electrochemical reactions in polymer electrolyte fuel cells. Journal of Power Sources, 2004. 125(1): p. 40-51.

50. Sivertsen, B.R. and N. Djilali, CFD-based modelling of proton exchange membrane fuel cells. Journal of Power Sources, 2005. 141(1): p. 65-78.

51. Mishra, V., F. Yang, and R. Pitchumani, Analysis and design of PEM fuel cells. Journal of Power Sources, 2005. 141(1): p. 47-64.

52. Kulikovsky, A.A., The effect of cathodic water on performance of a polymer electrolyte fuel cell. Electrochimica Acta, 2004. 49(28): p. 51875196. 
53. Hsuen, H.-K., Performance equations for cathodes in polymer electrolyte fuel cells with non-uniform water flooding in gas diffusers. Journal of Power Sources, 2004. 137(2): p. 183-195.

54. Electrochem, I. Membrane Electrode Assembly. 2006 [cited; Available from:

http://www.fuelcell.com/index.asp?PageAction=VIEWCATS\&Category=52.

55. U.S.D.o.E., I., Fuel Cell Handbook, Editor EG\&G Technical Services. 2004: Morgantown.

56. Hugh W. Coleman, W.G.S., Experimentation and Uncertainty Analysis for Engineers. 2nd ed. 1999, New York: Wiley - Interscience

57. FESEM types of signals, New Mexico Tech.

58. SEM technology, ETH Zürich website. [cited; Available from: http://www.quantachrome.com/gassorption/index.html. 
Appendices 


\section{Appendix A: Calibrations}

To ensure the accuracy and repeatability of the experimental results, all of the instrumentation was tested according to manufacturer specifications. If the measurements were determined erroneous then a calibration sequence was completed. In general, each type of input measurement is calibrated in a similar way. This rule applies to all of the thermocouples except for the feedback temperature for the environment chamber which will be discussed separately. The T-type thermocouples were calibrated with reference to a known temperature such as ice or boiling water at atmospheric pressure. Each thermocouple was submersed in both of these references and adjusted appropriately. A summary of the data acquisition system calibrations and approximate degree of accuracy are presented in the table below: 


\section{Appendix A (Continued)}

Table 1: Instrument calibrations

\begin{tabular}{|c|c|c|c|c|}
\hline Calibrations & & & & \\
\hline \multirow[t]{2}{*}{ 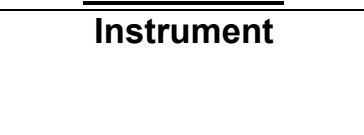 } & \multirow[t]{2}{*}{ Manufacturer/Model } & \multirow[t]{2}{*}{ Tested Parameter } & Additional & Uncertainty \\
\hline & & & $\begin{array}{l}\text { Associated } \\
\text { Controller }\end{array}$ & (+/- Error) \\
\hline T-type Thermocouple & Omega & Hydrogen Line & $\begin{array}{l}\text { Omega- } \\
\text { CN9000a }\end{array}$ & $1^{\circ} \mathrm{C}$ \\
\hline T-type Thermocouple & Omega & Oxygen Line & $\begin{array}{l}\text { Omega- } \\
\text { CN9000a }\end{array}$ & $1^{\circ} \mathrm{C}$ \\
\hline T-type Thermocouple & Omega & Anode & & $1^{\circ} \mathrm{C}$ \\
\hline T-type Thermocouple & Omega & Cathode & Omega-CNi32 & $1^{\circ} \mathrm{C}$ \\
\hline T-type Thermocouple & Omega & Hydrogen Bubbler & $\begin{array}{l}\text { Omega- } \\
\text { CN76000 }\end{array}$ & $1^{\circ} \mathrm{C}$ \\
\hline T-type Thermocouple & Omega & Oxygen Bubbler & $\begin{array}{l}\text { Omega- } \\
\text { CN76000 }\end{array}$ & $1^{\circ} \mathrm{C}$ \\
\hline T-type Thermocouple & Omega & Freezer & $\begin{array}{l}\text { Omega- } \\
\text { CN9000a }\end{array}$ & $1^{\circ} \mathrm{C}$ \\
\hline Mass Flow Controller & Cole Parmer/32708-xx & Hydrogen & & $1.50 \%$ \\
\hline Mass Flow Controller & Cole Parmer/32708-xx & Oxygen & & $1.50 \%$ \\
\hline Pressure Transducer & Cole Parmer/C206 & Hydrogen Line Back Pressure & & $0.13 \%$ \\
\hline Pressure Transducer & Cole Parmer/C206 & Hydrogen Line Back Pressure & & $0.13 \%$ \\
\hline Humidity/Temperature & Vaisala/HMT330 & Hydrogen Line Humidity & & $\begin{array}{c}\text { RH 5/Temp. } 2^{\circ} \mathrm{C} / \text { Press. } \\
20 \mathrm{hpa}\end{array}$ \\
\hline Humidity/Temperature & Vaisala/HMT330 & Oxygen Line Humidity & & $\begin{array}{c}\text { RH 5/Temp. } 2^{\circ} \mathrm{C} / \text { Press. } \\
20 \mathrm{hpa}\end{array}$ \\
\hline Current Transducer & $\begin{array}{c}\text { AAC(American } \\
\text { Aerospace } \\
\text { Controllers)/S770-30 }\end{array}$ & Fuel Cell Current & & $1 \%$ \\
\hline Voltage Transmitter & CR Magnetics/CR5320-1 & Fuel Cell Voltage & & $0.50 \%$ \\
\hline
\end{tabular}




\section{Appendix B: Uncertainty analysis}

In order to determining the accuracy of the measurements a general uncertainty analysis in the form of equations one and two below:

Equation one: $\quad r=r\left(X_{1}, X_{2}, \ldots, X_{j}\right)$

Equation two $U_{r}{ }_{r}=\left(\frac{\partial r}{\partial X_{1}}\right)^{2} * U^{2} X_{1}+\left(\frac{\partial r}{\partial X_{2}}\right)^{2} * U^{2} X_{2}+\ldots .+\left(\frac{\partial r}{\partial X_{j}}\right)^{2} * U^{2} X_{j}$

The uncertainty values of the measured voltage, current density, and power were determined to be as follows:

Table 2: Uncertainty

\begin{tabular}{cccc} 
Parameter & Associated Uncertainty & $\begin{array}{c}\text { Acquisition } \\
\text { Range }\end{array}$ & $\begin{array}{c}\text { Uncertainty } \\
\text { Range }\end{array}$ \\
\hline Voltage & $0.50 \%$ & $0-1$ Volts & $0-.005 \mathrm{v}$ \\
Current (Amps) & $1 \%$ & $0-30 \mathrm{Amps}$ & $0-.3 \mathrm{Amps}$ \\
& $U_{p}=\sqrt{.09 * V^{2}+.000025 * I^{2}}$ & & \\
Power (Watts) & $0-20$ Watts & $0-.3$ Watts
\end{tabular}

S.E.M. Uncertainty

The Hitatchi scanning electron microscopes generally have a measurement accuracy of $+/-5 \%$. In some cases measurement errors can be as high as $+/-15 \%$ if the insulative sample is not prepared properly. To ensure the highest degree of accuracy obtainable, the insulative sample was coated with $15 \mathrm{~nm}$ of gold, and secured to the sample holder with an electronically conducting copper tape to minimize the charging effects. 


\section{Appendix C: Scanning electron microscope (S.E.M.)}

The Scanning Electron Microscope (SEM) is a type of microscope capable of producing high resolution images of a sample surface using electrons rather than light to form an image. Electron microscopy takes advantage of the wave nature of rapidly moving electrons. Where visible light has wavelengths from 4,000 to 7,000 Angstroms, electrons accelerated to $10,000 \mathrm{KeV}$ have wavelengths of 0.12 Angstroms. Optical microscopes have their resolution limited by the diffraction of light to about 1000 diameters magnification. The Hitachi S800 scanning electron microscope in the present study is limited to magnifications of around 3,000,000 diameters [57].

The SEM uses the secondary electrons when a focused electron beam is incident on the specimen to form the image. The secondary electron signal provides information about the surface of a specimen. Since secondary electrons do not diffuse much inside the specimen, they are most suitable for observing fine structure of the specimen surface. figure 51 show the signals generated in an electron beam and specimen interaction. 


\section{Appendix C (Continued)}

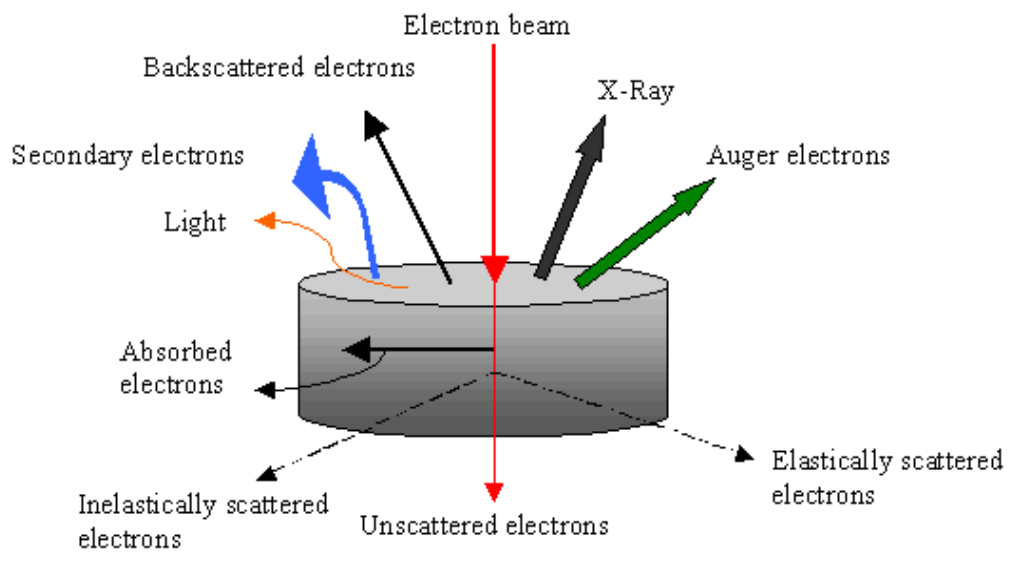

Figure 51: Sample electron scattering

The basic diagram of the operation of the Hitachi S800 SEM is shown in figure 52. Electrons from a filament in an electron gun are beamed at the specimen inside a vacuum chamber. That beam is collimated by electromagnetic condenser lenses, focused by an objective lens and then swept across the specimen at high speed. The secondary electrons are detected by a scintillation material that produces flashes of light from the electrons. The light flashes are then detected and amplified by a photomultiplier tube. 


\section{Appendix C (Continued)}

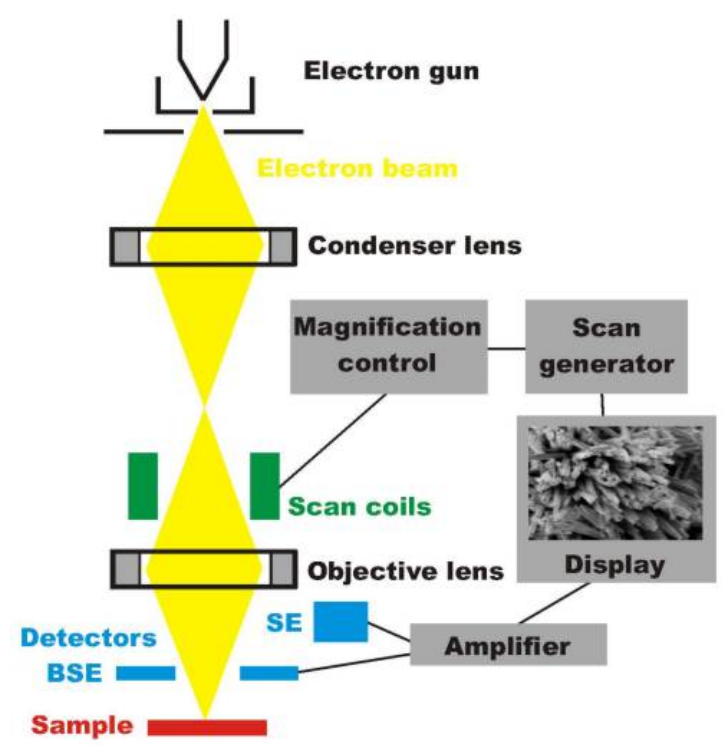

Figure 52: S.E.M. layout

Energy dispersive $x$-ray spectroscopy (EDS)

Another important signal that can be analyzed by the Hitachi S800 SEM (when the electron beam- specimen interaction occurs) is the x-ray emission. EDS identifies the elemental composition of materials imaged in a Scanning Electron Microscope (SEM) for all elements with an atomic number greater than boron (B). Most elements are detected at concentrations on the order of $0.1 \%$, excluding hydrogen. When the electron beam of the SEM hits the sample surface, it generates $x$-ray fluorescence from the atoms in its path. The energy of each x-ray photon is characteristic of the element which produced it. The EDS microanalysis system collects the x-rays, sorts and plots them by energy, and automatically identifies and labels the elements responsible for the peaks in this energy distribution. The liquid nitrogen-cooled detector is used to capture and map the x-ray counts continuously [58]. 


\section{Appendix C (Continued)}

Burnauer, Emmett and Teller (B.E.T.) surface area and pore size distribution measurements

Catalysts and photo catalysts are often characterized by their interaction with gases. At low temperatures, non-reactive gases (nitrogen, argon, krypton, etc.) are physisorbed by the surface. Through gas physisorption the total surface area of the sample can be calculated by the BET method [59]. The Autosorb-1C from Quantachrome Instruments has been employed to determine the surface area and pore size distribution of the electrode membranes. A known amount of sample ( $100 \mathrm{mg})$ was placed in a glass tube and the sample was out-gassed at $150^{\circ} \mathrm{C}$ for 3 hours. Multi point BET method using nitrogen as the adsorbate gas, the isotherms has been measured at $77 \mathrm{~K}$. The BET surface area and pore size measurement principles are given in the following figure 53 [59].

The tendency of all solid surfaces to attract surrounding gas molecules gives rise to a process called gas sorption. Monitoring the gas sorption process provides a wealth of useful information about the characteristics of solids such as surface area and pore size.

Before performing a surface area analysis or pore size measurement, solid surfaces must be freed from contaminants such as water and oils. Surface cleaning (degassing) is most often carried out by placing a sample of the solid in a glass cell and heating it under a vacuum, or a flow of dry, inert gas.

Once clean, the sample is brought to a constant temperature by means of an external bath, typically a Dewar flask containing a cryogen like liquid nitrogen. Then, small amounts of a gas (the absorbate) are admitted in steps into the evacuated sample chamber 


\section{Appendix C (Continued)}

Absorbate molecules quickly find their way either bounce off or stick to the surface. Gas molecules that stick to the surface are said to be adsorbed. The strength with which adsorbed molecules interact with the surface determines if the adsorption process is to be considered physical (weak) or chemical (strong) in nature.

\section{Figure 53: Nitrogen adsorption process}

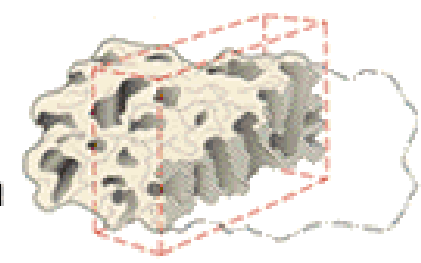

2) The monolayer of adsorbed molecules; approximately $30 \%$ saturation.

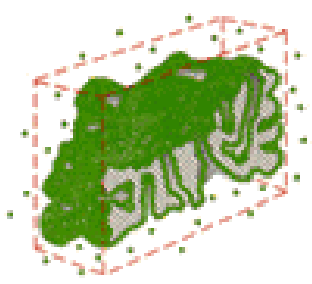

3) The multilayer/capillary condensation stage; approximately $70 \%$ saturation.

3) Total pore volume filling; approximately $100 \%$ saturation.

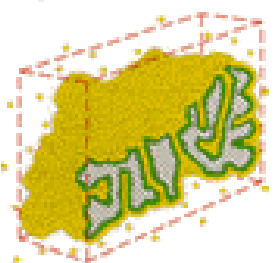

Figure 53 illustrates that the surface area is calculated from the monolayer amount, often using the B.E.T. method, and pore size is calculated from pore filling pressures. 